\title{
Production of levulinic acid and alkyl levulinates: A process insight
}

\author{
Daniele Di Menno Di Bucchianico ${ }^{\mathrm{a}, \mathrm{b}}$, Yanjun Wang ${ }^{\mathrm{c}}$, Jean-Christophe Buvat ${ }^{\mathrm{a}}$, Yong Panc, Valeria \\ Casson Moreno ${ }^{\mathrm{b}}$, Sébastien Leveneur*a

\begin{abstract}
The use of lignocellulosic biomass in the chemical industry has increased due to its non-competition with the alimentary sector. Several platform molecules can be produced from this biomass. Among them, levulinic acid and its esters have been produced in industrial scale. There are some reviews on the production of levulinic acid (LA) but few on the production of levulinates (LEs). To fill this gap, this review was written by also considering the environmental aspects. In the first stage, the recent progress on the production of these platform chemicals was discussed. Production processes of alkyl levulinates from levulinic acid esterification, precursors (HMF, furfural, etc.), sugar monomers (glucose, fructose, etc.), cellulose, hemicellulose, or cellulose directly from lignocellulosic biomass were described. In the second stage, process separation and purification of LA and LEs were discussed. The final stage proposed an economic and environmental consideration for the production of these chemicals.
\end{abstract}

\section{Introduction}

At the present moment, the global primary energy consumption is estimated to be $160 \times 10^{18} \mathrm{~J}$ per year and fossil sources still cover $80 \%$ of this demand, playing the role of the largest contributor to greenhouse gas emissions in EU, ${ }^{1}$ whereas renewable biomass contributes between $10-14 \% .^{2}$

With a potential contribution estimated up to $30-40 \%$ in the next 30 years, biomass is the main renewable source of energy (with an actual share of almost $60 \%$ in EU) and platform chemicals in Europe. . $^{3,4}$

According to the Paris agreement and its objective to keep the global temperature increase below $2{ }^{\circ} \mathrm{C}$ by reducing the greenhouse gas emissions, the European Union approved a new sustainable development scenario by setting up to reach $55 \%$ greenhouse gas reduction by 2030 compared to 1990 , with a binding renewable energy target of $32 \%$, and to achieve the climate neutrality by 2050 (NZE2050). .6

Although renewables overcome fossil fuels by one percentage point (38\% against $37 \%$ ) for the European production of electricity for the first time in 2020, the energy transition is still too slow and has to be accelerated to reach the ambitious targets, and the biomass plays a crucial role in this change. ${ }^{7}$

Since the beginning of the century, forestry, followed by specific crops and by-products, is the source that contributes most to the supply of biomass, specifically lignocellulosic biomass (LCB), overcoming the food versus fuel conflict. ${ }^{4,8}$

Regarding other renewable resources (e.g. solar, wind, wave, geothermal, etc.), lignocellulosic biomass (LCB) is the only carbon-fixing renewable resource generated from carbon dioxide and water through photosynthesis. ${ }^{9-12}$ The primary products of photosynthesis are sugars ( $\mathrm{C} 6$ and $\mathrm{C} 5$ ) that form the main components of the vegetal cell wall: cellulose (by polymerization of glucose, 25-55 \%), hemicellulose (a polymer of glucose and xylose, 24-50 \%), and lignin (a highly cross-linked polymer built of substituted phenols, 10-35 \%). 2,10,13,14 Therefore, biomass is mainly made of carbohydrates, divided into storage polysaccharides (e.g. starch and inulin), disaccharide, sucrose, and structural polysaccharides such as cellulose and hemicellulose. The other contributions to biomass composition are triglycerides (from fats and oils), proteins, terpene hydrocarbons, waxes tannins, and inorganic matter. ${ }^{2,14}$ As a consequence of biomass composition, the transition from a fossil-based to biomass-based chemical industry would imply to switch from hydrocarbons to carbohydrates as key chemicals. ${ }^{15}$ Carbohydrates (sugars) could be the starting point for the production of biofuels and biochemicals in the same way that fossil hydrocarbons are. According to the Green Chemistry Principles (Fig. 1 and Table 1), the use of renewable feedstocks should be preferred rather than depleting ones. ${ }^{16}$ Defined by the International Energy Agency (IEA) as "the sustainable processing of biomass into a spectrum of marketable products (food, feed, materials, chemicals) and energy (fuels, power, heat)", ${ }^{17}$ the biorefinery concept has foreseen the comanufacture of biofuels and biochemicals or intermediates, also referred to platform chemicals, similarly to the petrochemical industry. ${ }^{2}$ Indeed, biobased products have gained increasing importance in recent years to improve environmental issues by reducing the use of fossil sources. ${ }^{3}$

In this panorama, LCB is an abundant and relatively cheap carbon source that can produce biofuels, materials and biochemicals. ${ }^{3}$ However, the considerable benefits of using economical renewable feedstock must face several challenges; one of those is the demand for reliable, sustainable and costeffective biomass feedstock supply-chains that affect the costcompetitiveness of the biorefinery process, being an essential pre-requisite for its success. ${ }^{18,19}$ A combination of "many-tofew" and "one-to-one" harvesting-handling-processingstorage-transport operations feature the logistic chain. ${ }^{20}$ In this complex system, biomass transportation from the source to the final processing point is the major cost item, accounting for between $13 \%$ and $28 \%$ of biomass production and supply, depending on the biomass densification and transport mode. ${ }^{18}$ Lignocellulosic substrates are characterized by low bulk density (64-224 $\mathrm{kg} \mathrm{m}^{-3}$ ), low energy density (10-17 $\mathrm{MJ} \mathrm{kg}^{-1}$ ), irregular form and high moisture content. ${ }^{21}$ These factors complicate the transport step, requiring pre-processing transformations as densifying biomass feedstocks in many cases. Many studies suggest increasing the bulk density of biomass to produce a dense intermediate feedstock more easily and more economically transportable. ${ }^{22}$ Transportation modes of lignocellulosic biomass include roads, railways, waterways, 
pipelines and integrated-modes. ${ }^{18}$ Road transport is mainly used for short distances $(<100 \mathrm{~km})$, characterized by low fixed costs, high flexibility in terms of accessed sites but higher variable costs. On the other hand, railways, pipelines and waterways require significant fixed investment, stable flow of goods, incurring low variable costs and supplying large scale plants over long distances $(>100 \mathrm{~km})$. A possible solution for large-scale plants to take advantage of the high flexibility of road transport together with the low variable costs of rail or waterborne transportation is intermodal transportation that combines multiple transportation modes. ${ }^{18,23}$ Finally, the suitable transportation system depends on the feedstock type form and quality, biorefinery plant capacity, storage and pretreatment technology, together with infrastructures, facility configurations, regulation, policy and environmental impacts; all these parameters should be considered in the modelling and optimization of the biomass supply chain. ${ }^{18,24}$

The development of a sustainable and efficient biomass logistic system may provide socio-economic benefits, creating innovative job networks and job opportunities in rural zones thanks to the valorization of their natural products. ${ }^{19}$

Among all the possible derivatives from LCB as raw material for potential substitution of petroleum-based fuels and derivatives, Levulinic acid (LA) and Levulinates (LEs) are ones of the most promising products. ${ }^{25}$

Identified as one of the top value-added platform chemicals issued from biomass by the National Renewable Energy Laboratory and the $\mathrm{DOE},{ }^{25}$ LA can react with numerous functional groups due to its ketone carbonyl group and its acidic carboxyl group and to be transformed into many chemicals relevant for different market segments.

With a global market size of $\$ 27.2$ million in 2019 (\$28.3 million expected in 2020) and a compound annual growth rate (CAGR) of $8.8 \%$ in the forecast period $2020-2030,{ }^{26,27}$ LA and its derivatives are intensely investigated since their applications extend in various industrial market sectors; pharmaceutical and cosmetic industries, agriculture and food industries, chemical, polymer and fuels industries., $9,28-39$

Levulinic esters (LEs) have peculiar physicochemical properties (similar to fatty acid methyl esters) ${ }^{36}$, that can be adapted to both traditional chemical and process industry applications (e.g., solvents and additives for crude oil, flavoring, and fragrant agents and plasticizers ${ }^{36}$ as well as new one ${ }^{40}$ ). In addition, they are characterized by low toxicity, high stability, and high lubricity, ${ }^{36}$ characteristics indicating the high potential of LEs as fuel additives. These characteristics make them promising in the panorama of sustainability as they are derived from Table 1 Principles of Green Chemistry by Anastas and Warner. ${ }^{16}$
"Renewable Feedstocks" and they bring a positive contribution to "Less Hazardous Chemical Syntheses", "Safer Solvents and Auxiliaries", and "Inherently Safer Chemistry for Accident Prevention" principles. Esters, as ethyl levulinate (EL) and butyl levulinate (BL), have been positively tested as oxygenate additives, showing an improvement of the lubricity, conductivity, freezing point and combustion emission of the fuel into which they were blended. ${ }^{32,41,42}$

Lignocellulosic substrates comprising agricultural and forest residues, such as rice husk, sugarcane bagasse, and wheat straw, can lead to LA via carbohydrates hydrolysis. ${ }^{28}$ In general, hydrolysis of LCB is carried out in an acid environment at high temperatures; ${ }^{2}$ the hydrolysis processes will be widely discussed in the following sections.

Depending on the content of hexoses and/or pentoses in the initial substrate, LA is produced via the C6-sugars route or C5sugars, as depicted in Fig. 2 . In the hexoses path, the synthesis

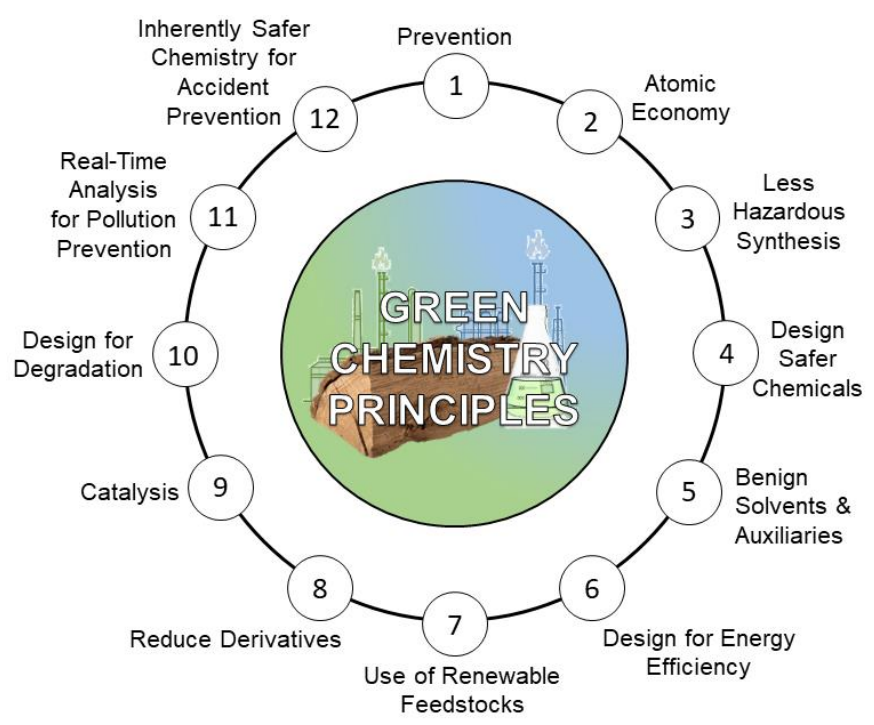

Fig. 1 Principles of Green Chemistry. ${ }^{16}$

of LA is commonly obtained by the acid-catalyzed dehydration of C6-sugars to 5-hydroxymethylfurfural (HMF) ${ }^{43}$, then hydrolyzed to LA. Homogeneous acid-catalysis is negative in terms of "Less Hazardous Chemical Syntheses", "Safer Solvents and Auxiliaries", "Inherently Safer Chemistry for Accident Prevention", but positive as "Catalytic reagents (as selective as possible) are superior to stoichiometric reagents" according to the Green Chemistry Principles. 


\begin{tabular}{|c|c|c|}
\hline Number & Principles & Description \\
\hline 1 & Prevention & $\begin{array}{l}\text { It relates to the prevention of waste generation. It is better to prevent waste } \\
\text { than treat it after its generation. }\end{array}$ \\
\hline 2 & Atomic economy & $\begin{array}{l}\text { The synthetic methods should be designed to maximize the incorporation of all } \\
\text { reactants into the final product, minimizing waste generation. }\end{array}$ \\
\hline 3 & Less Hazardous Synthesis & $\begin{array}{l}\text { Processes should be designed to use and generate safe and no-toxic } \\
\text { substances. The replacement of toxic solvents is strongly recommended. }\end{array}$ \\
\hline 4 & Design safer Chemicals & $\begin{array}{l}\text { Chemicals should be designed to fulfil their functions but present the lowest } \\
\text { toxic impact at the same time. }\end{array}$ \\
\hline 5 & $\begin{array}{l}\text { Benign Solvents \& } \\
\text { Auxiliaries }\end{array}$ & $\begin{array}{l}\text { The use of solvents and auxiliaries should be avoided or at least considered } \\
\text { safe substances. }\end{array}$ \\
\hline 6 & $\begin{array}{l}\text { Design for Energy } \\
\text { Efficiency }\end{array}$ & $\begin{array}{l}\text { Energy requirements should be considered to minimize the environmental and } \\
\text { economic impact of the process; therefore, favour low temperature and } \\
\text { pressure conditions. }\end{array}$ \\
\hline 7 & $\begin{array}{l}\text { Use of Renewable } \\
\text { Feedstocks }\end{array}$ & $\begin{array}{l}\text { Renewable raw materials should be preferred when they are economically and } \\
\text { technically feasible. }\end{array}$ \\
\hline 8 & Reduce Derivatives & $\begin{array}{l}\text { Derivatives steps in the process should be avoided or minimized in order to } \\
\text { not use other reactants and generate other waste. }\end{array}$ \\
\hline 9 & Catalysis & $\begin{array}{l}\text { The optimization of the synthesis method via catalysis should be preferred } \\
\text { than the use of stoichiometric reagents. }\end{array}$ \\
\hline 10 & Design for Degradation & $\begin{array}{l}\text { The synthesis should produce substances intended to decompose into } \\
\text { harmless products at the end of their function, without persisting in the } \\
\text { environment. }\end{array}$ \\
\hline 11 & $\begin{array}{l}\text { Real-Time Analysis for } \\
\text { Pollution Prevention }\end{array}$ & $\begin{array}{l}\text { The production process should be monitored in real-time to avoid the } \\
\text { formation of hazardous substances and possible accidents. }\end{array}$ \\
\hline 12 & $\begin{array}{l}\text { Inherently Safer } \\
\text { Chemistry for Accident } \\
\text { Prevention }\end{array}$ & $\begin{array}{l}\text { Chemicals and process operating units should be chosen to minimize the } \\
\text { possible occurrence of accidents, such as leaks, explosions and fires, and } \\
\text { maximize occupational and environmental safety. }\end{array}$ \\
\hline
\end{tabular}

On the other hand, the C5-sugars route (mainly xylose) shows furfural, as the first hydrolysis intermediate, which is hydrogenated to furfuryl alcohol and hydrolyzed to LA. This way is less used because of the lower yield and the complexity of the additional processing steps. ${ }^{37}$

Routes to produce LEs are multiple:29,33,44-46 from simple biomass-derived products like LA via esterification in an alcohol medium, ${ }^{46}$ or furfuryl alcohol (process characterized by high yield and selectivity), ${ }^{47}$ or 5-hydroxymethylfurfural and/or HMF intermediate ether in alcohol medium, ${ }^{28,48}$ or directly from LCB (limited yield). ${ }^{29}$

The acid hydrolysis of either biomass-derived molecules, as sugar monomers, HMF, furfural, or direct LCB is characterized by by-products where humins are the main ones. Humins are carbonaceous, heterogeneous, polydisperse materials with a not well-known molecular structure, ${ }^{55}$ constituted by furanic rings, and aldehydes, ketones and hydroxyls as main functional groups. ${ }^{56}$ Produced in insoluble or partially soluble forms, humins are responsible for lower yields due to reagent consumption by degradation, and fouling of the reactor and catalyst, with poisoning effect for heterogeneous catalysts. ${ }^{57}$ Measures to mitigate the fouling effect, i.e. production and deposit of humins, could be applied, as lowering of lignocellulosic feedstock concentration or use of solvents which ensure humins dissolution, having severe economic effects in terms of equipment size and separation costs. ${ }^{57}$

The route entailing furfural hydrogenation is negative in terms of "Less Hazardous Chemical Syntheses", "Safer Solvents and Auxiliaries", "Inherently Safer Chemistry for Accident Prevention" and, for the C6 route, potentially less "Designed for Energy Efficiency". Such aspects should be quantitatively studied using ad-hoc sustainability metrics able to rank the process alternatives. ${ }^{49}$

The synthesis of LA was first reported 150 years ago, ${ }^{29}$ and this route was typically homogeneous acid-catalysed by mineral acids (e.g., $\mathrm{HCl}, \mathrm{H}_{2} \mathrm{SO}_{4}$ ) at high temperatures and pressure (posing issues on "Inherently Safer Chemistry for Accident Prevention"). Even though characterized by high yields (Biofine process, $70-80$ mol\% yield), 50 it leads to difficult separation and recovery, equipment corrosion, and potential environmental pollution. ${ }^{28}$ Therefore, recently, industrial production is more oriented to carry out heterogeneous acid-catalyzed processes (typically Brønsted acids, such as zeolites, ion exchange resins, etc.) because of good yields achieved and the simplicity of downstream processing. ${ }^{28,29}$ Despite the insolubility of saccharide in alcohols, two routes are possible with glucose and fructose: transformation into 5-HMF and later into LA followed by final esterification or formation of its ether that finally 


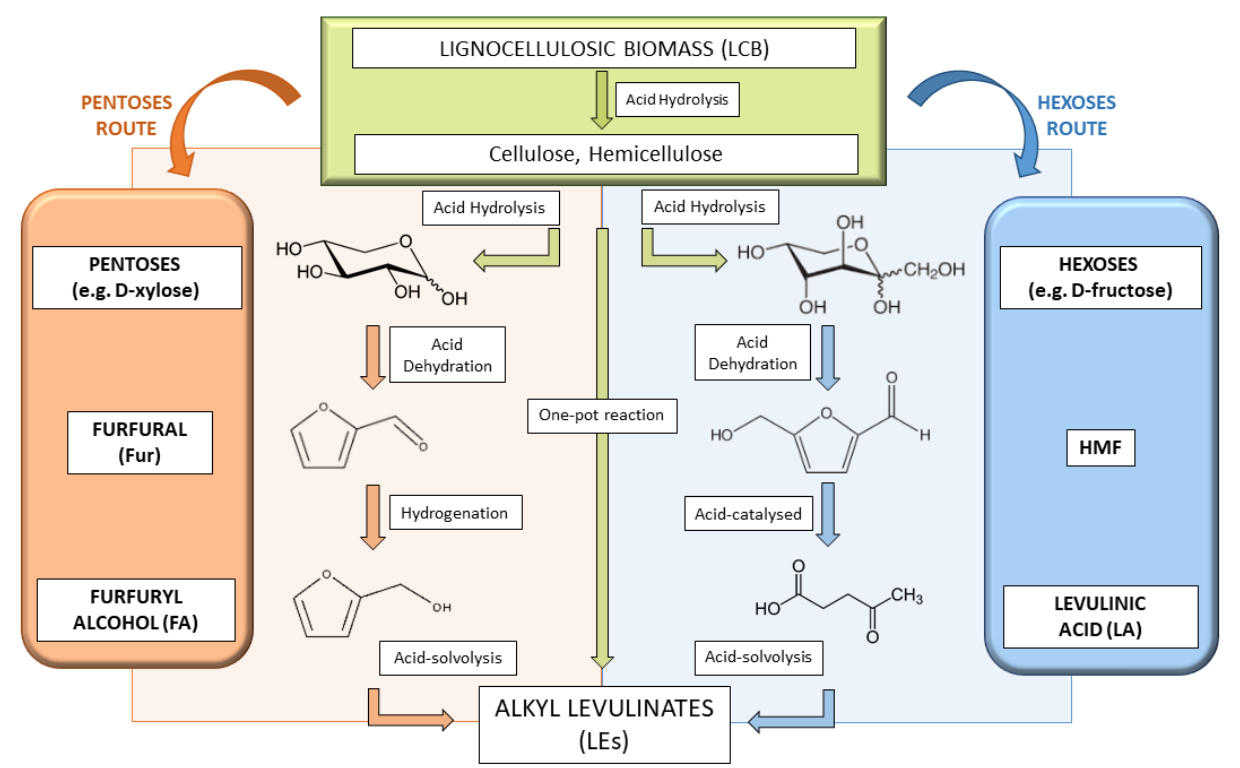

Fig. 2 Routes from lignocellulosic biomass (LCB) to levulinic acid (LA) and alkyl levulinates (ALs).

undergo dehydration or rehydration to the final levulinic ester, respectively. ${ }^{29}$ Finally, the polysaccharides present in LCB (e.g., from hemicellulose, starch and inulin) can also be transformed into alkyl levulinates, ${ }^{29}$ typically liquid acid catalyst systems, in the presence of alcohols, whereas the use of solid catalysts is less developed water. ${ }^{29}$ Such solutions lead to improved "Inherently Safer Chemistry for Accident Prevention" characteristics.

In this review, various processes and different upstream and downstream processes for the production of LA and its esters have been examined, considering different starting substrates and precursors. Keeping in view the promising market potential of levulinates and their green-friendly-benefit uses, the review aspires to highlight the status quo of current industrial technologies in use and indicate the promising future laboratory technologies, upcoming to the scale-up.

\section{Biomass feedstock pretreatments}

Despite the final product target (i.e. a liquid biofuel or a platform chemical), the LCB must undergo a first step where the depolymerization of the polysaccharides occurs. ${ }^{2}$ Whether the feedstock is a first or second-generation biomass, it can be depolymerized by hydrolysis or thermochemical processing.
Due to the crystalline structure of cellulose and the lignin content, LCB needs to be pre-treated, before undergoing hydrolysis or thermochemical processes, to open its structure, ${ }^{2,17}$ remove lignin in a reusable form, ${ }^{51}$ decrystallize the cellulose fibers, reduce mass transport limitation for a biological or chemical catalyst to be used in successive steps to generate a high amount of sugars. Pre-treatments can be chemical (e.g., acid, alkaline, organic solvents, ionic liquids), physical and/or physicochemical (e.g., steam explosion, wet air, oxidation, ammonia fiber explosion,...), mechanical (e.g., grinding, chipping, milling,..), or biological (e.g., microbial, enzymatic) as shown in Fig. $3 .^{28}$ The choice of the best pretreatment method is crucial for the product yield and also for the cost point of view, it could be more than $40 \%$ of the total process cost. ${ }^{52}$ This choice also has implications on the overall sustainability of the product obtained, having a direct impact (positive or negative) with respect to the Principles of Green chemistry, as displayed in Table 2. The mechanical treatments reduce the particle size, improve particle distribution, densification, the accessible surface area and porosity of the particles, i.e. improve mass transfer. Techniques such as milling, chipping, or grinding allow to mechanically transform the initial biomass without producing any secondary substances but are still considered expensive methods because of their high energy

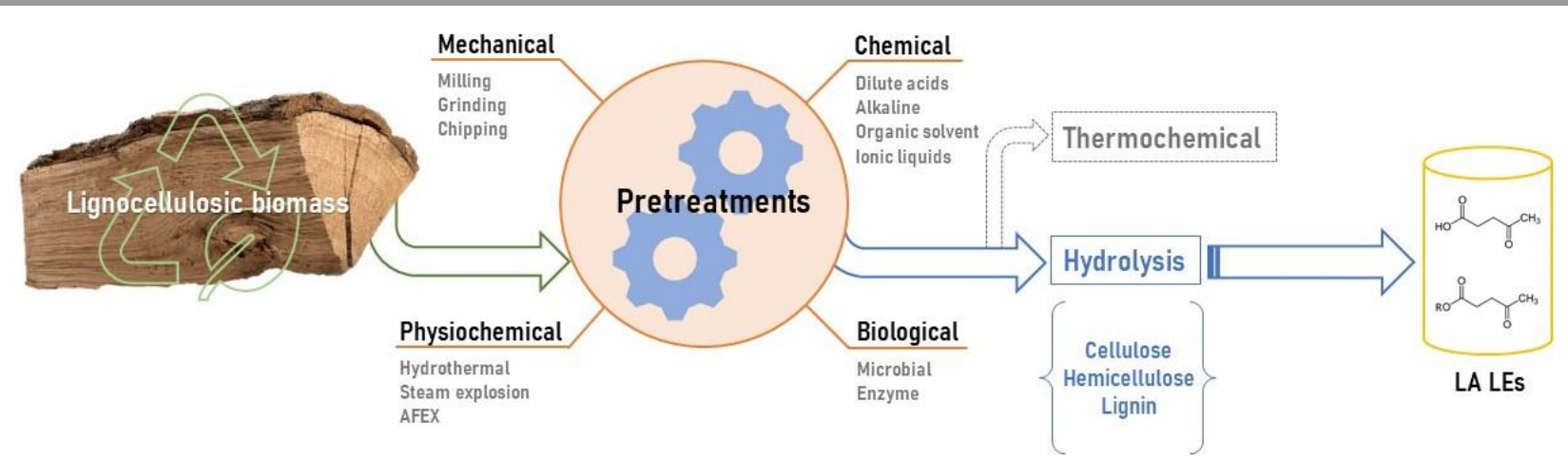

Fig. 3 Pre-Treatments methods and treatments for the primary conversion of lignocellulosic biomass (LCB). 
demands. ${ }^{53,54}$ One hand, mechanical pre-treatments allow to "Prevent" the formation of waste and minimize the potential for chemical accidents, including releases, explosions, and fires having a positive effect on the "Inherently Safer Chemistry for Accident Prevention" principle.

On the other hand, they cause a negative effect on the "Design for Energy Efficiency" principle and "Reduce Derivatives" principles. The chemical pre-treatments are more promising, usually less expensive, faster, and quite effective in degrading numerous complex-structured substrates. They include the use of diluted acids, ${ }^{55,56}$ alkaline, ${ }^{57}$ organic solvents, ${ }^{58}$ ionic liquids. ${ }^{59}$ Chemical pre-treatments enhance the substrate degradation and the availability of carbohydrates by removing lignin, decreasing the crystallinity of cellulosic components and the degree of its polymerization. Although highly efficient, the chemical techniques have some process limitations related to equipment corrosion, neutralization post-treatments and ecotoxicity. ${ }^{60}$ From a sustainability stand point, those chemical pretreatments requiring mild operating condition have a positive from a "Design for Energy Efficiency" stand point, but negative when considering the "Prevention", the "Safer Solvents and
Auxiliaries ", the "Reduce Derivatives", and the "Less Hazardous Chemical Syntheses" Green Chemistry Principles. The physiochemical pre-treatments are based on treating the substrate with specific temperature, pressure condition and moisture content, making the different lignocellulosic components soluble and easily available for the next steps, improving the "Prevention" and "Atom Economy" aspects (being the latter the maximisation of the incorporation of all materials used in the process into the final product). Therefore, methods such as steam explosion, ${ }^{61}$ hydrothermal, ${ }^{62}$ and ammonia fiber explosion, ${ }^{63}$ imply significant energy costs (i.e. negative effect on "Design for Energy Efficiency"), specific types of equipment, resulting in expensive and not very profitable on an industrial scale. ${ }^{54}$ Biological pre-treatments are based on the employment of different microorganisms, like white and brown fungi used to depolymerize the lignin, cellulose and hemicellulose. ${ }^{52}$ The microbial activity is due to the secretion of accessory enzymes (aryl alcohol oxidase, hydrolytic, glyoxyl oxidase, cellobiose dehydrogenase, copper oxidase enzymes), determining the simultaneous or selective radical degradation of the different part of the biomass. ${ }^{54}$

Table 2 Summary of Pre-Treatments methods lignocellulosic biomass (LCB). ${ }^{52,53,60}$

\begin{tabular}{|c|c|c|c|c|}
\hline \multirow{2}{*}{ Pretreatment } & \multirow{2}{*}{ Advantages } & \multirow{2}{*}{ Limitations } & \multicolumn{2}{|c|}{ Impact on Green Chemistry Principles ${ }^{16}$} \\
\hline & & & Positive & Negative \\
\hline Mechanical & $\begin{array}{l}\text { Substrate particle size reduction } \\
\text { and increased porosity (resulting in } \\
\text { higher hydrolysis yield). } \\
\text { Reduced cellulose crystallinity. } \\
\text { Reduce reaction time, exposing } \\
\text { more of the substrate. }\end{array}$ & $\begin{array}{l}\text { High energy demand and highly } \\
\text { energy inefficient operation. } \\
\text { Have to be combined with other } \\
\text { methods. }\end{array}$ & $\begin{array}{l}\text { "Prevention" } \\
\text { "Reduce Derivatives" } \\
\text { “Inherently Safer } \\
\text { Chemistry for Accident } \\
\text { Prevention" }\end{array}$ & $\begin{array}{l}\text { "Design for Energy } \\
\text { Efficiency" }\end{array}$ \\
\hline Chemical & $\begin{array}{l}\text { Low cost (not for ionic liquid and } \\
\text { organic solvent). } \\
\text { Required mild operating condition. } \\
\text { Low energy demanding. } \\
\text { High reaction rate. }\end{array}$ & $\begin{array}{c}\text { Not environmentally friendly } \\
\text { (except readily biodegradable } \\
\text { solvents). } \\
\text { (Eco)Toxicity. } \\
\text { Difficulty in recycling and reusing. } \\
\text { Neutralization post-treatments } \\
\text { for acid and alkaline methods. } \\
\text { Demanding specific equipment } \\
\text { anti-corrosion material. }\end{array}$ & $\begin{array}{l}\text { "Design for Energy } \\
\text { Efficiency" }\end{array}$ & $\begin{array}{c}\text { "Prevention" } \\
\text { "Safer Solvents and } \\
\text { Auxiliaries" } \\
\text { "Reduce Derivatives" } \\
\text { "Less Hazardous } \\
\text { Chemical Syntheses" }\end{array}$ \\
\hline $\begin{array}{l}\text { Physical/Physio- } \\
\text { chemical }\end{array}$ & $\begin{array}{l}\text { Modify the external and internal } \\
\text { structure of biomass. } \\
\text { Lower pretreatment severity. }\end{array}$ & $\begin{array}{c}\text { High energy demand } \\
\text { Specific equipment requirement. }\end{array}$ & $\begin{array}{l}\text { "Prevention" } \\
\text { "Atom Economy" }\end{array}$ & $\begin{array}{l}\text { "Design for Energy } \\
\text { Efficiency" }\end{array}$ \\
\hline Biological & $\begin{array}{l}\text { Low energy and operational cost } \\
\text { demanding. } \\
\text { More environmentally-friendly (low } \\
\text { carbon footprint and high energy } \\
\text { efficiency). } \\
\text { Mild process conditions. } \\
\text { No chemical addition. }\end{array}$ & $\begin{array}{l}\text { Using specific microorganisms, } \\
\text { adequate to the substrate. } \\
\text { Difficult to control } \\
\text { Low reaction rate, long process } \\
\text { time. } \\
\text { High space demanding (high } \\
\text { capital cost). }\end{array}$ & $\begin{array}{l}\text { "Inherently Safer } \\
\text { Chemistry for Accident } \\
\text { Prevention" } \\
\text { "Safer Solvents and } \\
\text { Auxiliaries" } \\
\text { "Less Hazardous } \\
\text { Chemical Syntheses" } \\
\text { "Design for Energy } \\
\text { Efficiency" }\end{array}$ & "Atom Economy" \\
\hline
\end{tabular}

From a sustainability point of view, the use of such methods improves aspects related to "Inherently Safer Chemistry for
Accident Prevention", "Safer Solvents and Auxiliaries", "Less Hazardous Chemical Syntheses" and "Design for Energy 
Efficiency", having a negative effect on "Atom Economy". Several factors affect the performance of the biological methods, as the type of microorganism used, incubation time and temperature, $\mathrm{pH}$, inoculums concentration, moisture content and aeration rate, and being relatively time-consuming with slow reaction rate and requiring large space, they are often unattractive from the commercial point of view. ${ }^{54,64}$

Finally, the choice of adequate pre-treatment or combined-pretreatments should be done considering that its cost should not affect the downstream processing steps and balance the tradeoff with operational, capital, and biomass costs (Table 2). Thus, it should have low capital and operational cost: low energy demand, avoiding expensive materials and large size equipment due to the use of highly corrosive chemicals and high operating pressure conditions. $.2,65$

\section{Production routes to LA and LEs}

\subsection{Production from levulinic acid esterification}

The simplest pathway to synthesize levulinic esters is the direct esterification of levulinic acid, using various acid catalysts and involving alcohols as reactants as well as solvents. Since the first attempts at synthesis using homogeneous acid catalysts in 1930 s, such as $\mathrm{HCl}$ in excess of the corresponding alcohol,66-68 the study of levulinic acid esterification has progressed towards the use of heterogeneous catalysts, due to their greater sustainability in terms of recyclability, regeneration, corrosivity and toxicity, reflecting some of the Principles of Green Chemistry such as "Prevention", "Design for Degradation", "Design for Energy Efficiency". Using acid catalysts, the reaction mechanism considers the coordination of the carbonyl oxygen with the catalyst. Hence, carbonyl carbon positivity increases, leading to the formation of a carbocation. Then, the carbocation can react with the nucleophilic alcoholic group and eliminate the protonated hydroxyl group, releasing water and the specific levulinate ester (Fig.4). ${ }^{69-71}$ Mineral acids, such as $\mathrm{H}_{2} \mathrm{SO}_{4}, \mathrm{H}_{3} \mathrm{PO}_{4}$, $\mathrm{HCl}$, and p-toluene sulphonic acid (PTSA), ${ }^{72}$ were strongly employed in the esterification for their high yields $(>95 \%)^{73}$, fast reaction rates, and low cost, but their downstream drawbacks made it mandatory their replacement, even though there were some efforts to develop acid more sustainable as the bio-glycerol derived carbon sulfonic-acid. ${ }^{74} \mathrm{Up}$ to now, various material catalysts ${ }^{88-91}$, ionic liquids ${ }^{92}$ and biocatalysts ${ }^{93-95}$ have been efficiently used to produce alkyl levulinates from LA (Table 3).

Zeolites are widely used as solid acid catalysts and ionexchangers in several processes thanks to the possibility of finetuning their properties. Micro/meso-HZ-5, modified and hierarchical H-ZSM-5 zeolite were tested to synthesize different levulinate esters obtaining yields above $90 \%$, operating at 120 ${ }^{\circ} \mathrm{C}$ up to $5 \mathrm{~h}$ and with the possibility of reusing the catalyst up to 7 runs. ${ }^{75,96,97}$ In general, zeolites show high selectivity, even though the main challenges are thermal stability and mass transfer diffusion limitations. Heteropoly acids are obtained as a combination of specific metals (tungsten, vanadium or molybdenum). Used as homogeneous or heterogeneous catalyst depending on the structural composition, the heteropoly acid supported catalysts show better esterification conversion. Possible drawbacks are their thermal instability, low surface area, solubility in polar solvent, reusability and catalyst regeneration. ${ }^{98}$ Using organic-salt of $\mathrm{H}_{4} \mathrm{SiW}_{12} \mathrm{O}_{40}$, Luan et al. ${ }^{78}$ produced ethyl levulinate and butyl levulinate with yields of $98.6 \%$ and $96.5 \%$, respectively, for $5 \mathrm{~h}$ at reflux condition. ${ }^{78}$ Similar yields have been obtained by Zhou et al. ${ }^{99}$ in the production of butyl levulinate using ammonium co-doped phosphotungstic acid and silver co-doped phosphotungstic acid, reporting $99 \%$ and $92 \%$ for $2 \mathrm{~h}$ at $120^{\circ} \mathrm{C} .99$

For solid acid catalysts, various resins have been investigated in the study of levulinic acid esterification, such as Amberlyst-15, Amberlyst-46, Amberlyst-70, Purolite, Dowex and Aquivion. A key factor in their activity is the swelling property; this characteristic is related to the amount of divinylbenzene (crosslinking) that can affect the incrementation of pore size, i.e. improve the surface area and mass transfer. ${ }^{71,80}$ For this reason, gel-type resins, as Dowex and Purolite, obtain better yields than macro-porous resins as Amberlyst, due to the greater swelling ability. Tejero et al. ${ }^{71}$ investigated the esterification of levulinic acid by butanol over different resins, obtaining a yield around $64 \%$ with Amberlyst-46 and yield of $93.5 \%$ with Dowex $50 \mathrm{~W} \times 2$. Ion resins can be easily separated from the product mixture, reused several times and prevent corrosion phenomena but at the same time they suffer from thermal-instability, disintegration at high temperature and in the presence of stirrer reactor; all these aspects combined with a high cost. $34,71,98$ Less expensive are silica-based catalysts; these inorganic porous

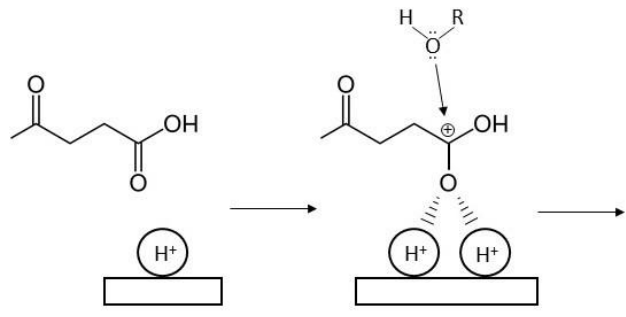

Fig. 4 Mechanism of acid catalysed levulinic acid esterification to levulinate esters.

heterogeneous catalysts, such as zeolites, ${ }^{75-77}$ heteropolyacids, ${ }^{78,79}$ acid ion exchange resins, ${ }^{71,80,81}$ nanostructured solid acid, 82 sulfonic acid-functionalized organic polymer, ${ }^{83}$ silica based, ${ }^{84-86}$ metal oxide, zirconia based, ${ }^{87}$ nano-

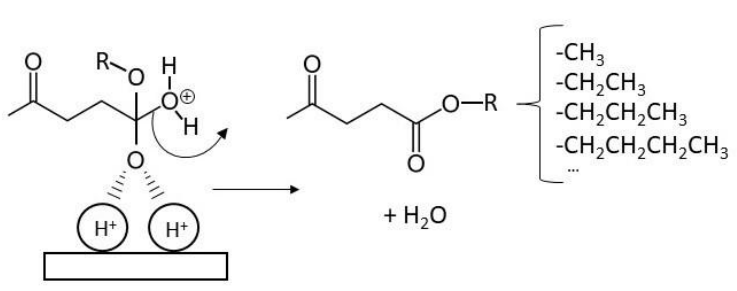

catalysts have been widely studied for their proper surface functionalization, high and active surface area, chemical and thermal stability. They can be functionalized with various acid, such as $\mathrm{HClO}_{4}, \mathrm{H}_{2} \mathrm{SO}_{4}, \mathrm{PTSA}$, and incorporate different metal 
oxides. ${ }^{84,85}$ Enumula et al..$^{85}$ analyzed the production of different levulinate esters using tungsten oxide incorporated SBA-16 catalyst obtaining yields up to $96 \% .{ }^{85}$ In addition to high yields, silica based catalysts show high recyclability; perchloric acid decorated nano-porous silica offered until five esterification cycles to ethyl levulinate without any regeneration posttreatments. ${ }^{84}$ Possible disadvantages to their use are the easy deactivation in polar solvents owing to $\mathrm{H}$-bonding formation and the complexity and cost of their functionalization. ${ }^{98,100}$

Besides tungsten oxide, other metal oxides have received enormous attention as zirconium metal-oxide catalysts. Zirconia has been tested in various forms in the synthesis of levulinate esters, as simple form, silicon-doped zirconia, hybrid zirconia, organo-hybrid zirconia, showing better catalytic activity in the presence of hydrophobic groups, with alkyl levulinate yields of up to $99.9 \% .{ }^{101}$ Furthermore, they are mechanically and thermally stable, non-corrosive, easy to regenerate, but they suffer from sulfated ions leaching and fouling. ${ }^{98,100,102}$

Some works also reported high yields by using ionic liquids as catalysts in levulinic acid esterification. One of the most active in the production of levulinates is the 1-Methylimidazolium hydrogen sulfate ([MIM] $\left.\left[\mathrm{HSO}_{4}\right]\right)$ with yields in propyl levulinate and butyl levulinate of $91 \%$ and $92 \%$, respectively. ${ }^{92}$ Ionic liquids have a bifunctional role: solvent and catalyst, thanks to their thermal stability, non-volatility, non-flammability and high ionic conductivity. Principal drawbacks are related to their viscosity, separation, recyclability, corrosiveness and high cost. ${ }^{92,103}$

Besides the catalyst choice, the selection of the solvent has a significant role in favouring an easy dissolution, mass transfer diffusion, and final products recovery, respecting the "Safer Solvent and Auxiliaries" principle. Alcohols are generally used as reactants and solvents. They are used in strongly excess to favor the acid esterification and decrease any reversible hydrolysis reaction. ${ }^{71,72}$ Due to the low solubility of levulinic acid in nonpolar solvents, ${ }^{104}$ polar solvents as methyl tert-butyl ether, diethyl ether, and $\gamma$-valerolactone may be preferred. Some works also consider the use of ionic liquids ${ }^{92}$ and supercritical carbon dioxide. ${ }^{105,106}$

The esterification can be carried out in different reactor systems: round bottom flask reactor with reflux condenser in order to avoid reactants and products evaporation; 80 stainless steel batch reactor, typically at high pressure by internal inert gas; ${ }^{71}$ continuous flow reactor equipped with a fixed catalytic bed and flow control system; 85 reactive membrane reactor allowing simultaneous reaction and separation; ${ }^{107}$ and supercritical fluid reactor, specific for fluid as supercritical carbon dioxide. ${ }^{106}$

Although the esterification of levulinic acid is a simple and effective route to produce levulinate esters, more promising production routes consider substrates and precursors further upstream in the LCB to levulinic acid/levulinic esters green chain.

Table 3 Production of levulinate esters from levulinic acid using various catalytic systems. (cyield after $\mathrm{N}$ reuse cycles tested without regeneration)

\begin{tabular}{|c|c|c|c|c|c|c|c|}
\hline Substrate & & Catalyst & Conditions ${ }^{\mathrm{a}}$ & Time & Yield $^{b}$ & $\begin{array}{c}\text { Catalyst } \\
\text { reuse }^{c}\end{array}$ & Ref. \\
\hline \multirow{3}{*}{ LA } & \multirow{3}{*}{ Mineral acid } & \multirow{3}{*}{$\mathrm{H}_{2} \mathrm{SO}_{4}$} & $60^{\circ} \mathrm{C}$ & $3 \mathrm{~h}$ & $91.2 \%$ (EL) & - & 108 \\
\hline & & & $90^{\circ} \mathrm{C}$ & $24 \mathrm{~h}$ & $100 \%(B L)$ & - & 108 \\
\hline & & & Reflux & $16 \mathrm{~h}$ & $100 \%$ (EL) & - & 109 \\
\hline \multirow{3}{*}{ LA } & \multirow{3}{*}{ Organic acid } & \multirow{2}{*}{$\mathrm{C}-\mathrm{SO}_{3}$} & Reflux & $3 \mathrm{~h}$ & $99 \%$ (ML) & - & 74 \\
\hline & & & Reflux & $3 \mathrm{~h}$ & $99 \%$ (EL) & $\sim 99 \%-5$ runs & 74 \\
\hline & & PTSA & $120^{\circ} \mathrm{C}$ & $0.08 \mathrm{~h}$ & $100 \%$ (EL) & - & 110 \\
\hline \multirow{7}{*}{ LA } & \multirow{7}{*}{ Zeolite } & \multirow{4}{*}{ Micro/Meso-HZ-5 } & $120^{\circ} \mathrm{C}$ & $5 \mathrm{~h}$ & $91 \%$ (ML) & - & 75 \\
\hline & & & $120^{\circ} \mathrm{C}$ & $5 \mathrm{~h}$ & $95 \%$ (EL) & - & 75 \\
\hline & & & $120^{\circ} \mathrm{C}$ & $5 \mathrm{~h}$ & $96 \%(B L)$ & - & 75 \\
\hline & & & $120^{\circ} \mathrm{C}$ & $5 \mathrm{~h}$ & $98 \%(O L)$ & $95 \%-6$ runs & 75 \\
\hline & & \multirow{2}{*}{ Modified H-ZSM-5 } & $120^{\circ} \mathrm{C}$ & $5 \mathrm{~h}$ & $95 \%(E L)$ & $93 \%-6$ runs & 96 \\
\hline & & & $130^{\circ} \mathrm{C}$ & $4 \mathrm{~h}$ & 99 \% (OL) & $95 \%-6$ runs & 111 \\
\hline & & Hierarchical H-ZSM-5 & $130^{\circ} \mathrm{C}$ & $5 \mathrm{~h}$ & $97.2 \%(H L)$ & $\sim 97 \%-6$ runs & 97 \\
\hline
\end{tabular}




\begin{tabular}{|c|c|c|c|c|c|c|c|}
\hline \multirow{4}{*}{ LA } & \multirow{4}{*}{ Zeolite } & H-BEA & $120^{\circ} \mathrm{C}$ & $4 \mathrm{~h}$ & $82.2 \%$ (BL) & $78.4 \%$ - 5 runs & 112 \\
\hline & & $\mathrm{H}-\mathrm{MOR}$ & $120^{\circ} \mathrm{C}$ & $4 \mathrm{~h}$ & $29.5 \%$ (BL) & - & 112 \\
\hline & & $\mathrm{H}-\mathrm{Y}$ & $120^{\circ} \mathrm{C}$ & $4 \mathrm{~h}$ & $32.2 \%(\mathrm{BL})$ & - & 112 \\
\hline & & $\mathrm{H}-\mathrm{SM}-5$ & $120^{\circ} \mathrm{C}$ & $4 \mathrm{~h}$ & $30.6 \%$ (BL) & - & 112 \\
\hline \multirow{9}{*}{ LA } & \multirow{9}{*}{ Heteropolyacid } & \multirow{4}{*}{$\mathrm{H}_{4} \mathrm{SiW}_{12} \mathrm{O}_{40}$} & $25^{\circ} \mathrm{C}$ & $8 \mathrm{~h}$ & $90 \%$ (EL) & - & 113 \\
\hline & & & $25^{\circ} \mathrm{C}$ & $8 \mathrm{~h}$ & $92 \%$ (ML) & - & 113 \\
\hline & & & $25^{\circ} \mathrm{C}$ & $8 \mathrm{~h}$ & $90 \%(P L)$ & - & 113 \\
\hline & & & $25^{\circ} \mathrm{C}$ & $8 \mathrm{~h}$ & $91 \%$ (BL) & - & 113 \\
\hline & & \multirow{3}{*}{$\begin{array}{l}\text { Organic salt of } \\
\mathrm{H}_{4} \mathrm{SiW}_{12} \mathrm{O}_{40}\end{array}$} & Reflux & $5 \mathrm{~h}$ & $98.6 \%$ (EL) & $90.5 \%-5$ runs & 78 \\
\hline & & & Reflux & $5 \mathrm{~h}$ & $100 \%$ (ML) & - & 78 \\
\hline & & & Reflux & $5 \mathrm{~h}$ & $87.8 \%$ (IBL) & - & 78 \\
\hline & & $\begin{array}{l}\text { Ammonium co-doped } \\
\text { phosphotungstic acid }\end{array}$ & $120^{\circ} \mathrm{C}$ & $2 \mathrm{~h}$ & $99 \%$ (BL) & $\sim 75 \%$ - 4 runs & 99 \\
\hline & & $\begin{array}{c}\text { Silver co-doped } \\
\text { phosphotungstic acid }\end{array}$ & $120^{\circ} \mathrm{C}$ & $2 \mathrm{~h}$ & $92 \%$ (BL) & - & 99 \\
\hline \multirow{5}{*}{ LA } & \multirow{5}{*}{$\begin{array}{l}\text { Ion exchange } \\
\text { resins }\end{array}$} & \multirow{3}{*}{ Amberlyst 15} & $64.7^{\circ} \mathrm{C}$ & $5 \mathrm{~h}$ & $82 \%(M L)$ & $75.3 \%$ - 5 runs & 80 \\
\hline & & & $78.4^{\circ} \mathrm{C}$ & $5 \mathrm{~h}$ & $71 \%$ (EL) & - & 80 \\
\hline & & & $117.74^{\circ} \mathrm{C}$ & $5 \mathrm{~h}$ & $55 \%(\mathrm{BL})$ & - & 80 \\
\hline & & Dowex 50Wx2 & $80^{\circ} \mathrm{C}$ & $8 \mathrm{~h}$ & $93.5(\mathrm{BL})$ & - & 71 \\
\hline & & Purolite (CT224) & $80^{\circ} \mathrm{C}$ & $8 \mathrm{~h}$ & $90.5 \%$ (BL) & - & 71 \\
\hline \multirow{6}{*}{ LA } & \multirow{6}{*}{ Silica } & \multirow{4}{*}{$\begin{array}{c}\text { Tungsten oxide } \\
\text { incorporated SBA-16 }\end{array}$} & $250^{\circ} \mathrm{C}$ & $10 \mathrm{~h}$ & 96 \% (ML) & - & 85 \\
\hline & & & $250^{\circ} \mathrm{C}$ & $10 \mathrm{~h}$ & $95 \%$ (EL) & $80 \%$ - 10 runs & 85 \\
\hline & & & $250^{\circ} \mathrm{C}$ & $10 \mathrm{~h}$ & $94 \%$ (PL) & - & 85 \\
\hline & & & $250^{\circ} \mathrm{C}$ & $10 \mathrm{~h}$ & $94 \%$ (BL) & - & 85 \\
\hline & & \multirow{2}{*}{$\mathrm{HClO}_{4} / \mathrm{SiO}_{2}$} & $100^{\circ} \mathrm{C}$ & $5 \mathrm{~h}$ & $99 \%$ (EL) & $90 \%-5$ runs & 84 \\
\hline & & & $100^{\circ} \mathrm{C}$ & $5 \mathrm{~h}$ & $90 \%$ (BL) & - & 84 \\
\hline \multirow{8}{*}{ LA } & \multirow{8}{*}{ Zirconia } & \multirow{3}{*}{$\begin{array}{c}\text { Mesoporous } \\
\mathrm{H}_{3} \mathrm{PW}_{12} / \mathrm{ZrO}_{2}-\mathrm{Si}(\mathrm{Ph}) \mathrm{Si}\end{array}$} & Reflux & $3 \mathrm{~h}$ & $99.9 \%$ (ML) & - & 101 \\
\hline & & & Reflux & $3 \mathrm{~h}$ & 91.5 \% (EL) & $75 \%$ - 3 runs & 101 \\
\hline & & & Reflux & $3 \mathrm{~h}$ & $82.8 \%$ (BL) & $75 \%$ - 3 runs & 101 \\
\hline & & Sulfated zirconia & $70^{\circ} \mathrm{C}$ & $7 \mathrm{~h}$ & $39.92 \%$ (EL) & $\sim 39 \%-5$ runs & 107 \\
\hline & & \multirow{4}{*}{$\begin{array}{l}\text { Super acid zirconia } \\
\text { UDCaT-5 }\end{array}$} & $160^{\circ} \mathrm{C}$ & $3 \mathrm{~h}$ & $100 \%$ (ML) & $95 \%-6$ runs & 87 \\
\hline & & & $160^{\circ} \mathrm{C}$ & $3 \mathrm{~h}$ & $100 \%(E L)$ & - & 87 \\
\hline & & & $160^{\circ} \mathrm{C}$ & $3 \mathrm{~h}$ & $95 \%$ (PL) & - & 87 \\
\hline & & & $160^{\circ} \mathrm{C}$ & $3 \mathrm{~h}$ & $98 \%$ (BL) & - & 87 \\
\hline
\end{tabular}




\begin{tabular}{|c|c|c|c|c|c|c|c|}
\hline \multirow{4}{*}{ LA } & \multirow{4}{*}{$\begin{array}{l}\text { Nano-material } \\
\text { catalyst }\end{array}$} & \multirow{2}{*}{$\begin{array}{l}\text { Sulphated } \mathrm{TiO} 2 \text { nano- } \\
\text { composite }\end{array}$} & $105^{\circ} \mathrm{C}$ & $3 \mathrm{~h}$ & $90.4 \%$ (EL) & $60 \%-5$ runs & 88 \\
\hline & & & $105^{\circ} \mathrm{C}$ & $3 \mathrm{~h}$ & $75 \%$ (EL) & - & 88 \\
\hline & & $\begin{array}{c}\text { Organico-silica } \\
\text { nanotube }\end{array}$ & $65^{\circ} \mathrm{C}$ & $1.5 \mathrm{~h}$ & $99.9 \%(\mathrm{ML})$ & $99 \%-3$ runs & 89 \\
\hline & & $\begin{array}{c}\text { Iron-phosphonate } \\
\text { nanoparticles }\end{array}$ & $60^{\circ} \mathrm{C}$ & $2 \mathrm{~h}$ & $98 \%$ (ML) & $90 \%-5$ runs & 90 \\
\hline \multirow{4}{*}{ LA } & \multirow{4}{*}{$\begin{array}{l}\text { Carbonaceous } \\
\text { catalyst }\end{array}$} & \multirow{2}{*}{ Sulphonated carbon } & $120^{\circ} \mathrm{C}$ & $9 \mathrm{~h}$ & $88.2 \%$ (EL) & $76.8 \%$ - 5 runs & 114 \\
\hline & & & $60^{\circ} \mathrm{C}$ & $1 \mathrm{~h}$ & $91.5 \%$ (EL) & - & 115 \\
\hline & & \multirow{2}{*}{$\begin{array}{l}\text { Carboncryogel } \\
\text { crystal }\end{array}$} & $78^{\circ} \mathrm{C}$ & $10 \mathrm{~h}$ & $61.4 \%(E L)$ & - & 116 \\
\hline & & & $150^{\circ} \mathrm{C}$ & $4 \mathrm{~h}$ & $86.5 \%(E L)$ & - & 117 \\
\hline \multirow{2}{*}{ LA } & \multirow{2}{*}{ Ionic liquid } & \multirow{2}{*}[\mathrm{MIM}]{$\left[\mathrm{HSO}_{4}\right]$} & $90{ }^{\circ} \mathrm{C}$ & $1.5 \mathrm{~h}$ & $91 \%(P L)$ & - & 92 \\
\hline & & & $90{ }^{\circ} \mathrm{C}$ & $1.5 \mathrm{~h}$ & $89.6 \%(B L)$ & $82 \%-6$ runs & 92 \\
\hline LA & Biocatalyst & CAL B lipase & $45^{\circ} \mathrm{C}$ & $8 \mathrm{~h}$ & 99 \% (BL) & - & 93 \\
\hline
\end{tabular}

\subsection{Production from precursors: 5-HMF, furfural and derivates}

Derived-biomass precursors can be employed in the synthesis of LA and LEs. 5-Hydroxymethylfurfural (HMF) and Furfural (Fur), followed by their respective derivatives, have been identified as promising forerunners for the production of levulinates. Defined as a "sleeping giant" for its unrealized potential, HMF is a carbon-neutral feedstock and a good starting platform for fuels and chemicals (positive on "Use of Renewable Feedstocks"). Various raw materials have been employed for HMF synthesis, including aldose monosaccharides as glucose, galactose, sorbose and fructose. Proving the highest conversion, fructose has been selected as the best sugar in its production through dehydration in an acid-catalyzed reacting medium (positive on "Reduce Derivatives"). ${ }^{28,118}$ Production of HMF from glucose or fructose-glucose mixture is also the subject of various studies; ${ }^{119-121}$ all of them agree on the significant catalytic complexity of the process (negative on " Catalysis"). Glucose is transformed into HMF through a first isomerization to fructose, then converted in a five-membered ring conformation (fructofuranose) and then undergone a series of three sequential dehydration to $\mathrm{HMF}, 122$ requiring the presence of two different acid-catalytic activities: Lewis acidity for the isomerization and Brønsted acidity for the dehydration. Thus, fructose is typically privileged for better yields and lower process complexity (positive on "Less Hazardous Chemical Syntheses"), but, on the other hand, glucose is an attractive precursor due to its higher availability and lower cost ${ }^{119,123}$ (better on "Design for Energy Efficiency"). Mineral acids, metal salts, and various solid acids have been employed over these years, emphasizing the most excellent efficiency of Brønstedtype catalysts $\left(\mathrm{H}_{2} \mathrm{SO}_{4}\right.$, zeolites, ion exchange resins, etc.) converting fructose to HMF, compared with Lewis-acid catalysts. ${ }^{124}$ Acid catalysis, mainly by Brønsted acids, is also required to transform 5-hydroxymethylfurfural into levulinic acid and its esters. While levulinic acid is produced by direct hydration of HMF under acid conditions, Quereshi's group ${ }^{125}$ proposed a mechanism for the synthesis of alkyl levulinates based on two reaction pathways (Fig. 5): hydration of HMF to LA, which is esterified to its ester depending on the alcohol used for the alcoholysis, and/or HMF is converted to alkyl levulinates via HMF-ether intermediate, as via 5-ethoxymethylfurfural (EMF) for ethyl levulinate production ${ }^{126}$ or 5butoxymethylfurfural (BMF) for butyl levulinate. ${ }^{127}$ Limited water content in the reacting mixture leads to favoring the second route in which 5-alcoxymethylfurfurals are major intermediates ${ }^{125}$ instead of hydration to levulinic acid. Also in this case, a dedicated sustainability assessment should be

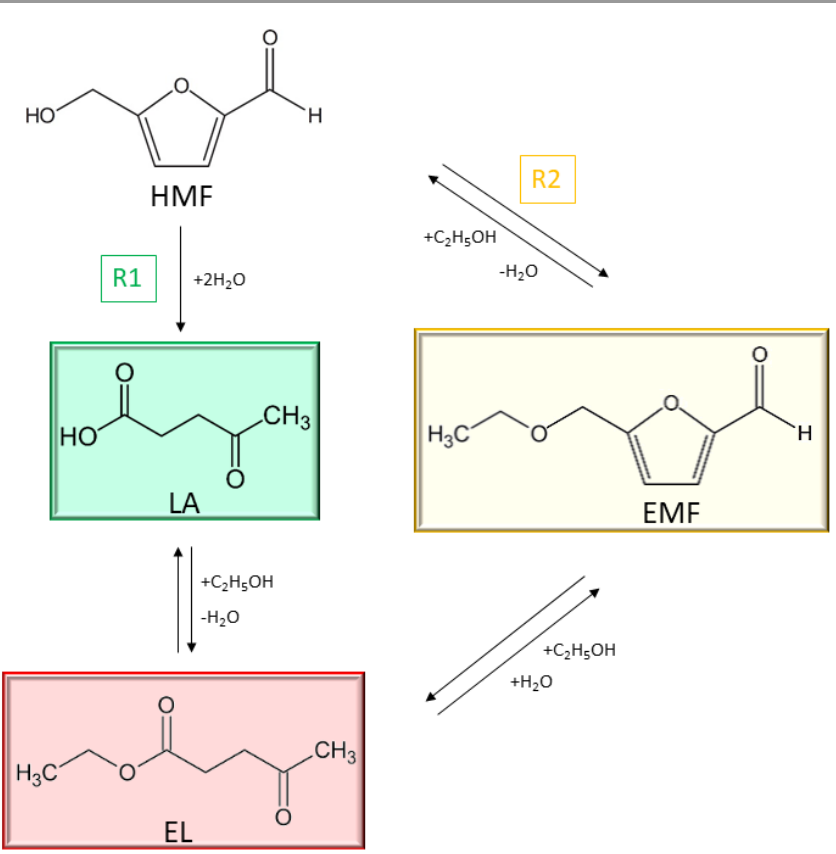

Fig. 5 Reaction scheme for the synthesis of Ethyl levulinate from HMF.

carried out to quantify the comparison among the routes. 
However, less explored than furan and cellulose as feedstock for the synthesis of levulinates, ${ }^{125}$ solvolysis of HMF has been tested with various acid-catalysts, mainly heterogeneous (Table 4), such as zeolites, ${ }^{128,129}$ zirconia, sulfated zirconia, mesoporous silica, ${ }^{129}$ heteropolyacid, ${ }^{126}$ ion exchange resins, ${ }^{130}$ and ionic liquids. ${ }^{131}$

Even though in the presence of a complete HMF conversion, literature experiment data measure low yields of levulinic esters and acid (low intensified process). For instance, some of the highest yields in ethyl levulinate was achieved by Wang et al. ${ }^{132}$ yield of $81 \%$ by using modified MOFs-derived carbon material catalyst, ${ }^{132}$ Chithra and Darbha with $85.5 \%$ using MZSM-5 zeolite, ${ }^{133}$ and Srinivasa rao et al. $92 \%$ with titanium exchanged heteropoly tungstate catalysts. ${ }^{134}$

Higher alkyl levulinate yields are achieved starting from furfuryl alcohol (FA). Neves and her group ${ }^{135}$ considered that due to a higher efficient theoretical carbon atom for the FA-to-alkyl levulinate system than for the HMF-to-alkyl levulinate, and lower production of by-products. ${ }^{125}$ Humins are also inevitably produced from the degradation of HMF and furfural in an acidic environment, leading to limitations on the catalytic activity and efficiency of downstream processes ${ }^{128,136}$ (negative effect on "Reduce Derivatives"). In addition to the use of special solvents to ensure its complete solubilization and prevent fouling and deactivation of the catalyst"137 (negative effect on "Safer Solvents and Auxiliaries"), oxygen has been tested as a possible suppressor of the formation of humins and promoter of the selectivity to desired products (positive effect on "Catalysis"). Wang and his group studied the production of methyl levulinate from HMF, catalyzed by zeolite, in the presence of oxygen; it resulted in a phenomenon of humins removal via oxidative species formed at high temperatures (up to $150{ }^{\circ} \mathrm{C}$ ), compared to nitrogen in the same conditions. ${ }^{128}$

Furthermore, the employment of inefficient technologies might lead to hotspots or/and non-uniformity of reacting temperature, facilitating the formation of by-products, with effects on "Inherently Safer Chemistry for Accident Prevention". Microwave-assisted heating has several advantages in rapid and homogeneous heating, reduced time-contact and higher product yield,138 being promising from "Inherently Safer Chemistry for Accident Prevention" point of view. Although tested on a laboratory scale, Microwave reactors are complex to scale-up, and, thus, any of them have been employed yet for large-scale production of alkyl levulinates. ${ }^{125}$ Quereshi and his group compared ethyl levulinate production from HMF, catalyzed by metal salts, via microwaves and non-microwave instant heating. They demonstrated that the non-microwave instant heating can be a promising alternative to microwave technology, leading to comparable results, more accessible to scale-up and, thus, more accepted in the industrial market. ${ }^{125}$ The scale-up is also favored by using a continuous flow production system, which allows greater control of the process parameters but is still scarce investigated in the literature related to HMF upgrading to levulinic acid and esters.

Table 4 Literature data on catalytic conversion of HMF to LA and LEs.

\begin{tabular}{|c|c|c|c|c|c|c|c|c|}
\hline Substrate & Cata & & Conditions $^{\mathrm{a}}$ & Time & $\begin{array}{c}\text { Conversion } \\
\text { HMF }\end{array}$ & Yield $^{b}$ & $\begin{array}{c}\text { Catalyst } \\
\text { reuse }^{c}\end{array}$ & Ref. \\
\hline HMF & $\begin{array}{l}\text { Mesoporous } \\
\text { silica }\end{array}$ & $\mathrm{SO}_{3} \mathrm{H}-\mathrm{SBA}-15$ & $140 \mathrm{C}^{\circ} \mathrm{C}$ & $24 \mathrm{~h}$ & $99 \%$ & $75 \%$ (EL) & $\sim 75 \%-3$ runs & 129 \\
\hline \multirow{2}{*}{ HMF } & \multirow{2}{*}{ Metal salts } & $\mathrm{CuCl} 2$ & $\begin{array}{c}160^{\circ} \mathrm{C} \\
\text { Microwaves }\end{array}$ & $5 \mathrm{~min}$ & $93.4 \%$ & $47.5 \%$ (EL) & - & 125 \\
\hline & & $\mathrm{FeCl}_{3}$ & $\begin{array}{c}160^{\circ} \mathrm{C} \\
\text { Microwaves }\end{array}$ & $5 \mathrm{~min}$ & $73.9 \%$ & $43.2 \%$ (EL) & - & 125 \\
\hline \multirow{2}{*}{ HMF } & \multirow{2}{*}{ Zeolite } & H-beta40 & $\begin{array}{c}170^{\circ} \mathrm{C} \\
\text { (under } \mathrm{O}_{2} \text { ) }\end{array}$ & $50 \mathrm{~min}$ & $100 \%$ & $69.6 \%$ (ML) & $50 \%-3$ runs & 128 \\
\hline & & MZSM-5 & $\begin{array}{c}150^{\circ} \mathrm{C} \\
\text { Ethanol/Hexan }\end{array}$ & $12 \mathrm{~h}$ & $94.2 \%$ & $85.5 \%$ (EL) & - & 133 \\
\hline HMF & $\begin{array}{c}\text { MOF-based } \\
\text { heteropolyacid }\end{array}$ & [Cu-BTC][HPM] & $140^{\circ} \mathrm{C}$ & $12 \mathrm{~h}$ & $100 \%$ & $20.2 \%(E L)$ & $\sim 20 \%-5$ runs & 126 \\
\hline HMF & $\begin{array}{c}\text { Heteropoly } \\
\text { tungstate cat. }\end{array}$ & $\mathrm{Ti}_{0.75} \mathrm{TPA}$ & $120^{\circ} \mathrm{C}$ & $6 \mathrm{~h}$ & $100 \%$ & $92 \%$ (EL) & - & 134 \\
\hline \multirow{2}{*}{ HMF } & \multirow{2}{*}{ Resins } & Amberlyst 15 & $100^{\circ} \mathrm{C}$ & $24 \mathrm{~h}$ & $95 \%$ & $17 \%$ (EL) & - & 130 \\
\hline & & Amberlyst 70 & $160^{\circ} \mathrm{C}$ & $2 \mathrm{~h}$ & - & $\begin{array}{c}61.7 / 11.9 \% \\
(E L / L A)\end{array}$ & - & 139 \\
\hline HMF & $\begin{array}{c}\text { Sulfonic-acid- } \\
\text { funct. carbon cat. }\end{array}$ & $\mathrm{C}-\mathrm{SO}_{3} \mathrm{H}$ & $140^{\circ} \mathrm{C}$ & $8 \mathrm{~h}$ & $100 \%$ & $81 \%$ (EL) & $61 \%-5$ runs & 132 \\
\hline
\end{tabular}


Key element in the pentoses-route from LCB, furfural is a pivotal intermediate for many bio-based chemicals, including for LA and its esters. This furanic aldehyde is synthesized mainly from hemicellulose-derived pentoses such as xylose and arabinose through acid-catalyzed dehydration. ${ }^{118,140}$ Traditionally, the transformation of hemicellulose is realized via chemical catalytic or physico-chemical processes, since the biological methods are inefficient, and xylose, a significant component of hemicellulose $(69,7-88,6 \text { relative } w / w \%)^{141}$ is acid-dehydrated by mineral acids as catalysts. Due to several limitations of the traditional furfural production such as high energy demand, corrosion, ecotoxicity and low furfural stability in acid medium, alternative processes have been considered, employing novel catalysts coupled with more effective and sustainable solvents. ${ }^{142}$ Numerous homogeneous and heterogeneous catalysts have been tested (Table 5 ), such as solid acids, ${ }^{143}$ oxides, ${ }^{144,145}$ metal chlorides, ${ }^{146}$ zeolites $^{147}$ and ion exchange resins, ${ }^{148}$ demonstrating high furfural yield (up to $90 \%$ starting from xylose) and excellent efficiency. Some of them coupled with biomass-derived organic solvents such as $\gamma$-valerolactone (GVL) in single-phase liquid or biphasic water/GVL systems, resulting positively in the absence of insoluble humins. ${ }^{140,142,148,149}$ The production of humins is one of the significant limitations in the conversion to LEs by furfural and $\mathrm{HMF}$, leading to the loss of substrate, catalyst fouling, deactivation and problematic separation post-treatments. ${ }^{128}$ Furfural can be converted into levulinic acid and esters via multiple steps (Fig. 6), involving the partial hydrogenation of furfural to furfuryl alcohol in gas or liquid phase and following by the acid-catalyzed conversion of furfuryl alcohol into levulinic acid or ester in the liquid phase, respectively aqueous or alcoholic. ${ }^{135,150-153}$ Although the pentoses route to furfural

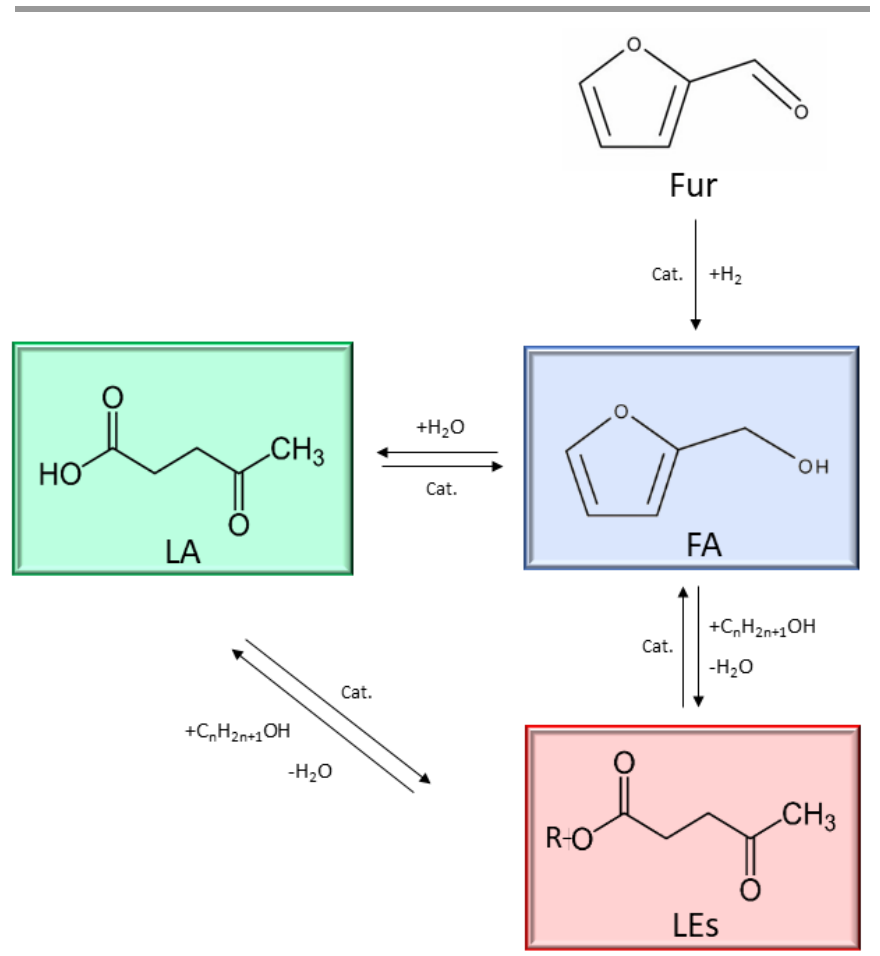

Fig. 6 Reaction scheme for the synthesis of Levulinate esters from Furfural.

has been deployed on an industrial scale for decades, the subsequent hydrogenation to FA and production of LEs are still being studied and in development. Firstly, the catalytic hydrogenation of furfural leads to various downstream products, including furfuryl alcohol, through to the employing of different kinds of materials, among non-noble metals ( $\mathrm{Ni}, \mathrm{Co}$, $\mathrm{Zr}$, etc. $)^{154-156}$ and noble metals (Ru, Pt, Pd, etc.) $)^{157-159}$ based catalysts. High furfuryl alcohol yield and selectivity (up to $99 \%$ ) can be achieved by the control and the fine-tuning of reaction conditions: temperature, high or mild temperature condition depending on the catalyst; $\mathrm{H}_{2}$ pressure, typically high for deeper hydrogenation; time, longer times lead to higher hydrogenation yields; solvents and catalyst, mono-metallic or synergistically coupled with a second metal or specific support. ${ }^{160}$ The need for hydrogenation catalysts, high-pressure conditions and the use of hydrogen as a reactant make this first intermediate step on the production of levulinates from furfural cost demanding and unfavoured in terms of process safety. A potential solution to the direct use of molecular hydrogen is the transfer hydrogenation $(\mathrm{TH})$; this reaction reduces targeted functional groups through hydrogen transferred from a donor species without the employment of molecular hydrogen. ${ }^{161}$ Recently, this technique has been applied in synthesizing alkyl levulinates (e.g., isopropyl levulinate and ethyl levulinate) from furfural via furfuryl alcohol in the presence of a hydrogen-donor solvent and a catalyst with bifunctional activity: hydrogen transfer to furfural and acid-solvolysis of furfuryl alcohol. ${ }^{152,162} \mathrm{Zr} / \mathrm{SBA}-15$ has been tested in a one-pot conversion of furfural into methyl levulinate by using near-critical methanol as hydrogen donor reporting a yield of $36.3 \%{ }^{163}$ Noble metals have also been tested, reporting promising results as $80.2 \%$ yield in isopropyl levulinate with $\mathrm{Au}-\mathrm{H}_{4} \mathrm{SiW}_{12} \mathrm{O}_{40} / \mathrm{ZrO}_{2}$ in mild condition. ${ }^{153}$ Although very active, the use of expensive noble metals is not economically attractive. Peng et al. combined simpler and more cost-effective catalysts: Zr-MCM-41 catalyst and Amberlyst-15 obtaining a yield of $85.3 \%$ comparable to the ones via noble metals catalysts. ${ }^{164}$ Through a different mechanism, furfural can also be converted in levulinic acid/esters via HMF and subsequence esterification of levulinic acid in the presence of alcohol, being furfural convertible into HMF by adding a hydroxymethyl group to the furan ring in the presence of electrophilic species. ${ }^{139}$ Applicable directly to xylose, this reaction not only avoids the hydrogenation step but also allows pentose sugars and/or furfural to be processed by only acid catalysis, as in the hexose route, enhancing the efficiency for the production of levulinic acid/ester from LCB. ${ }^{139}$

Subsequent to hydrogenation, the alcoholysis of furfuryl alcohol to levulinic products occurs in two acid-catalyzed steps: furfuryl alcohol reacts rapidly to form intermediates, mainly 2alcoxymethylfurane, ${ }^{151}$ in the presence of alcohol (or water), which are converted then into levulinic ester/acid. ${ }^{47,151}$ Being not fully exploited and oversupplied in the chemical market (about $65 \%$ of the overall use of furfural to produce FA), ${ }^{165,166}$ several studies have aimed to develop a feasible and competitive pathway for reforming and upgrade FA. ${ }^{165,167}$ The alcoholysis via acid catalysts represents a convenient and atomeconomic route to obtained value-added alkyl levulinates. ${ }^{168}$ Besides sulfuric acid and other acids, ${ }^{47,150}$ various homogeneous and heterogeneous catalysts have been investigated such as 
zeolites, ${ }^{151,169}$ sulfonic acid ion-exchange resins, ${ }^{151,170,171}$ organo-silica nanotubes, ${ }^{172}$ oxides, ${ }^{173}$ salts, ${ }^{174}$ and porous aluminosilicate acid catalysts ${ }^{135}$ (Table 6); generally operating at temperatures range between $110-140^{\circ} \mathrm{C}$ and pressure up to 20 bar to avoid to operate below the boiling point of the reagents. ${ }^{175}$ Even though mineral acids are still favored for their low cost and high availability, heterogeneous catalysts are gaining a foothold in the industry, avoiding corrosion effects, limiting downstream steps and ecotoxicity, all with the same efficiency. ${ }^{176}$ The overall furfural-via-furfuryl-alcohol process allows to achieve yields in LA in the range $83-93 \mathrm{~mol} \%,{ }^{177}$ and yields in levulinic esters around 95-98 mol\%. ${ }^{176}$ Nevertheless, this solution is less inherently safe.

Table 5 Literature data on catalytic conversion of furfural in levulinic acid (LA) and LEs.

\begin{tabular}{|c|c|c|c|c|c|c|c|c|}
\hline Substrate & & Catalyst & Conditions $^{\mathrm{a}}$ & Time & $\begin{array}{c}\text { Conversion } \\
\text { Subst. }\end{array}$ & Yield $^{b}$ & $\begin{array}{l}\text { Catalyst } \\
\text { reuse }^{c}\end{array}$ & Ref \\
\hline \multirow{2}{*}{ Furfural } & \multirow{2}{*}{ Oxide } & $\mathrm{Nb}_{2} \mathrm{O}_{5}-\mathrm{ZrO}_{2}$ & $180^{\circ} \mathrm{C}$ & $8 \mathrm{~h}$ & $92.6 \%$ & $66.5 \%(I P L)$ & $19.7 \%$ - 3 runs & 152 \\
\hline & & $\mathrm{Cu} / \mathrm{Nb}^{2} \mathrm{O}_{5}$ & $160^{\circ} \mathrm{C}$ & $3 \mathrm{~h}$ & $92.7 \%$ & $67 \%$ (LA) & $55.2 \%-4$ runs & 178 \\
\hline \multirow{4}{*}{ Furfural } & \multirow{4}{*}{$\begin{array}{c}\text { Silica based } \\
\text { cat. }\end{array}$} & $\mathrm{Zr} / \mathrm{SBA}-15$ & $270^{\circ} \mathrm{C}$ & $10 \mathrm{~h}$ & $100 \%$ & $\begin{array}{c}36.3 \% \\
(\mathrm{ML}) \\
\end{array}$ & $32 \%-5$ runs & 163 \\
\hline & & \multirow{3}{*}{ Zr-Al/SBA-15 } & $180^{\circ} \mathrm{C}$ & $3 \mathrm{~h}$ & $92.8 \%$ & $66.3 \%(E L)$ & $51 \%-4$ runs & 179 \\
\hline & & & $180^{\circ} \mathrm{C}$ & $3 \mathrm{~h}$ & $98.8 \%$ & $19.3 \%(P L)$ & - & 179 \\
\hline & & & $180^{\circ} \mathrm{C}$ & $3 \mathrm{~h}$ & $97.5 \%$ & $69.7 \%(B L)$ & - & 179 \\
\hline Furfural & $\begin{array}{c}\text { Silica based/ } \\
\text { Zeolite }\end{array}$ & $\mathrm{Zr} / \mathrm{SBA}-15, \mathrm{ZSM}-5$ & $180^{\circ} \mathrm{C}$ & $8 \mathrm{~h}$ & $100 \%$ & $55 \%$ (EL) & - & 162 \\
\hline \multirow{2}{*}{ Furfural } & \multirow{2}{*}{$\begin{array}{l}\text { Modified } \\
\text { zeolite }\end{array}$} & $(\mathrm{Sn})_{\text {SSIE }}$ beta 1 & $120^{\circ} \mathrm{C}$ & $24 \mathrm{~h}$ & $95 \%$ & $11 \%(2-B L)$ & - & 180 \\
\hline & & $(Z r)_{\text {SSIE }}$ beta 1 & $120^{\circ} \mathrm{C}$ & $24 \mathrm{~h}$ & $98 \%$ & $17 \%$ (2-BL) & - & 181 \\
\hline Furfural & Zeolite/Resins & $\begin{array}{c}\text { Zr-MCM-41 } \\
\text { Amberlyst-15 }\end{array}$ & $130^{\circ} \mathrm{C}$ & $24 \mathrm{~h}$ & $98.8 \%$ & $85.3 \%(P L)$ & $18.2 \%-5$ runs & 164 \\
\hline \multirow{3}{*}{ Furfural } & \multirow{3}{*}{$\begin{array}{l}\text { Ion exchange } \\
\text { resins }\end{array}$} & Amberlyst 70 & $\begin{array}{c}160{ }^{\circ} \mathrm{C} \\
\text { DMM/water }\end{array}$ & $2 \mathrm{~h}$ & $96.2 \%$ & $\begin{array}{c}26.5 \% \\
(\mathrm{ML}+\mathrm{LA}) \\
\end{array}$ & - & 139 \\
\hline & & Amberlyst 70 & $\begin{array}{c}160^{\circ} \mathrm{C} \\
\text { DMM/methanol }\end{array}$ & $2 \mathrm{~h}$ & $89.3 \%$ & $\begin{array}{c}46.8 \% \\
(\mathrm{ML}+\mathrm{LA})\end{array}$ & - & 139 \\
\hline & & Amberlyst 70 & $\begin{array}{l}160^{\circ} \mathrm{C} \\
\mathrm{DMM}\end{array}$ & $2 \mathrm{~h}$ & $98.9 \%$ & $\begin{array}{c}30 \% \\
(\mathrm{ML}+\mathrm{LA}) \\
\end{array}$ & - & 139 \\
\hline Furfural & Acidic resin & D008 & $\begin{array}{c}190{ }^{\circ} \mathrm{C} \\
\text { DMM/methanol }\end{array}$ & $1 \mathrm{~h}$ & $71.6 \%$ & $\begin{array}{c}39.1 \% \\
(\mathrm{ML}+\mathrm{LA})\end{array}$ & - & 182 \\
\hline Furfural & $\begin{array}{l}\text { Nanoparticles } \\
\text { supported }\end{array}$ & $\mathrm{Ir} / \mathrm{ZrNbPO}_{4}$ & $130^{\circ} \mathrm{C}$ & $6 \mathrm{~h}$ & $95.7 \%$ & $55.2 \%$ (EL) & - & 183 \\
\hline \multirow{4}{*}{ Furfural } & \multirow{4}{*}{$\begin{array}{c}\text { Modified } \\
\text { mesoporous }\end{array}$} & \multirow{4}{*}{$\mathrm{SO}_{3} \mathrm{H} @ \mathrm{Ni}-\mathrm{A}$} & $120^{\circ} \mathrm{C}$ & $1.6 \mathrm{~h}$ & $100 \%$ & $\begin{array}{c}98.6 \% \\
(\mathrm{ML}) \\
\end{array}$ & - & 184 \\
\hline & & & $120^{\circ} \mathrm{C}$ & $1.6 \mathrm{~h}$ & $100 \%$ & $97.2 \%$ (EL) & $\begin{array}{c}\sim 97 \%-20 \\
\text { runs }\end{array}$ & 184 \\
\hline & & & $120^{\circ} \mathrm{C}$ & $1.6 \mathrm{~h}$ & $100 \%$ & $85.3 \%(P L)$ & - & 184 \\
\hline & & & $120^{\circ} \mathrm{C}$ & $1.6 \mathrm{~h}$ & $100 \%$ & $72.7 \%(B L)$ & - & 184 \\
\hline Furfural & Noble metal & $\mathrm{Au}-\mathrm{H}_{4} \mathrm{SiW}_{12} \mathrm{O}_{40} / \mathrm{ZrO}_{2}$ & $120^{\circ} \mathrm{C}$ & $24 \mathrm{~h}$ & $100 \%$ & $80.2 \%(I P L)$ & $\sim 80 \%$ - 5 runs & 153 \\
\hline Furfural & Heteropolyacid & $\mathrm{H}_{3} \mathrm{PW}_{12} \mathrm{O}_{40} / \mathrm{SiO}_{2}$ & $170^{\circ} \mathrm{C}$ & $12 \mathrm{~h}$ & - & $51 \%$ (LA) & $\sim 50 \%-3$ runs & 185 \\
\hline
\end{tabular}

${ }^{a}$ using water or alcohols as solvent, unless otherwise specified. ${ }^{b}$ Methyl (ML), ethyl (EL), propyl (PL), butyl (BL) levulinate. ${ }^{c} y i e l d$ after $\mathrm{N}$ reuse cycles tested without regeneration. 
Table 6 Literature data on catalytic conversion of furfuryl alcohol (FA) in levulinic acid (LA) and LEs.

\begin{tabular}{|c|c|c|c|c|c|c|c|c|}
\hline Substrate & $\mathrm{Ca}$ & lyst & Conditions $^{\mathrm{a}}$ & Time & $\begin{array}{c}\text { Conversion } \\
\text { Subst. }\end{array}$ & Yield $^{b}$ & $\begin{array}{l}\text { Catalyst } \\
\text { reuse }^{d}\end{array}$ & Ref \\
\hline \multirow{2}{*}{ FA } & \multirow{2}{*}{ Mineral acid } & \multirow{2}{*}{$\mathrm{H}_{2} \mathrm{SO}_{4}$} & $125^{\circ} \mathrm{C}$ & $3 \mathrm{~h}$ & $100 \%$ & $72 \%$ (LA) & - & 150 \\
\hline & & & $\begin{array}{c}110{ }^{\circ} \mathrm{C} \\
\text { Butanol/water }\end{array}$ & $10 \mathrm{~h}$ & $100 \%$ & $97 \%(B L)$ & - & 186 \\
\hline FA & Mixed-acid cat. & $\mathrm{CrCl}_{3} / \mathrm{H}_{3} \mathrm{PO}_{4}$ & $130{ }^{\circ} \mathrm{C}$ & $8 \mathrm{~h}$ & $99 \%$ & $95 \%(B L)$ & - & 187 \\
\hline FA & Aluminium salt & $\mathrm{AlCl}_{3}$ & $123^{\circ} \mathrm{C}$ & $2.7 \mathrm{~h}$ & $100 \%$ & $95.7 \%$ (EL) & $94.5 \%-6$ runs & 188 \\
\hline FA & \multirow{3}{*}{$\begin{array}{l}\text { Ion exchange } \\
\text { resins }\end{array}$} & Amberlyst 70 & $110^{\circ} \mathrm{C}$ & $6.5 \mathrm{~h}$ & $100 \%$ & $99 \%$ (BL) & - & 151 \\
\hline FA & & Ambelyst 35 & $110^{\circ} \mathrm{C}$ & $6.5 \mathrm{~h}$ & $100 \%$ & $93 \%(B L)$ & - & 151 \\
\hline FA & & Ambelyst 15 & $140{ }^{\circ} \mathrm{C}$ & $24 \mathrm{~h}$ & $100 \%$ & $90 \%(E L)$ & $75 \%-3$ runs & 135 \\
\hline FA & \multirow{8}{*}{ Zeolites } & ZSM-5 & $125^{\circ} \mathrm{C}$ & $3 \mathrm{~h}$ & $100 \%$ & $45 \%$ (LA) & - & 150 \\
\hline FA & & HZSM-5 & $110^{\circ} \mathrm{C}$ & $6 \mathrm{~h}$ & $100 \%$ & $40 \%(B L)$ & - & 151 \\
\hline FA & & HZSM-5 & $170^{\circ} \mathrm{C}$ & $-c$ & - & $80 \%(\mathrm{ML})$ & - & 175 \\
\hline FA & & HZSM-5 & $170^{\circ} \mathrm{C}$ & $-c$ & - & $59 \%$ (EL) & - & 175 \\
\hline FA & & HZSM-5 & $170^{\circ} \mathrm{C}$ & $-c$ & - & $60 \%(n-P L)$ & - & 175 \\
\hline FA & & $\mathrm{H}$-ferrierite & $110^{\circ} \mathrm{C}$ & $6 \mathrm{~h}$ & $100 \%$ & $12 \%(B L)$ & - & 151 \\
\hline FA & & H-Beta & $140{ }^{\circ} \mathrm{C}$ & $24 \mathrm{~h}$ & $100 \%$ & $60 \%(E L)$ & - & 135 \\
\hline FA & & H-MCM-22 & $140{ }^{\circ} \mathrm{C}$ & $24 \mathrm{~h}$ & $100 \%$ & $47 \%(E L)$ & - & 135 \\
\hline FA & Mesoporous & Al-TUD-1 & $140{ }^{\circ} \mathrm{C}$ & $24 \mathrm{~h}$ & $100 \%$ & $80 \%(E L)$ & $50 \%-3$ runs & 135 \\
\hline FA & aluminosilic. & Beta/TUD-1 & $140{ }^{\circ} \mathrm{C}$ & $24 \mathrm{~h}$ & $100 \%$ & $63 \%$ (EL) & - & 135 \\
\hline \multirow{2}{*}{ FA } & \multirow{2}{*}{$\begin{array}{l}\text { Mesoporous } \\
\text { silica }\end{array}$} & $\mathrm{SBA}-15-\mathrm{SO}_{3} \mathrm{H}$ & $110^{\circ} \mathrm{C}$ & $4 \mathrm{~h}$ & $100 \%$ & $96 \%$ (BL) & - & 151 \\
\hline & & Ti-KIT-6 & $110^{\circ} \mathrm{C}$ & $5 \mathrm{~h}$ & $94 \%$ & $94 \%(B L)$ & $88 \%-5$ runs & 189 \\
\hline FA & $\begin{array}{c}\text { Mesoporous } \\
\text { carbon }\end{array}$ & $\mathrm{ArSO}_{3} \mathrm{H}-\mathrm{HMCSS}$ & $120^{\circ} \mathrm{C}$ & $2 \mathrm{~h}$ & $100 \%$ & $81.3 \%(E L)$ & $\begin{array}{c}\sim 80 \%-10 \\
\text { runs }\end{array}$ & 190 \\
\hline FA & $\begin{array}{l}\text { Sulfated } \\
\text { zirconia }\end{array}$ & $\begin{array}{c}\text { 1M-SZF } \\
\text { Magnetical. } \\
\text { separable }\end{array}$ & $120^{\circ} \mathrm{C}$ & $2 \mathrm{~h}$ & $100 \%$ & $96 \%(E L)$ & $87.8 \%-8$ runs & 191 \\
\hline \multirow{2}{*}{ FA } & \multirow{2}{*}{$\begin{array}{c}\text { Sulfonic acid } \\
\text { functionalized }\end{array}$} & \multirow{2}{*}{ p-TSA } & Reflux & $6 \mathrm{~h}$ & $100 \%$ & $96 \%(E L)$ & $\sim 96 \%-5$ runs & 192 \\
\hline & & & Reflux & $6 \mathrm{~h}$ & $100 \%$ & $97 \%$ (BL) & - & 192 \\
\hline \multirow{2}{*}{ FA } & \multirow{2}{*}{ Indium based } & \multirow{2}{*}{$\ln (\mathrm{OTf})_{3}$} & Reflux & $1.5 \mathrm{~h}$ & - & $92 \%(B L)$ & - & 193 \\
\hline & & & Reflux & $3 \mathrm{~h}$ & - & $83 \%(P L)$ & - & 193 \\
\hline FA & Nanomaterial & $\begin{array}{c}\mathrm{Al} / \mathrm{DFNS} / \mathrm{Pr}- \\
\mathrm{SO}_{3} \mathrm{H}\end{array}$ & $140{ }^{\circ} \mathrm{C}$ & $4 \mathrm{~h}$ & $100 \%$ & $93.5 \%(\mathrm{HL})$ & $85.7 \%-4$ runs & 194 \\
\hline \multirow{3}{*}{ FA } & \multirow{3}{*}{$\begin{array}{l}\text { Supported } \\
\text { Heteropoly } \\
\text { acid }\end{array}$} & $\mathrm{Sn}_{1}-\mathrm{TPA} / \mathrm{K}-10$ & $110^{\circ} \mathrm{C}$ & $5 \mathrm{~h}$ & $100 \%$ & $98.4 \%(B L)$ & $93.6 \%$ - 5 runs & 195 \\
\hline & & $\mathrm{Zn}_{1} \mathrm{TPA} / \mathrm{Nb}_{2} \mathrm{O}_{5}$ & $110^{\circ} \mathrm{C}$ & $5 \mathrm{~h}$ & $100 \%$ & $94 \%(B L)$ & $90 \%-4$ runs & 196 \\
\hline & & TPA/SBA-16 & $110^{\circ} \mathrm{C}$ & $3 \mathrm{~h}$ & $100 \%$ & $97 \%(B L)$ & $84 \%-4$ runs & 197 \\
\hline
\end{tabular}

${ }^{a}$ using water or alcohols as solvent, unless otherwise specified. ${ }^{b}$ Methyl (ML), ethyl (EL), propyl (PL), butyl (BL), hexyl (HL) levulinate. ${ }^{\mathrm{c} C o n t i n u o u s}$ reactor. ${ }^{d}$ yield after $\mathrm{N}$ reuse cycles tested without regeneration. 
Although very appealing, the pentoses route, mainly the furfural pathway, is still too limiting by the excessive formation of by-products, variety and cost of feedstocks and high cost of precursors as furfural; furfural price ranged between $\$ 800 / \mathrm{t}$ and $\$ 1600 / \mathrm{t}$ in 2006-2016 and increased to $\$ 2700 / \mathrm{t}$ in $2017^{198}$ and furfuryl alcohol price is $\$ 1500 / t$ or even higher. ${ }^{199}$ Therefore, the high cost of these precursors makes the production of levulinic products via the pentoses route too economically unattractive than via hexoses.

Most biomass conversion processes into chemical platforms are in batch systems, as they are mainly based on chemical or biological technologies. ${ }^{160,200}$ The industrial production of precursors, such as furfural, HMF, and final products, is a wellconsolidated batch technology. However, several research groups have highlighted the evident benefits of continuousflow biomass conversion processes. ${ }^{160,200,201}$

Compared to batch processes, continuous processes provide:

- Enhanced control of reaction conditions. Better tuning and flexibility of process variables, especially in the presence of consecutive reactions and intermediates.

- Facilitating the process scale-up. Most of the processes about biomass valorization are still on the laboratory scale, mainly batch, and potentially industrialized by being turned into a continuous process.

- Major process intensification. Biomass processes are typically complex multi-steps; continuous flow technologies lead to the escalation of the process, simplifying the reaction and the downstream steps, as catalyst re-generation.

- Process safety. Biomass processes often require the removal of oxygen, which is released in the form of $\mathrm{H}_{2} \mathrm{O}$ and/or $\mathrm{COx}$, resulting potentially in the increasing of pressure in batch systems and, thus, in new and uncontrolled processes. The continuous flow process allows removing oxygen without interfering with the reacting conditions.

The advantages of continuous flow processes have been investigated deeply related to the furfural pathway: Audemar and his group compared the heterogeneously catalysed conversion of furfural to furfuryl alcohol in batch and continuous reactor. They demonstrated that a continuous flow reactor can be a solution in the case of catalyst poisoning as it is characterized by a shorter contact time between catalyst and reactive species (in this case furan molecules) than the batch process, prolonging the activity of the catalyst, its stability and increasing the space-time yield. ${ }^{202}$ Following these results, Wang's group remarked how further efforts should be done to scale-up furfural valorization and challenges for continuous technologies, also in laboratory scale, as needing of specific dedicated equipment for continuous dosing, connections, etc.; defining of procedure for start-up and shutdown steps; storing safely reactive materials. ${ }^{160}$ Alcoholysis of furfuryl alcohol to alkyl levulinates in a continuous system was investigated by Zhao and his group. ${ }^{175}$ Comparing a closed pressure-controlled batch vessel and a continuous catalytic bed packed reactor, they reported an increase in the final yield of levulinate ester, particularly promising for methyl levulinate whose yield increased by $11-15 \%$ compared to the batch case. Therefore, research into innovative processes for converting precursors using continuous mode is crucial in intensifying these processes and their development on an industrial scale. ${ }^{203}$

\subsection{Production from glucose/fructose or sugar monomer}

Monosaccharides are the basic unit of carbohydrate molecules hydrolysable from LCB, such as disaccharides and polysaccharides. Among these, hexose sugars are the most commonly occurring monosaccharides, mainly including glucose and fructose, and more simply used as precursor molecules to synthesize of LA or LEs. ${ }^{204}$ The reaction of dehydration of $\mathrm{C} 6$ sugar to $\mathrm{HMF}$ and further rehydration and ring-opening of HMF to LA or LEs have attracted lots of research in reaction mechanism and system design to gain insight into this process. Table 7 shows the conversion of hexose monosaccharides to LA and LEs by different catalysts and under different conditions. Because of its greater abundance in cellulose and hemicellulose and consequently its lower cost, glucose is preferred over fructose. Nevertheless, fructose gives a higher yield in levulinate products than glucose, due to its greater molecular instability, which leads to easier opening of the ring structure. Indeed, glucose needs to be isomerized to fructose and then further dehydrated to HMF and rehydrated to LA (Fig. 7). ${ }^{205}$ The mechanism difference between the

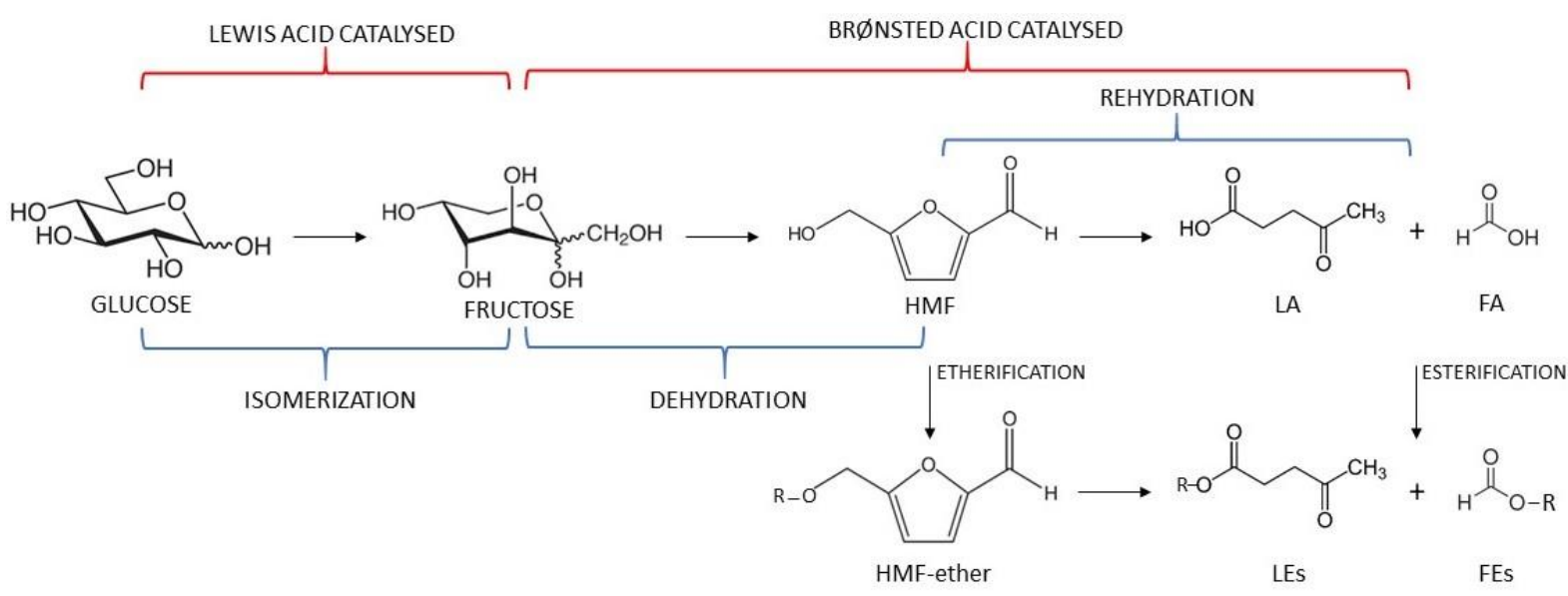

Fig. 7 Reaction scheme of conversion of glucose to LA and LEs. 
production of LA and LEs is the formation of an alkylated intermediate, such as 5-(ethoxymethyl)furfural for ethyl levulinate case, and co-products as formic acid esters. Over the past decade, numerous studies have tested both homogeneous and heterogeneous catalysts in the LA and LEs production from C6 and sugar. The easy contact with the substrate, combined with the low cost, make the homogeneous acid catalyst, as $\mathrm{H}_{2} \mathrm{SO}_{4}, \mathrm{HCl}, \mathrm{HNO}_{3}$, and $\mathrm{H}_{3} \mathrm{PO}_{4}$ the subject of various studies about the production of levulinic acid and alkyl levulinates via solvolysis. The use of $\mathrm{H}_{2} \mathrm{SO}_{4}$ with different monosaccharide substrates, such as glucose, ${ }^{206,207}$ and fructose, ${ }^{199}$ have reported promising results in terms of LA yields, always taking into account its corrosive and pollutant effects. Other homogeneous acids, as $\mathrm{HCl}$, trifluoroacetic acid (TFA), and PTSA, have been also tested in LA production. Heeres et al. reported a LA yield of $35 \%$ from glucose and of $45 \%$ from fructose by using TFA; ${ }^{208}$ LA yield of $16 \%$ from fructose hydrolysis with PTSA; ${ }^{207}$ and Brasholz et al. tested $\mathrm{HCl}$ obtaining a LA yield of $72 \%$ from fructose. ${ }^{209}$ Transition metal chlorides, especially $\mathrm{CrCl}_{3}$, have been coupled with mineral acids, affecting the conversion of glucose positively to LA due to their key role in the isomerization of glucose to fructose. ${ }^{210,211}$ However, this Lewis acid catalyst also promoted the overall conversion rate of glucose when combining with $\mathrm{Br} \varnothing n s t e d$ acid $\mathrm{HCl}$ for further rehydration of HMF, resulting in side reactions and by-products. Optimization of both concentrations of Lewis acid and Brønsted acid in this cascade reactions should be done to maximize the desired product yield, ${ }^{211}$ i.e. improving simultaneously two principles of the Green Chemistry, namely "Catalysts" and "Reduce Derivatives". A fine-tuning Lewis/Brønsted acid activities using this metal chloride was presented by Ya'aini et al.; ${ }^{212}$ developing a hybrid catalyst $\left(\mathrm{CrCl}_{3} / \mathrm{HY}\right)$ and using central composite design (CCD) under the response surface methodology (RSM) for LA production, $47 \mathrm{wt} \%$ yields of LA-based on hexoses content was obtained at $145.2^{\circ} \mathrm{C}$ and $147 \mathrm{~min} . .^{212}$ Not limited to typical batch systems, homogeneous acid catalysts have also been applied in the continuous flow process for different products, including 5(chloromethyl)-furfural (CMF), HMF and LA from carbohydrates such as sucrose, glucose and fructose. A mixture with $2 \mathrm{M} \mathrm{HCl}$ aqueous-methanol ( $v: v=1: 2)$ was inserted into a continuous flow reactor and gave $46 \mathrm{wt} \%$ yield of LA under $140{ }^{\circ} \mathrm{C}$ and 80 min after filtering insoluble by-products. ${ }^{209}$ The industrial application should always be supported by the maximization of Green Chemistry Principles such as "Less Hazardous Chemical Syntheses", "Safer Solvents and Auxiliaries", "Design for Energy Efficiency", "Reduce Derivatives" and "Inherently Safer Chemistry for Accident Prevention". Although homogeneous catalysts are used on a large scale, the conversion of monosaccharides to LA in heterogeneous catalysis has attracted extensive attention in recent years, due to their easier recovery, environmental benign properties. Futhermore heterogeneous catalysts may provide an efficient methodology with higher selectivity to LA and reaction rates. ${ }^{117}$ Heterogeneous catalysts such as zeolites, ${ }^{213}$ acid resins and polymers, ${ }^{214-216}$ metal oxides, ${ }^{217}$ heteropoly acids ${ }^{218}$ have been tested, obtaining up to LA yields exceeding $70 \%$. These same classes of acid catalysts have also been studied in the production of alkyl levulinate from C6 monosaccharides, being the reaction mechanism similar to that of its precursor acid. Besides the use of single Brønsted acid catalysts, as reported by Xu et al. ${ }^{219}$ for the production of ethyl levulinate via zeolites, or by Kuo et al. ${ }^{220}$ for the synthesis of methyl levulinate via titanium oxide nanoparticles, several researchers investigated the synergic combination of LewisBrønsted catalysts in fructose alcoholysis. Glucose isomeration to fructose represents the rate-limiting step of biomass conversion to levulinates. Thus, using a dual-activity catalyst ${ }^{221}$ or coupling a Lewis acid catalyst, which is considered to act as isomeration catalyst, with a Brønsted catalyst, responsible for the alcoholysis, the selectivity to alkyl levulinate is strongly favoured. Metal salts have been deeply analysed for this purpose, since they can act as Lewis catalysts and they are commonly stable, recyclable and inexpensive. Zhou et al. studied the use of $\mathrm{Al}_{2}\left(\mathrm{SO}_{4}\right)_{3}$ as single catalyst in methanolysis of glucose. Obtaining a $\mathrm{ML}$ yield of $64 \%$ at $160{ }^{\circ} \mathrm{C}$, this catalyst showed to provide Lewis and Brønsted sites through $\mathrm{Al}^{3+}$ ions. ${ }^{221} \mathrm{Al}^{3+}$ ions have been studied also by Liu et al. ${ }^{222}$, coupled with montmorillonite catalysts. In this case, the catalyst determined a ML yield of $60 \%$, with the possibility of recycling up to 5 times. ${ }^{222}$ Lewis acidic activity can also be achieved by using metal oxides. Heda et al. highlighted the synthesis of EL from glucose by the combination of H-USY zeolite and metal oxides as $\mathrm{TiO}_{2}, \mathrm{ZrO}_{2}$ and $\mathrm{SnO}_{2} .{ }^{223}$ The highest $\mathrm{EL}$ yield have been resulted from the combination with $\mathrm{SnO}_{2}$ which increases the yield up to $81 \%$, by increasing the rate of isomerisation and the solubility of glucose in ethanol. ${ }^{223}$ Improving the overall reaction rates, higher glucose concentration may be handled, following the green chemistry principles such as utilization of renewable materials and omission of derivatization steps and output-led design. ${ }^{223}$ In any case, the choice of developing a "high-gravity" process must consider the increase in monosaccharide concentration as being directly related to the increase in possible undesirable reactions, such as the production of the by-product humins. ${ }^{203}$ One of the advantages of glucose alcoholysis, reported by $\mathrm{Hu}$ et al., ${ }^{224}$ is that the alkylated intermediate formed in alcohol can suppress the formation of humins. The alkyl group can protect the reactive intermediate and enhance the production of LA esters. Their group also identified this advantage of using alcohol for one-pot synthesis of LEs from xylose.225 Despite this advantage, it is worth noticing that intermolecular dehydration of alcohols to ethers was significant in the alcoholysis reactions, which can hinder the scale-up of this process, ${ }^{226}$ having a negative effect also on the "Inherently Safer Chemistry for Accident Prevention", and "Safer Solvents and Auxiliaries".

Among the literature listed in Table 7, the highest yield values of alkyl levulinate are obtained from fructose alcoholysis. Liu et al. ${ }^{227}$ reported a maximum 84 mol\% yield of ethyl levulinate, obtained at $120{ }^{\circ} \mathrm{C}$ for $24 \mathrm{~h}$ through different sulfonic acidfunctionalized carbon nanotubes catalyzing fructose dehydration to ethyl levulinate. ${ }^{227} \mathrm{~A}$ linear relationship between catalytic activity and acid density of the catalyst was found and this catalyst showed its facile separation, high thermal stability, and ease of recovery. High catalytic activity and good thermal 


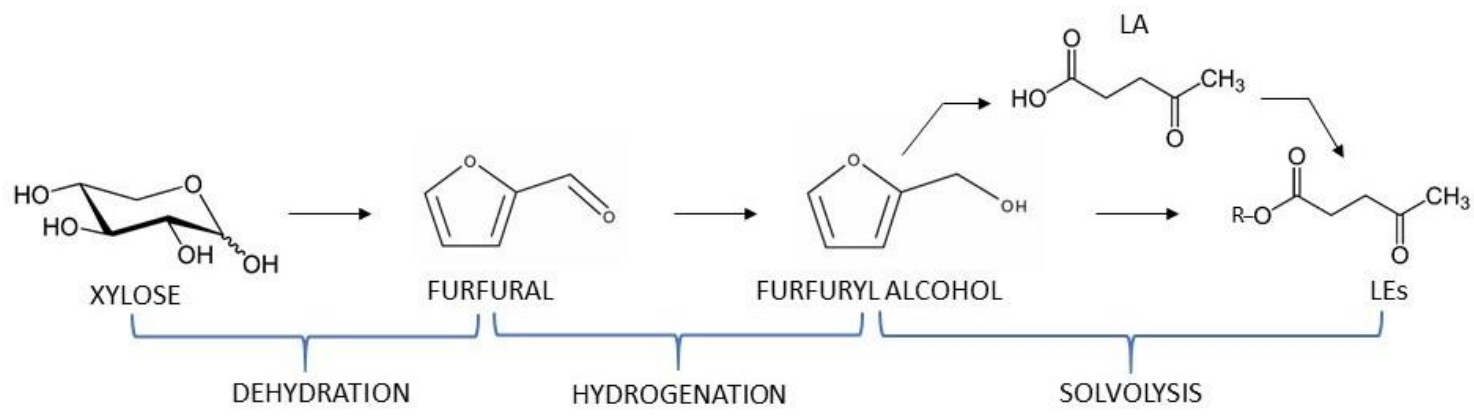

Fig. 8 Reaction scheme of conversion of xylose to LA and LEs.

stability over other solid catalysts have been demonstred by metal oxides. Oprescu et al. ${ }^{228}$ investigated the production of methyl levulinate from fructose by using $\mathrm{TiO}_{2}-\mathrm{La}_{2} \mathrm{O}_{3}$ mixed oxides on solid $\mathrm{Fe}_{3} \mathrm{O}_{4}$ nanoparticles. Fructose conversion was complete with a $\mathrm{ML}$ yield of $95 \%$, and the catslyst and reusability of the catalyst showed a decreasing by almost $10 \%$ after five cycles without any regeneration. ${ }^{228} \mathrm{Xu}$ et al. studied the synthesis of $\mathrm{ML}$ via sulfated montmorillonite $\left(\mathrm{SO}_{4}{ }^{2-} / \mathrm{MMT}\right)$, reporting a yield of $65 \%$. They reported a $36 \%$ reduction in yield after the third run without regeneration, showing that, unlike metal oxides, solid sulfated catalysts suffer from instability due to the easy loss of the sulfate group. Acid resins are also highly active, but regeneration of the catalyst is necessary to preserve their activity. Ramirez et al. ${ }^{127}$ studied the fructose butanolysis over both gel-type and macroreticular sulfonic PS-DVB resins. The catalyst screening showed that gel-type resins tend to swell highly, having a less acid site density in the swollen state and resulting in the most effective activity in term of BL yield (73.4 $\%)$. The yield decreased by $22 \%$ after 3 cycles due to the loss of active sites and the formation of polymers (solid humins) covering the resin during the reaction. ${ }^{127}$ Dehydration of $\mathrm{C} 6$ sugar to LA and LEs consists of several reaction steps; to better understand this system, it is necessary to consider all of the different parameters that can affect the final yield, such as catalyst design, process temperature, thermal safety, substrate concentration, solvent systems, etc.

There are few articles ${ }^{150,225}$ on the production of LA from C5 compounds such as xylose (Fig. 8; Table 8). However, some articles on the production of LEs from pentose route intermediates, as furfuryl alcohol, have been published in recent years. ${ }^{135,173,175,188,229-232}$ The reason may be because LA and LEs cannot be solely produced by solvolysis from these C5 compounds. After hydrolysis of xylose to stable molecular furfural, it needs an additional hydrogenation step to furfural alcohol, which was previously regarded as a precursor for the target production of levulinate ester by alcoholysis reaction in alcohols. We have already discussed the negative effect of hydrogenation from a sustainability perspective. However, as the acid-catalyzed conversion of furfural alcohol to LA in aqueous solutions resulted in different intermediate or final products, side reactions such as polymerization and rearrangement can reduce the yield and selectivity of LA.233-235 As for glucose, some researchers have observed the high efficiency of metal chlorides, in particular $\mathrm{FeCl}_{3}$, in the conversion of xylose biomass-derived to levulinic acid and its esters. Wang and co-workers reported a maximum LA yield of 68 mol\% employing $\mathrm{FeCl}_{3}$, together with $\mathrm{NaCl}$, at $180{ }^{\circ} \mathrm{C}$ for 2 hours and lower yields by the catalytic action of $\mathrm{CuCl}_{2}, \mathrm{AlCl}_{3}$ and $\mathrm{CrCl}_{3} .{ }^{84}$ Zeolites were also tested as heterogeneous catalysts in the xylose dehydration to levulinic acid, obtaining a LA yield of $31 \mathrm{~mol} \%$ at $170{ }^{\circ} \mathrm{C}$ for 3 hours. ${ }^{236}$ Homogeneous catalysts, like sulfuric acid and methanesulfonic acid, allowed higher yields (up to $60 \mathrm{~mol} \%$ ) with both xylose and glucose-xylose mixture as substrates. ${ }^{237}$

To improve the yield of LA from xylose, a novel strategy employing biphasic systems was developed by using alkylphenol solvents as the organic layer for direct conversion of hemicellulose in three steps. ${ }^{150}$ Hydrolysis of xylose in low concentration occurs in a biphasic aqueous-organic system; organic solvent 2-sec-butylphenol (SBP) was added for dehydrating xylose and extracting furfural from aqueous layer saturated with $\mathrm{NaCl}$. Then by hydrogenation of furfural in the second step, furfural alcohol was slowly fed into another biphasic reactor, where conversion of furfural alcohol to LA occurs in an aqueous layer. It is worth noting that most of the furfural alcohol remains in SBP, which decreases its concentration in the aqueous layer and the rates of side reactions as well, with negative implications in terms of "Reducing Derivatives". Adding $\mathrm{NaCl}$ into the system can significantly improve the partition coefficient of furfural from 50 $\%$ to $90 \%$, allowing a high yield of furfural in the organic phase $70 \%$ yield of LA was obtained in this system at $25^{\circ} \mathrm{C}$.

Due to the high boiling point, 4-n-hexylphenol (NHP) and 4propylguaiacol ${ }^{207}$ were selectively used as solvents to remove LA to the organic phase and further distillation of LA from the top column. This strategy was proved to be efficient for converting xylose-hemicellulose-derived to LA with alkylphenol solvents in a biphasic reactor system, and should be further investigated in terms of "Inherent Safety".

The organic solvent in specific biphasic organo-aqueous systems can play as an electrophile, transforming furfural into HMF by electrophilic substitution and avoiding the mandatory hydrogenation step in the pentoses route. Hu and co-workers have investigated the production of levulinic acid, methyl levulinate and ethyl levulinate through biphasic systems, dimethoxymethane DMM-water and DMM-alcohol, reporting levulinate yields up to $50 \%$ using xylose as starting substrate. ${ }^{139}$ 
Table 7 Conversion of C-6 monosaccharides and disaccharide (Sucrose) to LA or LEs.

\begin{tabular}{|c|c|c|c|c|c|c|c|}
\hline Feedstock & & Catalyst & Conditions $^{a}$ & Time & Yield $^{b}$ & Cat. reuse ${ }^{c}$ & Ref. \\
\hline \multicolumn{8}{|l|}{ LA production } \\
\hline \multirow{10}{*}{ Glucose } & \multirow{2}{*}{ Mineral acids } & \multirow{2}{*}{$\mathrm{H}_{2} \mathrm{SO}_{4}$} & $140{ }^{\circ} \mathrm{C}$ & $2 \mathrm{~h}$ & $38 \%$ & - & 48 \\
\hline & & & $170^{\circ} \mathrm{C}$ & $2 \mathrm{~h}$ & $34 \%$ & - & 206 \\
\hline & Organic acid & TFA & $180^{\circ} \mathrm{C}$ & $1 \mathrm{~h}$ & $35 \%$ & - & 208 \\
\hline & Mineral acid & $\mathrm{CrCl}_{3}, \mathrm{HCl}$ & $140^{\circ} \mathrm{C}$ & $6 \mathrm{~h}$ & $46 \%$ & - & 211 \\
\hline & & $\mathrm{CrCl}_{3}, \mathrm{HY}$ & $145.2^{\circ} \mathrm{C}$ & $2.45 \mathrm{~h}$ & $55.2 \%$ & - & 212 \\
\hline & & $\mathrm{Cr} / \mathrm{HZSM}-5$ & $180^{\circ} \mathrm{C}$ & $3 \mathrm{~h}$ & $64.4 \%$ & $50 \%-4$ runs & 213 \\
\hline & $\begin{array}{l}\text { Graphene } \\
\text { oxide }\end{array}$ & $\mathrm{GO}-\mathrm{SO}_{3} \mathrm{H}$ & $200^{\circ} \mathrm{C}$ & $2 \mathrm{~h}$ & $74 \%$ & $60 \%-5$ runs & 238 \\
\hline & \multirow{2}{*}{$\begin{array}{l}\text { Ion exchange } \\
\text { resins }\end{array}$} & Amberlyst-36TM & $140{ }^{\circ} \mathrm{C}$ & $3 \mathrm{~h}$ & $52.3 \%$ & - & 214 \\
\hline & & Sn-Beta,Amberlyst-15 & $140^{\circ} \mathrm{C}$ & $12 \mathrm{~h}$ & $45 \%$ & - & 215 \\
\hline & $\begin{array}{l}\text { Heteropoly } \\
\text { acid }\end{array}$ & $\mathrm{ChH}_{4} \mathrm{PWTi}$, & $130^{\circ} \mathrm{C}$ & $8 \mathrm{~h}$ & $76.1 \%$ & $73 \%$ - 12 runs & 218 \\
\hline \multirow{5}{*}{ Fructose } & \multirow{2}{*}{ Organic acid } & TFA & $180^{\circ} \mathrm{C}$ & $1 \mathrm{~h}$ & $45 \%$ & - & 208 \\
\hline & & PTSA & $88^{\circ} \mathrm{C}$ & $8.33 \mathrm{~h}$ & $16 \%$ & - & 207 \\
\hline & Mineral acid & $\mathrm{HCl}$ & $\begin{array}{c}140{ }^{\circ} \mathrm{C} \\
\text { Water/Methanol }\end{array}$ & $1.33 \mathrm{~h}$ & $72 \%$ & - & 209 \\
\hline & & $\mathrm{NaCl}, \mathrm{HCl}$ & $88^{\circ} \mathrm{C}$ & $8.33 \mathrm{~h}$ & $34 \%$ & - & 207 \\
\hline & $\begin{array}{c}\text { Ion exchange } \\
\text { resins } \\
\end{array}$ & Amberlyst XN & $100^{\circ} \mathrm{C}$ & $9 \mathrm{~h}$ & $16 \%$ & - & 239 \\
\hline \multicolumn{8}{|c|}{ LA esters production } \\
\hline \multirow{10}{*}{ Glucose } & $\begin{array}{c}\text { Aluminium } \\
\text { sulfate }\end{array}$ & $\mathrm{Al}_{2}\left(\mathrm{SO}_{4}\right)_{3}$ & $160^{\circ} \mathrm{C}$ & $2.5 \mathrm{~h}$ & $64 \%$ (ML) & $\sim 64 \%$ - 5 runs & 221 \\
\hline & $\begin{array}{c}\text { Sulfated } \\
\text { metal oxides }\end{array}$ & $\mathrm{SO}_{4}^{2-} / \mathrm{TiO}_{2}$ & $200^{\circ} \mathrm{C}$ & $2 \mathrm{~h}$ & $\begin{array}{c}33.2 \% \\
(\mathrm{ML}) \\
\end{array}$ & $20 \%-7$ runs & 210 \\
\hline & \multirow{2}{*}{$\begin{array}{l}\text { Montmorillon } \\
\text { ites }\end{array}$} & $\mathrm{SO}_{4}{ }^{2-} / \mathrm{MMT}$ & $200{ }^{\circ} \mathrm{C}$ & $4 \mathrm{~h}$ & $48 \%$ (ML) & - & 241 \\
\hline & & $\mathrm{Al}^{3+} / \mathrm{MMT}$ & $220^{\circ} \mathrm{C}$ & $6 \mathrm{~h}$ & $60 \%(M L)$ & $\sim 60 \%$ - 5 runs & 222 \\
\hline & \multirow{3}{*}{ Zeolite } & Sn-Al- $\beta$ & $160^{\circ} \mathrm{C}$ & $5 \mathrm{~h}$ & $43 \%$ (ML) & $39 \%$ - 5 runs & 242 \\
\hline & & USY & $180^{\circ} \mathrm{C}$ & $3 \mathrm{~h}$ & $45 \%$ (EL) & $\sim 35 \%-6$ runs & 219 \\
\hline & & $\mathrm{H}$-USY, $\mathrm{SnO}_{2}$ & $180^{\circ} \mathrm{C}$ & $3 \mathrm{~h}$ & $81 \%(E L)$ & - & 223 \\
\hline & Ionic liquids & $\mathrm{NEt}_{3} \mathrm{~B}-\mathrm{SO}_{3} \mathrm{H}$ & $140^{\circ} \mathrm{C}$ & $24 \mathrm{~h}$ & $6 \%(E L)$ & - & 243 \\
\hline & Nanoparticles & Nano- $\mathrm{TiO}_{2}$ & $175^{\circ} \mathrm{C}$ & $9 \mathrm{~h}$ & $61 \%(\mathrm{ML})$ & - & 220 \\
\hline & $\begin{array}{l}\text { Heteropoly } \\
\text { acid }\end{array}$ & $\mathrm{H}_{2} \mathrm{Zr}_{1} \mathrm{PW}_{12} \mathrm{O}_{40}, \mathrm{Sn}-\beta$ & $180^{\circ} \mathrm{C}$ & $3 \mathrm{~h}$ & $55 \%$ (EL) & - & 244 \\
\hline \multirow{4}{*}{ Fructose } & Mineral acid & $\mathrm{H}_{2} \mathrm{SO}_{4}$ & $120^{\circ} \mathrm{C}$ & $30 \mathrm{~h}$ & $56 \%(E L)$ & - & 245 \\
\hline & Ionic liquids & $\mathrm{NEt}_{3} \mathrm{~B}-\mathrm{SO}_{3} \mathrm{H}$ & $140^{\circ} \mathrm{C}$ & $24 \mathrm{~h}$ & $72 \%(E L)$ & $\sim 72 \%$ - 3 runs & 243 \\
\hline & \multirow{2}{*}{ Zeolite } & \multirow{2}{*}{ H-USY } & $160^{\circ} \mathrm{C}$ & $20 \mathrm{~h}$ & $51 \%(\mathrm{ML})$ & $45 \%-5$ runs & 246 \\
\hline & & & $160^{\circ} \mathrm{C}$ & $20 \mathrm{~h}$ & $40 \%$ (EL) & $\sim 40 \%-5$ runs & 246 \\
\hline
\end{tabular}




\begin{tabular}{|c|c|c|c|c|c|c|c|}
\hline & $\begin{array}{l}\text { Sulfonic acid } \\
\text { func. SBA-15 }\end{array}$ & $\mathrm{SO}_{3} \mathrm{H}-\mathrm{SBA}-15$ & $140^{\circ} \mathrm{C}$ & $24 \mathrm{~h}$ & $57 \%$ (EL) & $57 \%-3$ runs & 129 \\
\hline & $\begin{array}{c}\text { Supported } \\
\text { phosphotung. } \\
\text { acid } \\
\end{array}$ & HPW/H-ZSM-5 & $160^{\circ} \mathrm{C}$ & $2 \mathrm{~h}$ & $43.1 \%$ (EL) & $25 \%-4$ runs & 247 \\
\hline & $\begin{array}{l}\text { Modified } \\
\text { metal }\end{array}$ & K-HPW-1 & $\begin{array}{c}150{ }^{\circ} \mathrm{C} \\
\text { Ethanol/Toluene }\end{array}$ & $2 \mathrm{~h}$ & $64.6 \%$ (EL) & $50 \%-5$ runs & 248 \\
\hline \multirow{14}{*}{ Fructose } & \multirow{3}{*}{$\begin{array}{c}\text { Sulfated } \\
\text { metal oxides }\end{array}$} & $\mathrm{SO}_{4}{ }^{2-} / \mathrm{MMT}$ & $200^{\circ} \mathrm{C}$ & $4 \mathrm{~h}$ & $65 \%(M L)$ & - & 241 \\
\hline & & $\mathrm{SO}_{4}^{2-} / \mathrm{TiO}_{2}$ & $200{ }^{\circ} \mathrm{C}$ & $2 \mathrm{~h}$ & $59 \%(\mathrm{ML})$ & $20 \%-7$ runs & 210 \\
\hline & & $\mathrm{SO}_{4}^{2-} / \mathrm{TiO}_{2}-\mathrm{ZrO}_{2}$ & $200^{\circ} \mathrm{C}$ & $1 \mathrm{~h}$ & $71 \%(\mathrm{ML})$ & $30 \%-5$ runs & 249 \\
\hline & \multirow{4}{*}{$\begin{array}{c}\text { Grafted } \\
\text { carbon } \\
\text { nanotubes }\end{array}$} & \multirow{4}{*}{ CNT-PSSA } & $120^{\circ} \mathrm{C}$ & $24 \mathrm{~h}$ & $69 \%$ (ML) & - & 227 \\
\hline & & & $120^{\circ} \mathrm{C}$ & $24 \mathrm{~h}$ & $84 \%$ (EL) & $69 \%-5$ runs & 227 \\
\hline & & & $120^{\circ} \mathrm{C}$ & $24 \mathrm{~h}$ & $86 \%$ (PL) & - & 227 \\
\hline & & & $120^{\circ} \mathrm{C}$ & $24 \mathrm{~h}$ & $87 \%(B L)$ & - & 227 \\
\hline & \multirow{3}{*}{$\begin{array}{l}\text { Ion exchange } \\
\text { resins }\end{array}$} & \multirow[b]{2}{*}{ Amberlyst-15 } & $120^{\circ} \mathrm{C}$ & $24 \mathrm{~h}$ & $73 \%(E L)$ & - & 227 \\
\hline & & & $120^{\circ} \mathrm{C}$ & $24 \mathrm{~h}$ & $89 \%(B L)$ & - & 227 \\
\hline & & Dowex 50Wx2 & $120^{\circ} \mathrm{C}$ & $8 \mathrm{~h}$ & $73.4 \%$ (BL) & $51 \%-3$ runs & 127 \\
\hline & $\begin{array}{l}\text { Silicotung. } \\
\text { based }\end{array}$ & SnSiW-423 & $150{ }^{\circ} \mathrm{C}$ & $2 \mathrm{~h}$ & $70 \%(E L)$ & $\sim 70 \%$ - 7 runs & 250 \\
\hline & $\begin{array}{c}\text { Phosphotung. } \\
\text { acid based }\end{array}$ & 3-FPYPW & $120^{\circ} \mathrm{C}$ & $10 \mathrm{~h}$ & $\begin{array}{c}82.5 \% \\
(\mathrm{ML})\end{array}$ & $73 \%$ - 4 runs & 251 \\
\hline & Nanoparticles & Nano- $\mathrm{TiO}_{2}$ & $175^{\circ} \mathrm{C}$ & $1 \mathrm{~h}$ & $80 \%(\mathrm{ML})$ & $40 \%-5$ runs & 220 \\
\hline & $\begin{array}{l}\text { Carbon } \\
\text { cryogel }\end{array}$ & UCC-S-Fe-300 & $200{ }^{\circ} \mathrm{C}$ & $6 \mathrm{~h}$ & $55 \%(E L)$ & - & 252 \\
\hline \multirow{9}{*}{ Sucrose } & $\begin{array}{l}\text { Sulfonic acid } \\
\text { func. SBA-15 }\end{array}$ & $\mathrm{SO}_{3} \mathrm{H}-\mathrm{SBA}-15$ & $140^{\circ} \mathrm{C}$ & $24 \mathrm{~h}$ & $27 \%(E L)$ & - & 129 \\
\hline & $\begin{array}{l}\text { Modified } \\
\text { metal }\end{array}$ & K-HPW-1 & $\begin{array}{c}150^{\circ} \mathrm{C} \\
\text { Ethanol/Toluene }\end{array}$ & $2 \mathrm{~h}$ & $35.4 \%$ (EL) & - & 248 \\
\hline & $\begin{array}{c}\text { Supported } \\
\text { phosphotung. } \\
\text { acid } \\
\end{array}$ & HPW/H-ZSM-5 & $160^{\circ} \mathrm{C}$ & $2 \mathrm{~h}$ & $27.3 \%$ (EL) & - & 247 \\
\hline & \multirow{2}{*}{$\begin{array}{c}\text { Sulfated } \\
\text { metal oxides }\end{array}$} & $\mathrm{SO}_{4}^{2-} / \mathrm{TiO}_{2}$ & $200^{\circ} \mathrm{C}$ & $2 \mathrm{~h}$ & $43 \%(\mathrm{ML})$ & - & 210 \\
\hline & & $\mathrm{SO}_{4}^{2-} / \mathrm{TiO}_{2}-\mathrm{ZrO}_{2}$ & $200{ }^{\circ} \mathrm{C}$ & $1 \mathrm{~h}$ & $54 \%(\mathrm{ML})$ & - & 249 \\
\hline & $\begin{array}{l}\text { Modified } \\
\text { carbon }\end{array}$ & $\mathrm{AC}-\mathrm{Fe}-\mathrm{SO}_{3} \mathrm{H}$ & $200{ }^{\circ} \mathrm{C}$ & $3 \mathrm{~h}$ & $29 \%(E L)$ & - & 253 \\
\hline & $\begin{array}{l}\text { Tungsten } \\
\text { disulfide }\end{array}$ & $\mathrm{WS}_{2}$ & $\begin{array}{c}160^{\circ} \mathrm{C} \\
\text { Microwaves }\end{array}$ & $0.5 \mathrm{~h}$ & $23 \%(E L)$ & - & 254 \\
\hline & \multirow{2}{*}{$\begin{array}{c}\text { Acid- } \\
\text { sulfonated } \\
\text { carbon }\end{array}$} & $\mathrm{Zn}-\mathrm{SC}$ & $\begin{array}{c}100^{\circ} \mathrm{C} \\
\text { Ultrasonic system } \\
\text { THF/Ethanol } \\
\end{array}$ & $1 \mathrm{~h}$ & $72.1 \%$ (EL) & $66 \%-7$ runs & 255 \\
\hline & & $\mathrm{Zn}-\mathrm{SC}$ & $\begin{array}{c}100{ }^{\circ} \mathrm{C} \\
\text { Reflux system } \\
\text { THF/Ethanol } \\
\end{array}$ & $12 \mathrm{~h}$ & $64.2 \%$ (EL) & - & 255 \\
\hline
\end{tabular}


Table 8 Conversion of C5 monosaccharides to LA and LES

\begin{tabular}{|c|c|c|c|c|c|c|c|}
\hline Feedstock & & Catalyst & Conditions $^{a}$ & Time & Yield $^{b}$ & $\begin{array}{l}\text { Catalyst } \\
\text { reuse }^{c}\end{array}$ & Ref. \\
\hline \multirow{10}{*}{ Xylose } & Mineral acid & $\mathrm{H}_{2} \mathrm{SO}_{4}$ & $200^{\circ} \mathrm{C}$ & $0.13 \mathrm{~h}$ & $64.4 \%(\mathrm{LA})$ & - & 237 \\
\hline & Organic acid & $\begin{array}{l}\text { Methanesulfonic } \\
\text { acid (MSA) }\end{array}$ & $180^{\circ} \mathrm{C}$ & $0.25 \mathrm{~h}$ & $64.7 \%(\mathrm{LA})$ & - & 237 \\
\hline & \multirow{4}{*}{ Metal salts } & $\mathrm{FeCl}_{3} / \mathrm{FeCl}_{3}+\mathrm{NaCl}$ & $180^{\circ} \mathrm{C}$ & $2 \mathrm{~h}$ & $48.5 / 68 \%$ (LA) & $52.5 \%-4$ runs & 235 \\
\hline & & $\mathrm{CuCl}_{2} \cdot 2 \mathrm{H}_{2} \mathrm{O}$ & $180^{\circ} \mathrm{C}$ & $2 \mathrm{~h}$ & $34 \%$ (LA) & - & 235 \\
\hline & & $\mathrm{CrCl}_{3} \cdot 6 \mathrm{H}_{2} \mathrm{O}$ & $180^{\circ} \mathrm{C}$ & $2 \mathrm{~h}$ & $25 \%(\mathrm{LA})$ & - & 235 \\
\hline & & $\mathrm{AlCl}_{3} \cdot 6 \mathrm{H}_{2} \mathrm{O}$ & $180^{\circ} \mathrm{C}$ & $2 \mathrm{~h}$ & $26 \%$ (LA) & - & 235 \\
\hline & \multirow{2}{*}{$\begin{array}{l}\text { Ion exchange } \\
\text { resins }\end{array}$} & \multirow{2}{*}{ Amberlyst 70} & $150^{\circ} \mathrm{C}$ & $6 \mathrm{~h}$ & $41.6 \%$ (ML) & - & 139 \\
\hline & & & $160^{\circ} \mathrm{C}$ & $2 \mathrm{~h}$ & $21.8 \%(E L)$ & - & 139 \\
\hline & $\begin{array}{c}\text { Mesoporous } \\
\text { zirconium silicate }\end{array}$ & KITZ20 & $200{ }^{\circ} \mathrm{C}$ & $5 \mathrm{~h}$ & $87.7 \%(B L)$ & $79.8 \%-4$ runs & 256 \\
\hline & Dual catalyst & $\begin{array}{c}\mathrm{Zr}(20)-\mathrm{MCM}-41 \\
+\mathrm{H}_{3} \mathrm{O}_{40} \mathrm{PW}_{12}\end{array}$ & - & - & $53 \%(B L)$ & $50 \%-4$ runs & 257 \\
\hline \multirow{4}{*}{$\begin{array}{l}\text { Xylose } \\
\text { +Glucose }\end{array}$} & Mineral acid & $\mathrm{H}_{2} \mathrm{SO}_{4}$ & $200^{\circ} \mathrm{C}$ & $0.13 \mathrm{~h}$ & $61.6 \%(\mathrm{LA})$ & - & 237 \\
\hline & Organic acid & $\begin{array}{c}\text { Methanesulfonic } \\
\text { acid (MSA) }\end{array}$ & $180^{\circ} \mathrm{C}$ & $0.25 \mathrm{~h}$ & $54.8 \%$ (LA) & - & 237 \\
\hline & $\begin{array}{c}\text { Ion exchange } \\
\text { resins }\end{array}$ & Amberlyst 70 & $160^{\circ} \mathrm{C}$ & $2 \mathrm{~h}$ & $40.7 \%$ (ML) & - & 139 \\
\hline & Zeolite & Modified- $H \beta$ & $\begin{array}{c}160{ }^{\circ} \mathrm{C} \\
\text { 1,3,5-trioxane }\end{array}$ & $18 \mathrm{~h}$ & $50.4 \%(\mathrm{ML})$ & 50 \% - 5 runs & 258 \\
\hline
\end{tabular}

${ }^{a}$ using water or alcohols as solvent, unless otherwise specified. ${ }^{b}$ Methyl (ML), ethyl (EL), butyl (BL) levulinate. ${ }^{\mathrm{c}}$ yield after $\mathrm{N}$ reuse cycles tested.

\subsection{Direct production from cellulose, hemicellulose and biomass (LCB)}

Compared to the use of pure monomeric sugars, as fructose, glucose and xylose, and other precursors, the employment of raw complex lignocellulosic substrates in the production of levulinic acid and alkyl levulinates can provide a cheap and promising alternative for the industrial-scale production sustainability, reducing the disposal of potentially usable waste and increasing the development of agribusinesses and rural sectors, even though to date monosaccharides processing offers the highest product yields. ${ }^{176}$ Besides the raw lignocellulosic feedstocks, many researchers have investigated the production of levulinates via hydrolysis of single-cell wall components of plants: cellulose and hemicellulose. Both abundant in nature, they lead to the production of value-added chemicals through hydrolysis to simple sugars and the subsequent acid catalysis of the latter; in particular for cellulose, the synthesis of levulinic acid and its esters passes through the production of the intermediate 5-HMF, being mainly rich in glucose, while for hemicellulose through the pentose pathway and thus by the route of furfural. ${ }^{259}$ On the other hand, the use of raw lignocellulosic matrix, often of variable composition and unknown sugar content, determines the production of sugar mixture (both hexoses and pentoses) and consequently the increased complexity of the process. To economize the production, low cost raw lignocellulosic sources should be selected as fast-growing grasses and trees: switchgrass, giant reed, miscanthus, poplar; but also low-value municipal and industrial wastes: wheat straw, sugarcane bagasse, rice husk, corn stover, sawdust, pulp sludge, olive tree pruning, fruit peels. ${ }^{44,176,259}$ The complexity and heterogeneity of these substrates require pre-treatment steps to improve subsequence yields and reaction rates.

Given the high efficiency and the relatively low cost, mineral acids have been intensely used and still employed in the industrial-scale production of levulinic acid and esters from LCB (Table 9). The most commonly used mineral acid catalysts are $\mathrm{H}_{2} \mathrm{SO}_{4}$ and $\mathrm{HCl}$. The reactivity of the catalyst is highly related to the nature and concentration of the initial feedstocks; for example, $\mathrm{HCl}$ is particularly suitable for converting high calciumcontaining biomass, as a paper mill and tobacco chops, because of the $\mathrm{H}_{2} \mathrm{SO}_{4}$ tendency to form precipitating $\mathrm{CaSO}_{4}$, with possible reactor clogging effect. ${ }^{260}$ Significant levulinic acid yields have resulted from the use of these acids in various 
lignocellulosic feedstocks: pretreated rice husks are employed by Bevilaqua et al. ${ }^{261}$ at $170{ }^{\circ} \mathrm{C}$ for $1 \mathrm{~h}$, resulting LA yields of 59.4 and $45.7 \mathrm{wt} \%$ for $\mathrm{HCl}$ and $\mathrm{H}_{2} \mathrm{SO}_{4}$ respectively; ${ }^{261}$ paper sludge led to $31.4 \mathrm{wt} \%$ and $15.4 \mathrm{wt} \%$ of LA yield at $200{ }^{\circ} \mathrm{C}$ for $1 \mathrm{~h}$ under the action of diluted $\mathrm{HCl}$ and concentrated $\mathrm{H}_{2} \mathrm{SO}_{4}$ in Raspolli Galletti et al. studies; 260 wheat straw is another promising feedstock, analyzed by Chang et al. ${ }^{262}$ who reported yields around 20 wt $\%$ at $200{ }^{\circ} \mathrm{C}$ for both catalysts; ${ }^{262}$ liquefaction of bagasse and paddy straw have been tested with $\mathrm{HCl}$ at $220^{\circ} \mathrm{C}$ by Yan et al., ${ }^{263}$ reporting LA yield of 22.8 and 23.7 wt\%; ${ }^{263}$ and fast-growing plants as giant reed that leads to producing LA yield of $24 \mathrm{wt} \%$ at $190{ }^{\circ} \mathrm{C}$ for $1 \mathrm{~h} .{ }^{264}$ On the other hand, the direct production from cellulose leads to higher yields, as $40.8 \mathrm{wt} \%$ at $150{ }^{\circ} \mathrm{C}$ for $6 h^{265}$ or $43 w t \%$ for 2 h. ${ }^{266}$ The final LA concentration is strongly affected by the initial substrate concentration; a low feedstock concentration results in a higher yield of LA and esters because exceeding a particular biomass loading is conducive to the excessive occurrence of unwanted secondary reactions. ${ }^{267}$ At the same time to ensure the industrial intensification of the process and avoid too high separation costs due to the low concentration products, the concept of high-gravity should be applied; i.e., a process operating at the highest possible concentrations of raw material. 203,268

Given the difficult recovery of LA from the reacting mixture, a higher LA concentration is favorable since it leads to a lower energy-demanding purification and a reduced amount of wastewater, but this cannot be achieved by increasing the substrate loading infinitely. Thus, smart solutions have to be applied to optimize production. ${ }^{176,203} \mathrm{~A}$ possible solution is the use of a biphasic system (water-organic system) in which the presence of the organic solvent helps stabilize the intermediates formed, decreasing the unwanted reactions and improving the product selectivity. Furthermore, selecting a solvent immiscible in water with a higher LA partition coefficient than water allows efficient LA extraction. ${ }^{269}$ All polar aprotic solvents, as tetrahydrofuran (THF), gammavalerolactone (GVL), dimethyl sulfoxide (DMSO), can stabilize the reactive intermediates and, for those miscible in water, it is possible to increase the immiscibility by adding salts to the aqueous phase. Cellulose deconstruction in a biphasic system (water-gamma-valerolactone) has been reported by Wettstein et al., ${ }^{270}$ performed in $\mathrm{GVL}$ and an aqueous solution of $\mathrm{HCl}$ and $\mathrm{NaCl}$. The majority of LA was extracted by $\mathrm{GVL}$ at $155{ }^{\circ} \mathrm{C}$, obtaining a yield of $51.6 \mathrm{wt} \%$ after 1.5 h. ${ }^{270}$ The effect of GVL as solvent has also been analyzed in the conversion of hemicellulose in the presence of sulfuric acid by Mellmer et al.; ${ }^{271}$ in this work, they highlighted how this polar aprotic solvent increased product selectivities and reaction rates, thanks to the stabilizing effect on the acidic proton relative to the protonated transition states. In particular, the solvent affected the activation energies of reaction steps, as dehydration of xylose to furfural. ${ }^{271}$ Benefits on the reaction time and the occurrence of unwanted reactions have been shown by the substitution of traditional heating with microwave heating ( $\mathrm{MW}$ ); positive $\mathrm{MW}$ effects were confirmed in the conversion to LA of paper sludge, poplar sawdust, olive tree pruning ${ }^{260}$ and cellulose ${ }^{272}$ as raw starting substrates. The same or even higher yield was observed applying MW technologies but observing an evidence reaction time reduction: increasing LA yield from 21.3 to $26.4 \mathrm{wt} \%$ and decreasing time from $1 \mathrm{~h}$ to 15 min in the presence of $\mathrm{HCl}$ for conversion of poplar sawdust; LA yield from 18.6 to 20.1 wt\% using olive tree pruning as substrate and reduction of reaction time by $45 \mathrm{~min}^{260}$ The improved production and rapidity of the system are due to sidewall effects decreasing and higher homogeneous heat distribution by microwave heating, which results in being more selective for polar substances changing their selectivities, and avoiding their thermal decompositions. ${ }^{44,203,273}$

Mineral acids have been successfully used even in the direct production of levulinate esters from cellulose and raw lignocellulosic biomass. Methanolysis of raw biorenewable materials, as bamboo and corn starch, has been reported by Feng et al. ${ }^{274}$ Liquified bamboo was treated in a batch system in the presence of sulfuric acid in subcritical methanol, reporting a methyl levulinate (ML) yield of $27.7 \mathrm{wt} \%$ at $200{ }^{\circ} \mathrm{C}$ for $1 \mathrm{~h}$. The group has tested various other substrates: corn starch resulting in $\mathrm{ML}$ yield of $48.7 \mathrm{wt} \%$ at $180{ }^{\circ} \mathrm{C}$ and microcrystalline cellulose with ML yield of 23.9 wt\% at $200{ }^{\circ} \mathrm{C}$, both after 2 h. ${ }^{274}$ Wood, bagasse, and wheat straw were employed in the direct production of methyl levulinate and also waste sources as paper sludge; this last substrate has determined an overall $\mathrm{ML}$ yield of 27.7 wt\% under mineral acid condition at $220^{\circ} \mathrm{C} .{ }^{275}$ Using low concentration of sulfuric acid $(\leq 0.02 \mathrm{~mol} / \mathrm{L}$ ), cellulose (concentration range 30-100 g/L) have reported $\mathrm{ML}$ molar yields around $50 \mathrm{~mol} \%$, near $200{ }^{\circ} \mathrm{C}$ and up to $2 \mathrm{~h}$, according to different research groups. ${ }^{276,277}$ Sulfuric acid was found to be very active also in the degradation of cellulose and more complex biomass matrix with ethanol, giving ethyl levulinate molar yields up to $60 \mathrm{~mol} \% .^{278}$ Several one-pot conversions to EL of different substrates have been reported in the literature: wheat straw was remarked by Chang et al., ${ }^{279}$ as a promising, cheap, widely available raw substrate rich in cellulose, efficiently converted into ethyl levulinate under the action of sulfuric acid in ethanol medium, resulting in an optimum yield of 17.9 wt\%;279 paper pulp, wood chips and switch grass have produced comparable results in term of EL, yield of 25.9, 16.6, 13.8 wt\%, respectively. ${ }^{280}$ The optimization of the acidalcoholysis process has been investigated by Dai et al., ${ }^{278}$ thanks to the combination of sulfuric acid with an Al-salt (Al(OTf) 3 ); being a Lewis acid catalyst, the salt catalyst can better catalyze than sulfuric acid, which is a Brønsted acid, the isomerisation of glucose to fructose leading to higher EL yields. Comparing the production from cellulose in the absence and in the presence of the salt, obtained EL yield was 20.2 versus $53.7 \mathrm{~mol} \%$; and considering different substrates, the mixed-acid system determined yield of 64.7 mol\% employing paper pulp, 54.3 mol\% with pine wood and 53.7 mol\% using bamboo as starting feedstock. ${ }^{278}$ Changing the alcohol medium, mineral acids lead to the production of higher molecular levulinates as butyl levulinate; cellulose was tested in the presence of sulfuric acid in 1-butanol medium, obtaining a yield of $50 \mathrm{~mol} \%$ in an autoclave at $200{ }^{\circ} \mathrm{C}$ for $30 \mathrm{~min}^{281}$ or a yield exceeding $60 \mathrm{~mol} \%$ operating with higher acid concentration. ${ }^{282}$ Yield up to $40 \mathrm{~mol} \%$ was obtained by using raw biomass, as Eucalyptus nitens 
wood $^{283}$ and rice straw. ${ }^{284}$ Démolis et al. ${ }^{281}$ also investigated the influence of different butanol isomers, highlighting that the primary alcohol group is more efficient, giving higher levulinates yields. ${ }^{281}$

Table 9 Production of LA and LEs from LCB via homogeneous catalysis.

\begin{tabular}{|c|c|c|c|c|c|c|}
\hline Catalyst & Substrate & Conditions $^{\mathrm{a}}$ & Time & Yield $^{\mathrm{b}}$ & Catalyst reuse ${ }^{c}$ & Ref. \\
\hline \multicolumn{7}{|l|}{ Mineral acids } \\
\hline \multirow{11}{*}{$\mathrm{HCl}$} & Pretreated rice husks & $170{ }^{\circ} \mathrm{C}$ & $1 \mathrm{~h}$ & $59.4 \%(L A)$ & - & 261 \\
\hline & Paper sludge & $200{ }^{\circ} \mathrm{C}$ & $1 \mathrm{~h}$ & $31.4 \%$ (LA) & - & 260 \\
\hline & Wheat straw & $200^{\circ} \mathrm{C}$ & $1 \mathrm{~h}$ & $20 \%(L A)$ & - & 262 \\
\hline & Bagasse & $220^{\circ} \mathrm{C}$ & $0.75 \mathrm{~h}$ & $22.8 \%(L A)$ & - & 263 \\
\hline & Paddy straw & $220^{\circ} \mathrm{C}$ & $0.75 \mathrm{~h}$ & $23.7 \%(\mathrm{LA})$ & - & 263 \\
\hline & Giant reed & $190{ }^{\circ} \mathrm{C}$ & $1 \mathrm{~h}$ & $24 \%$ (LA) & - & 264 \\
\hline & Poplar sawdust & $200{ }^{\circ} \mathrm{C}$ & $1 \mathrm{~h}$ & $21.3 \%(\mathrm{LA})$ & - & 260 \\
\hline & Poplar sawdust & $200{ }^{\circ} \mathrm{C} \mathrm{MW}$ & $0.25 \mathrm{~h}$ & $26.4 \%(L A)$ & - & 260 \\
\hline & Olive tree pruning & $200{ }^{\circ} \mathrm{C}$ & $1 \mathrm{~h}$ & $18.6 \%(L A)$ & - & 260 \\
\hline & Olive tree pruning & $200{ }^{\circ} \mathrm{C} \mathrm{MW}$ & $0.25 \mathrm{~h}$ & $20.1 \%(L A)$ & - & 260 \\
\hline & Cellulose & $\begin{array}{c}155^{\circ} \mathrm{C} \\
\text { GVL/Water }\end{array}$ & $1.5 \mathrm{~h}$ & $51.6 \%$ (LA) & - & 270 \\
\hline \multirow{14}{*}{$\mathrm{H}_{2} \mathrm{SO}_{4}$} & Pretreated rice husks & $170{ }^{\circ} \mathrm{C}$ & $1 \mathrm{~h}$ & $45.7 \%$ (LA) & - & 261 \\
\hline & Paper sludge & $200{ }^{\circ} \mathrm{C}$ & $1 \mathrm{~h}$ & $15.4 \%(\mathrm{LA})$ & - & 260 \\
\hline & Wheat straw & $200{ }^{\circ} \mathrm{C}$ & $1 \mathrm{~h}$ & $20 \%(\mathrm{LA})$ & - & 262 \\
\hline & Cellulose & $150^{\circ} \mathrm{C}$ & $2 \mathrm{~h}$ & $43 \%(L A)$ & - & 266 \\
\hline & Cellulose & $150{ }^{\circ} \mathrm{C}$ & $6 \mathrm{~h}$ & $40.8 \%(L A)$ & - & 265 \\
\hline & Liquified bamboo & $200{ }^{\circ} \mathrm{C}$ & $1 \mathrm{~h}$ & $27.7 \%$ (ML) & - & 274 \\
\hline & Corn starch & $180^{\circ} \mathrm{C}$ & $2 \mathrm{~h}$ & $48.7 \%$ (ML) & - & 274 \\
\hline & Cellulose & $200{ }^{\circ} \mathrm{C}$ & $2 \mathrm{~h}$ & $23.9 \%(\mathrm{ML})$ & - & 274 \\
\hline & Wheat straw & $183^{\circ} \mathrm{C}$ & $0.6 \mathrm{~h}$ & $17.9 \%(E L)$ & - & 279 \\
\hline & Paper pulp & $190{ }^{\circ} \mathrm{C}$ & $1.7 \mathrm{~h}$ & $25.9 \%(E L)$ & - & 280 \\
\hline & Wood chips & $190{ }^{\circ} \mathrm{C}$ & $1.7 \mathrm{~h}$ & $16.6 \%$ (EL) & - & 280 \\
\hline & Switch grass & $190^{\circ} \mathrm{C}$ & $1.7 \mathrm{~h}$ & $13.8 \%(E L)$ & - & 280 \\
\hline & Bamboo & $180^{\circ} \mathrm{C}$ & $3 \mathrm{~h}$ & $53.7 \%(E L)$ & - & 278 \\
\hline & Cellulose & $200{ }^{\circ} \mathrm{C}$ & $0.5 \mathrm{~h}$ & $50 \%(B L)$ & - & 281 \\
\hline $\mathrm{H}_{2} \mathrm{SO}_{4}+\mathrm{CrCl}_{3}$ & Potato peel & $180^{\circ} \mathrm{C}$ & $0.25 \mathrm{~h}$ & $49 \%(\mathrm{LA})$ & $42 \%-3$ runs & 285 \\
\hline $\mathrm{H}_{3} \mathrm{PO}_{4}$ & Cigarette butts & $200^{\circ} \mathrm{C}$ & $6 \mathrm{~h}$ & $49.6 \%$ (LA) & - & 286 \\
\hline \multicolumn{7}{|l|}{ Ionic Liquids } \\
\hline$[\mathrm{BSMim}] \mathrm{H}_{2} \mathrm{SO}_{4}$ & Cellulose & $160{ }^{\circ} \mathrm{C}$ & $0.5 \mathrm{~h}$ & $39.4 \%$ (LA) & $\sim 39 \%$ - 4 runs & 287 \\
\hline$[\mathrm{Bmim}] \mathrm{Cl}$ & Wood residues & $220^{\circ} \mathrm{C}$ & $1.25 \mathrm{~h}$ & $38.7 \%$ (ML) & $36.6 \%-5$ runs & 288 \\
\hline$[\mathrm{BSMim}] \mathrm{H}_{2} \mathrm{SO}_{4}$ & Mesocarp fiber & $130{ }^{\circ} \mathrm{C}$ & $1.4 \mathrm{~h}$ & $14.7 \%(E L)$ & - & 33 \\
\hline$\left[\mathrm{C}_{4} \mathrm{H}_{8} \mathrm{SO}_{3} \mathrm{Hmim}\right] \mathrm{HSO}_{4}$ & Cellulose & $180^{\circ} \mathrm{C}$ & $0.75 \mathrm{~h}$ & $31.1 \%$ (BL) & $\sim 31 \%-6$ runs & 289 \\
\hline
\end{tabular}


Industrial scale production of LA and LEs is currently available on the market but not in sufficient quantities. Some of the reasons for the limited commercial-scale production of levulinic acid are production low yields, anti-corrosion equipment and materials cost, energy demand, and post-treatments cost. Difficulties in recovering LA at high concentration are due to the inherent physical properties of levulinic acid, which make this compound difficult to isolate. In addition, the low selectivity of homogeneous acid catalysts (mineral acids) leads to multiple undesirable products. ${ }^{290}$ Developed by Fitzpatrick and patented by the Biofine Corporation ${ }^{291}$, the Biofine technology eliminated some of the drawbacks in LA production, becoming one of the most known and industrially deployed technologies for the industrial production of LA from lignocellulosic biomass. Based on the acid-solvolysis by homogeneous mineral acids, the process involves a two-stages acid-catalysed reaction process. In a first plug flow reactor biomass feedstock is dehydrated to HMF between $200-230{ }^{\circ} \mathrm{C}, 20-25$ bar, for less than 30 seconds and using mineral acids (1-4\%). Subsequently, LA production occurs by hydrolysis of HMF at $190-220{ }^{\circ} \mathrm{C}, 10-15$ bar, for $15-30$ $\min$ in a second continuous stirred reactor ${ }^{292}$ (Fig. 9). The second reactor operates in the condition that allows to kept formic acid and furfural in the vapour phase, leading to a more simple separation of these products from LA. With yields between $59-83 \%$ of the theoretical value, this semi-commercial technology can produce LA from 0.42 to $0.595 \mathrm{~kg}$ per kilo of cellulose. ${ }^{50,293}$ The process co-produces also other valuable commodities including furfural, formic acid and lignin char. ${ }^{285}$ The process defined conditions to suppress the formation of byproducts and achieve high yields strongly. It employs reduced reactor volumes, minimised corrosion resistant materials, reducing the high equipment costs, but post-treatment neutralization steps for the catalyst are still necessary. Besides the Biofine process, the WALEVA project's technology proposes to convert waste LCB residues, as rice straw, ${ }^{294}$ into levulinic acid. Exploiting 2.4 million tonnes of rice residues (referred to rice production in Europe in 2012) that would normally be incinerated, the Waleva process is able to reduce the $\mathrm{CO}_{2}$ resulting from the disposal of this waste by $80 \%$, producing LA with a total yield of between $16-18 \%$, and a final product of $90-$
$95 \%$ purity. ${ }^{295}$ For the production of levulinate esters as ethyl levulinate, Dibanet project aims to design a sustainable costeffective process for the production of ethyl levulinate from lignocellulosic biomass, by combining the hydrolysis of monosaccharides to LA, then esterified to ethyl levulinate via mineral acids, with pyrolysis of the degradation biomass residues. ${ }^{296,297}$ Among its various objectives, the project seeks to replace mineral acids with more environmentally and economically sustainable catalysts in terms of purification and recycling; solid acid heteropolyacids (HPAs) have been tested, obtaining yields of $76 \%$ for ethyl levulinate with up to 4 times recycling. ${ }^{298}$ At present, the use of mineral acids is still privileged in several industrial production plants or pilot plants (GFBiochemicals, ${ }^{299,300}$ Segetis (acquired by GFBiochemicals in 2016), ${ }^{301,302}$ Biofine $\left.^{291}\right),{ }^{303}$ although research is moving towards the design of competitive heterogeneous catalysts or different homogeneous catalysts. These same advantages of mineral acids in downstream steps, i.e. purification and recycling, are not present in other homogeneous catalysts. The ionic liquids (ILs) gained great attention thanks to their stability, low vapor pressure, and easy separation and recyclability. Being easily tuned by varying ionic components, ionic liquids are versatile in cellulose and biomass transformation. $\mathrm{SO}_{3} \mathrm{H}$-functionalized ionic liquids have been tested in the production of LA from cellulose, obtaining its yield of $39.4 \mathrm{wt} \%$ at $160{ }^{\circ} \mathrm{C}$ for $30 \mathrm{~min}^{230}$ and in the production of EL from oil palm empty fruit bunch and mesocarp fiber with yields of 13.1 wt\% and 14.7 wt\%, respectively. ${ }^{33}$ Particularly active in the direct esterification of biomass-derived LA, ionic liquids, as 1-Methyl imidazolium hydrogen sulphate $[\mathrm{MIM}]\left[\mathrm{HSO}_{4}\right]$, catalysed the LA esterification to $\mathrm{BL}$, obtaining a final yield of $89.6 \mathrm{~mol} \%$ at $90{ }^{\circ} \mathrm{C}$ in $90 \mathrm{~min} .{ }^{92}$ In addition to the efficient catalytic activity, with the possibility to be recycled without loss of functionality (demonstrated 10 cycles for $\left.[\mathrm{Hmim}]\left[\left(\mathrm{HSO}_{4}\right)\left(\mathrm{H}_{2} \mathrm{SO}_{4}\right)_{2}\right]\right),{ }^{304}$ ionic liquids have been tested as a solvent in alkyl levulinate production from biomass. Liang et al. ${ }^{288}$ reported the important role of 1-butyl-3-methyl imidazolium chloride $(\mathrm{BmimCl})$ in the depolymerization of cellulose, derived from wood residue, which produced a ML yield of 38.7 mol\% in the optimum conditions. ${ }^{288}$ Nevertheless, ionic liquid also present several drawbacks: not completely

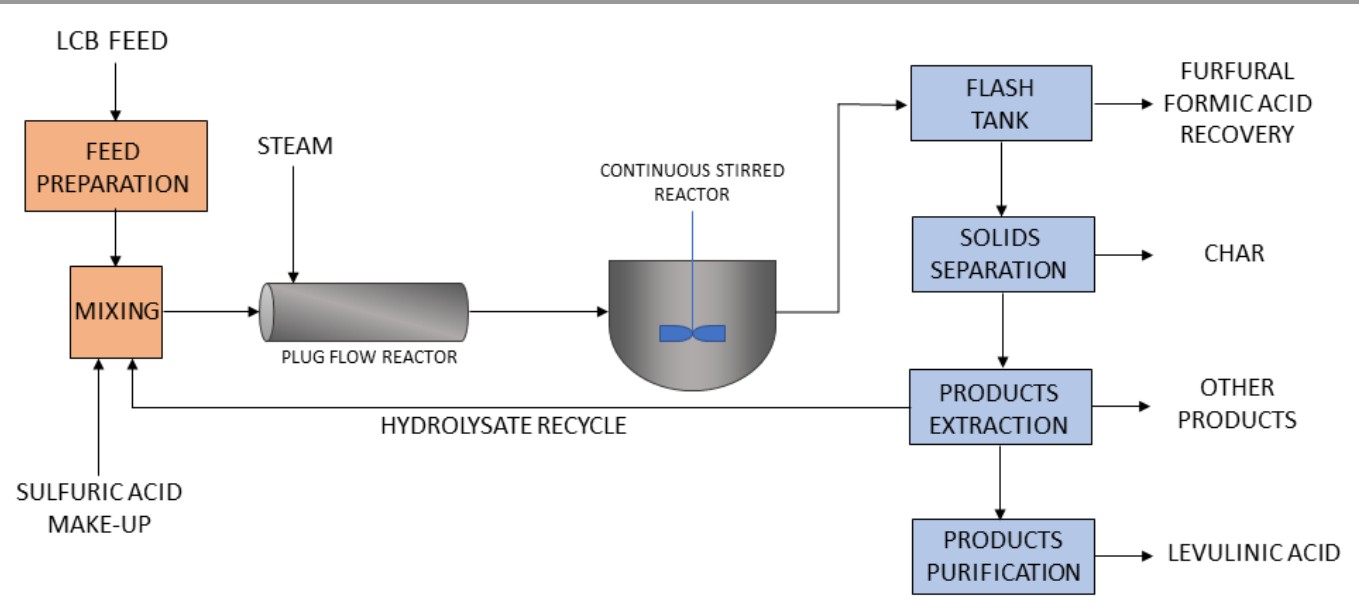

Fig. 9 Process scheme of the Biofine technology. ${ }^{292}$ 
environmentally friendly; ${ }^{305}$ high viscosity, which reduces mass transfer in the liquid and requires the presence of water to improve it; 44,306 possible equipment corrosion, especially in fact of water; their low vapor pressure makes their recovery by distillation not suited; and last but not least, their high cost which undermines their use on an industrial scale (up to 100 times higher cost than organic solvents). ${ }^{44,176,307}$

Although homogeneous catalysts resulted strongly in biomass valorization, the industrial introduction of heterogeneous catalysis is one of the greatest challenges that industry faces moving towards a bio-based market and solving technological disadvantages, such as equipment corrosion, environmental pollution, and difficult recycling, typical of homogeneous acid catalysts. However, the development of heterogeneous catalysts is imperative from a practical and environmental industrial perspective. Most of the new synthesized and characterized catalysts are restricted to academic investigations, due to factors limiting their catalytic action (Table 10). ${ }^{44}$

The limited catalytic yield is mainly due to the difficult solidsolid interaction between catalyst and substrate and the catalyst deactivation. Mass transport is troubled by the difficult access to the active catalytic species into the solid or swelled biomass and further prevented by the deposition of solid byproducts, such as humins and lignin-derived residues, leading to catalyst deactivation. ${ }^{176,259}$ To increase productivity, solid acidcatalysts are developed and properly tuned, considering that an appropriate acid strength is crucial for converting cellulose and biomass to levulinates, especially in the reaction rate of $\mathrm{H}$ bonded cellulose structure opening. Several studies demonstrated benefits by tuning the catalysts in the presence of two types of acid sites: Lewis and Brønsted acid sites. Although Brønsted acids generally carry out the hydrolysis of cellulose and hemicellulose and the subsequent conversion of fructose, xylose and other monomers, the presence of Lewis acid sites is also crucial for isomerisation reactions, such as glucose-cellulose-derived to fructose. Peng et al. ${ }^{267}$ investigated the conversion of cellulose to levulinic acid, catalyzed by different metal chlorides, since metal salts show high catalytic activity and both types of acidity. Among those, $\mathrm{CrCl}_{3}$ resulted quite effectively with LA yield of $67 \%$ in $3 \mathrm{~h}^{267} \mathrm{CrCl}_{3}$ was also tested with $\mathrm{H}_{2} \mathrm{SO}_{4}$ to produce levulinic acid from potato peel waste, reporting a LA yield of $49 \%$ at $180{ }^{\circ} \mathrm{C}$ for $15 \mathrm{~min} .{ }^{285}$ Particularly effective also aluminium phosphate $\left(\mathrm{Al}_{2}\left(\mathrm{SO}_{4}\right)_{3}\right)$, it allowed high alkyl levulinate production: $\mathrm{ML}$ yield of $52 \mathrm{wt} \%$ at $200{ }^{\circ} \mathrm{C}$ for $6 \mathrm{~h}$ starting from softwood bark as substrate, ${ }^{308} \mathrm{EL}$ production yield of $36.4 \mathrm{wt} \%$ using cassava for $6 \mathrm{~h}$ at $200{ }^{\circ} \mathrm{C} .{ }^{309}$ Among the commercially available heterogeneous acidic catalysts reported for levulinic acid and esters production are zeolites, sulphated metal oxides, metal oxides, solid superacid $^{310}$ and ion-exchange resins. ${ }^{308}$

Zeolites have been deeply investigated in the acid-hydrolysis of sugar monomers but potentially employed also in the conversion of cellulose and raw biomass. The hierarchical Mordenite zeolites (H-MOR) has been synthesized and tested by Velaga and co-workers, obtaining promising results in the production of levulinic acid: yield of $56 \%$ for $3 \mathrm{~h}$ using cellulose, and improved yield of $61 \%$ using bamboo sawdust as starting substrate. ${ }^{311}$ Furthermore, HY zeolite has been selected, thanks to its high catalytic reactivity as Brönsted acid, and with the addition of $\mathrm{CrCl}_{3}$ (Lewis acid site properties), to obtain a hybrid catalyst and to catalyze the levulinic acid production from empty fruit bunch and kenaf with a yield of 29.2 and 22.7 wt\%, respectively. ${ }^{212} \mathrm{Bi}$-functionalized with zirconia, zirconia-zeolite hybrid (ZrY6) showed high efficiency in methyl levulinate production, leading to $\mathrm{ML}$ molar yields of $53 \%$ from starch and $27 \%$ from cellulose at $180{ }^{\circ} \mathrm{C} .{ }^{157}$ Zirconia and other metals are also very effective in the form of oxide, leading to the hydrolysis of cellulose and subsequence production of levulinic acid or esters with promising results: LA yield of $53.9 \mathrm{~mol} \%$ from cellulose at $180{ }^{\circ} \mathrm{C}$ for $3 \mathrm{~h}$ catalyzed by zirconium dioxide; 312 sulfated metal oxides (especially $\mathrm{SO}_{4}{ }^{2-} / \mathrm{TiO}_{2}$ ) produced a LA yield around $30 \mathrm{~mol} \%$ starting from starch and lower yield, $10 \mathrm{~mol} \%$, using cellulose. ${ }^{210}$ The acid solvolysis of lignocellulosic biomass can also be catalyzed by ion-exchange resins, such as Dowex and Amberlyst; these insoluble polymers can exchange specific ions in the reaction mixture to convert the initial substrates. Alonso et al. ${ }^{313}$ reported converting cellulose to levulinic acid on Amberlyst 70, obtaining a high yield of $69 \% ; 313$ while Amberlyst 36 was tested in the production from sugar beet molasses, obtaining $78 \mathrm{~mol} \%$ of LA yield. ${ }^{214}$ Due to stericity issues in the interaction catalyst particles and biomass and the consequent low yield, few studies are present on their use in biomass conversion to levulinic esters.

In contrast, they have been extensively tested in the production reaction from simple monosaccharides, precursors and esterification of levulinic acid. ${ }^{127}$ Heterogeneous catalysts can provide an efficient and sustainable route in the synthesis of levulinic acid and its esters, replacing the problematic homogeneous acid catalysts. Furthermore, the possibility of precisely tuning and functionalizing them improves the process versatility and efficiency, especially in cascade biomass processes.

Although numerous functionalized heterogeneous catalysts have been already developed, as magnetic catalysts to facilizing the downstream separation steps, or multifunctional catalysts with ample amount of active sites, further advances are still necessary in view of greener biorefineries, keeping into account the "PYSSVR" concept: production cost; yield; stability; selectivity; versatility and reusability. ${ }^{314}$

Recent studies on the conversion of raw biomass as starting substrates to value-added chemicals have evidenced the promising use of macroalgae, as the third generation of biomass; some advantages of this class than lignocellulosic biomass are related to the absence of lignin in the structure and to the rapid growth rate associated to the high consumption of $\mathrm{CO}_{2} .259$

Kang and co-workers tested the potentiality of Gelidium amansii (macroalgae) in the production of levulinic acid catalyzed by mineral acid, obtaining a yield of $43 \%,{ }^{315}$ and Yamaguchi et al. ${ }^{316}$ got a ML yield of $37 \%$ from algae residues. ${ }^{316}$ 
Table 10 Production of LA and ELs from LCB via heterogeneous catalysis.

\begin{tabular}{|c|c|c|c|c|c|c|c|}
\hline & Catalyst & Substrate & Conditions ${ }^{a}$ & Time & Yield ${ }^{b}$ & Catalyst reuse ${ }^{c}$ & Ref. \\
\hline \multirow{10}{*}{ Metal sulfated } & \multirow{9}{*}{$\mathrm{Al}_{2}\left(\mathrm{SO}_{4}\right)_{3}$} & Softwood bark & $200^{\circ} \mathrm{C}$ & $6 \mathrm{~h}$ & $62 \%(M L)$ & $10 \%-3$ runs & 308 \\
\hline & & Cassava & $\begin{array}{c}200{ }^{\circ} \mathrm{C} \\
\text { Ethanol/Water }\end{array}$ & $6 \mathrm{~h}$ & $47.05 \%$ (EL) & $5 \%-2$ runs & 309 \\
\hline & & Bagasse & $180^{\circ} \mathrm{C}$ & $0.6 \mathrm{~h}$ & $65.1 \%(M L)$ & - & 317 \\
\hline & & Poplar powder & $180^{\circ} \mathrm{C}$ & $0.6 \mathrm{~h}$ & $62.7 \%$ (ML) & - & 317 \\
\hline & & Bamboo powder & $180^{\circ} \mathrm{C}$ & $0.7 \mathrm{~h}$ & $64.2 \%$ (ML) & - & 317 \\
\hline & & \multirow{4}{*}{ Cellulose } & $180^{\circ} \mathrm{C}$ & $0.7 \mathrm{~h}$ & 70.6 \% (ML) & $65.3 \%-5$ runs & 317 \\
\hline & & & $180^{\circ} \mathrm{C}$ & $0.9 \mathrm{~h}$ & $70.1 \%$ (EL) & - & 317 \\
\hline & & & $180^{\circ} \mathrm{C}$ & $1.25 \mathrm{~h}$ & $53.7 \%$ (iPL) & - & 317 \\
\hline & & & $180^{\circ} \mathrm{C}$ & $1.25 \mathrm{~h}$ & $63.1 \%(B L)$ & - & 317 \\
\hline & $\mathrm{Fe}_{2}\left(\mathrm{SO}_{4}\right)_{3}$ & Cellulose & $220^{\circ} \mathrm{C}$ & $3 \mathrm{~h}$ & $30.5 \%(B L)$ & - & 318 \\
\hline \multirow{7}{*}{ Zeolite } & \multirow{2}{*}{ H-MOR } & Cellulose & $180^{\circ} \mathrm{C}$ & $2.5 \mathrm{~h}$ & $56 \%(\mathrm{LA})$ & - & 311 \\
\hline & & Bamboo sawdust & $180^{\circ} \mathrm{C}$ & $4 \mathrm{~h}$ & $61 \%(L A)$ & - & 311 \\
\hline & \multirow{2}{*}{$\mathrm{HY}+\mathrm{CrCl}_{3}$} & Empty fruit bunch & $145.2^{\circ} \mathrm{C}$ & $2 \mathrm{~h}$ & $29.2 \%$ (LA) & - & 212 \\
\hline & & Kenaf & $145.2^{\circ} \mathrm{C}$ & $2 \mathrm{~h}$ & $22.7 \%(\mathrm{LA})$ & - & 212 \\
\hline & \multirow{2}{*}{ ZrY6 } & Cellulose & $\begin{array}{c}180{ }^{\circ} \mathrm{C} \\
\text { Microwaves }\end{array}$ & $3 \mathrm{~h}$ & $27 \%(\mathrm{ML})$ & - & 319 \\
\hline & & Starch & $180^{\circ} \mathrm{C}$ & $3 \mathrm{~h}$ & $53 \%(\mathrm{ML})$ & - & 319 \\
\hline & $\begin{array}{c}\text { Micro-meso acidic } \\
\text { H-USY }\end{array}$ & Wheat straw & $200^{\circ} \mathrm{C}$ & $12 \mathrm{~h}$ & $24.5 \%$ (EL) & - & 320 \\
\hline Metal oxide & $\mathrm{ZrO}_{2}$ & Cellulose & $180^{\circ} \mathrm{C}$ & $3 \mathrm{~h}$ & $53.9 \%(\mathrm{LA})$ & $\sim 53 \%-3$ runs & 312 \\
\hline \multirow{2}{*}{$\begin{array}{l}\text { Sulphonic acid } \\
\text { functionalised }\end{array}$} & $\mathrm{SBA}-\mathrm{SO}_{3} \mathrm{H}$ & Cotton straw & $180^{\circ} \mathrm{C}$ & $6 \mathrm{~h}$ & $18 \%(\mathrm{LA})$ & - & 321 \\
\hline & $\mathrm{KCC}-1 / \mathrm{Al}-\mathrm{SO}_{3} \mathrm{H}$ & Cellulose & $200{ }^{\circ} \mathrm{C}$ & $6 \mathrm{~h}$ & $28.8 \%(E L)$ & $15.1 \%$ - 5 runs & 322 \\
\hline \multirow{4}{*}{$\begin{array}{l}\text { Mixed acid } \\
\text { catalyst }\end{array}$} & $\begin{array}{c}\mathrm{Sn} / \mathrm{ZrP}-\mathrm{SO}_{3} \mathrm{H}, \\
\mathrm{Al}(\mathrm{OTf})_{3}\end{array}$ & Kitchen waste & $163^{\circ} \mathrm{C}$ & $7.6 \mathrm{~h}$ & $52 \%(E L)$ & - & 323 \\
\hline & $\mathrm{Al}(\mathrm{acac})_{3}, \mathrm{PTSA}$ & Cellulose & $180^{\circ} \mathrm{C}$ & $5 \mathrm{~h}$ & $72 \%(\mathrm{ML})$ & $61 \%-5$ runs & 324 \\
\hline & $\ln (\mathrm{OTf})_{3}, \mathrm{PTSA}$ & Cellulose & $180^{\circ} \mathrm{C}$ & $5 \mathrm{~h}$ & $70 \%(\mathrm{ML})$ & - & 325 \\
\hline & $\begin{array}{c}\ln (\mathrm{OTf})_{3} \\
\text { Benzenesulfonic } \\
\text { acid }\end{array}$ & Eucalyptus & $200^{\circ} \mathrm{C}$ & $5 \mathrm{~h}$ & $67 \%(\mathrm{ML})$ & - & 326 \\
\hline \multirow{2}{*}{$\begin{array}{l}\text { lon-exchange } \\
\text { resin }\end{array}$} & Amberlyst 70 & Cellulose & $\begin{array}{c}160^{\circ} \mathrm{C} \\
\text { GVL/Water }\end{array}$ & $16 \mathrm{~h}$ & $69 \%$ (LA) & $28 \%-4$ runs & 313 \\
\hline & Amberlyst 36 & Beet molasses & $140^{\circ} \mathrm{C}$ & $3 \mathrm{~h}$ & $78 \%(L A)$ & $18 \%-5$ runs & 214 \\
\hline Ionic liquid & {$\left[\mathrm{C}_{4} \mathrm{H}_{8} \mathrm{SO}_{3} \mathrm{Hmim}\right] \mathrm{HSO}_{4}$} & Cellulose & $180^{\circ} \mathrm{C}$ & $0.75 \mathrm{~h}$ & $31.1 \%(B L)$ & $28.9 \%-6$ runs & 289 \\
\hline
\end{tabular}




\section{Separation and Purification Processes}

In oil refineries, separation and purification steps are based on distillation technologies, together with liquid extraction, crystallization, absorption, adsorption, and use of membranes, accounting for $40-50 \%$ of the total costs. ${ }^{327}$ However, similar to a classical refinery, the biorefinery has to consider several factors that increase the complexity and the energy demand of downstream processes compared to oil refineries; such as low feed concentration, heterogeneity of the feedstock, inhibition issues, low product yields, and the high content of water and oxygenated compounds which might lead to complex mixture and azeotropes. These drawbacks affect the economy of scale and the total costs in which separation accounts for $60-80$ $\% .^{328,329}$ In particular, the presence of high functionalized lignocellulosic-derived groups, as hydroxyls, aldehydes, ketones, carboxylic, makes biorefinery's streams susceptible to thermal instability and therefore not favorably separable at high temperature. ${ }^{329}$ The separation process is also aggravated by the high dilution of product streams, a direct consequence of reduced feed concentration to avoid the formation of degradation products such as humins. ${ }^{28,330,331}$

The presence of humins, along with the presence of mineral acid catalysts, is one of the major challenges in LA downstream processing. ${ }^{28}$ On one hand, LA can form a wide range of derivatives that can make its recovery even more difficult. On the other hand, currently investigated methods to improve LA recovery are based on its reactivity and include the esterification to LEs, which can be considered, in this sense, easier to handle.

The recovery and purification of LA is strongly dependent on the type of lignocellulosic substrate and the technology used for its production. Unlike other biomass-derived platform molecules that can be produced via bioprocessing, LA can only be produced by acid-catalyzed chemical processes. Clearly enough, the use of homogeneous or heterogeneous acid catalysis already affects LA purification method. Typical biomass hydrolysis produces a diluted stream of LA (3-8 wt\%), formic acid (1-5 wt\%) and furfural (1-5 wt\%) in water. Although levulinic acid does not form any azeotrope, water-furfural mixture gives a minimum-boiling heterogeneous azeotrope at $97{ }^{\circ} \mathrm{C}$ and a furfural content of $64.5 \mathrm{wt} \%$ and formic-acid-water mixture a maximum-boiling homogeneous azeotrope at 106.8 ${ }^{\circ} \mathrm{C}$. This results in downstream processing, typically based on conventional separation schemes, mainly expensive and hostile

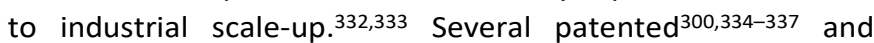
experimental technologies have been developed to purify LA via gravimetric separation or liquid-liquid extraction combined with advanced distillation technologies. ${ }^{32,333,338}$ For dilute high boilers as levulinic acid, liquid-liquid extraction results to be a potential efficient technique for fractioning the mixture. Traditionally based on the use of high molecular weight aliphatic amines and organophosphorus, liquid-liquid extraction has the main advantage to high recovery boiling and thermosensitive components, avoiding or minimizing the need to distill enormous amounts of solvent, usually water, which is highly energy demanding. ${ }^{329}$ Recently, different solvents, such as ketones, alcohols, esters, ethers, and hydrocarbons, have been tested showing a high selectivity for LA over sulfuric acid in homogeneous acid-hydrolysis. Brouwer and his group ${ }^{338}$ first designed a recovery process based on a furfural extraction section and then an acid fractioning of the mixture LA-FA. Nonpolar solvents, as toluene and methyl isobutyl ketone (MIBK), showed high potential in removing furfural, while the extraction of LA and FA from the acid aqueous acid solution was by polar solvents as 4-tert-butylbenzenediol (TB) and 1-octanol. ${ }^{338}$ Instead, energy and environmental comparison between MIBK and 2-Methyltetrahydrofuran (2Me-THF) as extractants of LA has been by Isoni and his group in order to define a technoeconomic analysis and sustainability of biorefinery processes. Since the extracting organic solvent is recovered by distillation, MIBK leads to twice the amount of energy required for heating to boiling point, having a higher specific heat capacity $(2.14$ $\mathrm{kJ} /(\mathrm{kg} \mathrm{K})$ versus $1.96 \mathrm{~kJ} /(\mathrm{kg} \mathrm{K})$ of 2-MeTHF) and higher normal boiling point $\left(118^{\circ} \mathrm{C}\right.$ versus $\left.80.3^{\circ} \mathrm{C}\right) . .^{339}$ 2-MeTHF was identified as the best choice for energy cost, gases emissions and environmental sustainability, since it can be produced by biomass. Besides to alkyl levulinate, 2Me-THF is another potential fuel additive LA-derived and a promising solvent in biomass processing, thanks to its high stability in acidic conditions and low miscibility with water that leads to creating organic-aqueous biphasic system, extracting LA and other organic from the aqueous phase. ${ }^{340}$

The production of LA using ionic liquids (molten salts at ambient temperature), seems to be promising in terms of separation, ${ }^{33,341}$ even though some research evidenced their tendency to co-extract sulfuric acid, making them less suited for LA extraction in sulfuric acid medium. ${ }^{338}$

A summary of the technologies investigated in the literature is proposed in Table 1, where a technical comparison is offered. ${ }^{28}$ Sustainability issues related to downstream processes are discussed in the following section.

Being acid-free and highly volatile, alkyl levulinate are easily separable from alcoholysis products derived from carbohydrates and lignocellulose via distillation. ${ }^{342} \mathrm{Li}$ and coworkers reported separating products from methanolysis of cellulose by distillation technique that combines an atmospheric and vacuum distillation. ${ }^{276}$ The downstream scheme leads to a product stream in which methyl levulinate was the major component of lower heavy fraction with purity over 96 mol\%. N-dodecane was added to the mixture to help distill the heavy products as a desorption driving agent, and it has been detected in a small percentage in the final stream, together with levulinic acid. ${ }^{276}$ Instead a new process for the preparation and purification of butyl levulinate (BL) from cellulose has been developed by Liang and his group; the purification scheme combines an extraction operation where the final $B L$ is recycled and used to partially extract LA (its residue is further esterified to $\mathrm{BL}$ ) with distillation steps. A final BL purity of 98 wt\% is obtained after distilling the unreacted alcohol and washed with saturated sodium carbonate and water to neutralize the sulfuric acid and salts. ${ }^{343}$ Distillation processes are also employed to separate and purify ethyl levulinate; in particular, several groups reported introducing techniques that combine reaction and separation steps in a 
single unit, as reactive distillation (RD). The advantages of RD are related to the continuous removal of products, pulling the chemical equilibrium towards the products, and particularly suitable for reactions hindered by the chemical equilibrium limitations, as esterification of LA to EL and other esters. ${ }^{329,344}$ Vazquez-Castillo and his group designed a reactive distillation process which couples an RD column with two separation columns and leads to EL with a purity of 99.5 mol\%; additionally, applying thermal coupling to RD, energy and cost reductions are in the range of $24-63 \%$ and $8-43 \%$, respectively. ${ }^{344}$ In literature, some works reported using pervaporation catalytic membrane reactor system (PVCMR) in which reaction and separation occur simultaneously, based on the permselective evaporation through the membrane. Unlu and coworkers obtained EL almost pure using a catalytic composite membrane in a PVCMR system. ${ }^{107}$ The presence of humins, in soluble and/or insoluble form, increases the complexity of separation processes; extraction and/or membrane filtration allow to remove the humins in the products mixture. The use of toluene and other non-polar solvents has been tested with high extraction rates as an agent of selective extraction of EL without humins. ${ }^{342}$ Being one of the most significant responsible for the total costs, choosing a specific separation technology has to be done in favorable conditions. Industrially, distillation is a good option in the following cases: ${ }^{329}$
- Boiling temperature in distillation (atmospheric or vacuum condition) has to be firmly lower than thermal degradation temperature for all components.

- The temperature difference between the boiling point of products to separate might exceed $5{ }^{\circ} \mathrm{C}$.

- The product concentration in the distillate stream should be higher by $10 \mathrm{wt} \%$ than in the feed stream.

Separation technologies based on the affinity between components, as liquid-liquid extraction, absorption and adsorption are economically suitable in case of:

- Product and medium have to present differences in chemical affinity to obtain an efficient separation.

- The extractant owns a moderate level of bonding, strong enough to allow efficient extraction but not too strong to ensure successful regeneration.

- Low product concentration is only economically viable if it presents a high affinity for the extracting component.

- Minimising interactions with impurities in the reaction medium.

- Advantageous extractant/sorbent regeneration processes.

Finally, permeation processes are strongly dependent on the right material available. They can be applied in conditions:

- The product and medium have to show a difference in diffusivity, i.e. with the permeable material.

- Choice of a permeable, available, cost-effective material, which shows versatility with the feed variability.

Table 11 LA separation and purification processes (Adapted from ${ }^{28}$ ).

\begin{tabular}{|c|c|c|c|c|}
\hline \multirow{2}{*}{ Downstream process } & \multirow{2}{*}{ Pros } & \multirow{2}{*}{ Cons } & \multicolumn{2}{|c|}{ Impact on Green Chemistry Principles ${ }^{16}$} \\
\hline & & & Positive & Negative \\
\hline Vacuum distillation & $\begin{array}{l}\text { Well-established } \\
\text { technology }\end{array}$ & $\begin{array}{l}\text { Energy demanding } \\
\text { Undesired by-products } \\
\text { formation }\end{array}$ & - & $\begin{array}{l}\text { "Design for Energy } \\
\text { Efficiency" } \\
\text { "Reduce Derivatives" } \\
\text { "Inherently Safer } \\
\text { Chemistry for Accident } \\
\text { Prevention" } \\
\end{array}$ \\
\hline Liquid-Liquid Extraction & $\begin{array}{l}\text { Well-established } \\
\text { technology }\end{array}$ & $\begin{array}{l}\text { Large volume of solvent is } \\
\text { required: sustainability } \\
\text { disadvantageous }\end{array}$ & $\begin{array}{l}\text { "Design for Energy } \\
\text { Efficiency" }\end{array}$ & $\begin{array}{c}\text { "Reduce Derivatives" } \\
\text { "Less Hazardous Chemical } \\
\text { Syntheses" }\end{array}$ \\
\hline $\begin{array}{l}\text { Reactive Liquid-Liquid } \\
\text { Extraction }\end{array}$ & $\begin{array}{c}\text { No additional processing } \\
\text { required }\end{array}$ & Complicated & $\begin{array}{l}\text { “Design for Energy } \\
\text { Efficiency” } \\
\text { “"Reduce Derivatives” }\end{array}$ & Depending on chemicals \\
\hline Stripping with steam & High purity is obtained & Energy demanding & $\begin{array}{c}\text { "Inherently Safer } \\
\text { Chemistry for Accident } \\
\text { Prevention" }\end{array}$ & $\begin{array}{l}\text { "Design for Energy } \\
\text { Efficiency" }\end{array}$ \\
\hline Membrane separation & $\begin{array}{l}\text { Minimizes undesired by- } \\
\text { products formation }\end{array}$ & $\begin{array}{l}\text { Costly } \\
\text { Fouling problems }\end{array}$ & "Reduce Derivatives" & $\begin{array}{l}\text { "Design for Energy } \\
\text { Efficiency" }\end{array}$ \\
\hline Adsorption & $\begin{array}{l}\text { Simple and well- } \\
\text { established technology }\end{array}$ & $\begin{array}{l}\text { Low efficiency at industrial } \\
\text { scale }\end{array}$ & $\begin{array}{c}\text { "Inherently Safer } \\
\text { Chemistry for Accident } \\
\text { Prevention" }\end{array}$ & $\begin{array}{l}\text { "Design for Energy } \\
\text { Efficiency" }\end{array}$ \\
\hline Ionic liquids & $\begin{array}{l}\text { No additional process } \\
\text { required }\end{array}$ & $\begin{array}{c}\text { Costly } \\
\text { Under development }\end{array}$ & $\begin{array}{c}\text { "Prevention " } \\
\text { "Reduce Derivatives" }\end{array}$ & $\begin{array}{l}\text { "Design for Energy } \\
\text { Efficiency" }\end{array}$ \\
\hline
\end{tabular}




\section{Considerations on economic and environmental sustainability}

To date, several technological issues have limited the economical manufacture of platform chemicals such as LA and LEs, e.g., the cost of raw material and equipment, the low yield of LA due to undesirable side reactions, difficulties in efficient product recovery, catalyst recovery costs, low energy inefficiency of the processes. ${ }^{28}$

Exploring some of these aspects, a necessary first consideration is related to the starting biomass or precursor. The required pretreatments typically account for a substantial fraction of the total energy requirements and up to $20 \%$ of the capital and operating costs, ${ }^{2}$ thus being an obstacle to commercialization. Low cost, low input cultivation and highly available lignocellulosic biomasses, such as agricultural and forest residues and energy crops, should be preferred, also for laboratory scale-up. ${ }^{203}$ The choice of the starting substrate has to be done considering the biomass supply chains and its economic analysis, which includes collection, processing and transport of the biomass but also the plant locations and social criteria like workers, investors and government. ${ }^{203}$ Isoni et al. ${ }^{339}$ have realized a techno-economic investigation of the levulinic acid production in Southeast Asia comparing two different scenarios, accounting location factors, such as biorefinery next to biomass source or biomass shipped to the biorefinery, and also sustainability factors like deforestation (impact on the $\mathrm{CO}_{2-}$ emissions) and soil depletion. ${ }^{339}$ Selected the substrate, the specific pre-treatment is crucial for the optimization of the process; the research is advancing in this sense, for example substituting pre-treatments water-based to with others that use more favorable media: cheap, non-toxic, biodegradable, recyclable, and preferably derived from renewable resources in order to be economically and environmentally appealing. Examples under investigation are organic solvents, ionic liquids, and deep eutectic solvents. ${ }^{2}$ Deep eutectic solvents have been identified not only for pre-treatments, favoring the delignification and solubilization of cellulose, but also as solvent for the subsequent conversion to added-value chemicals, as alkyl levulinates. ${ }^{203}$

A second aspect is related to the inefficient product separation and recovery for LA production, as discussed in the previous section. On the one hand, distillation is typically used for this purpose, but because of the wide range of the boiling points of the products, it is neither efficient nor economical. On the other hand, solvent extraction is complicated as by-products have similar polarity with respect to the main product and the use of large amounts of solvent is necessary to achieve high recovery. ${ }^{37}$ Reactive extraction and reactive distillation methods are widely investigated. Concerning LA, the production of LEs overcome such limitations being more easily separated.

A third aspect is related to waste disposal and corrosion, which is related to the use of mineral acid catalysts, requiring expensive construction materials for both reactor and acid recovery plants, increasing the capital investment and operating costs. ${ }^{37,176}$ Recycling the acid solvent mixture would be beneficial to the disposal problem from both environmental and economic standpoints, despite additional operating costs. The introduction of heterogeneous catalysts could be the only alternative to carrying out a more efficient and environmentally friendly acid-catalyzed biomass process. Although currently scarcely used on an industrial scale, heterogeneous catalysis does not suffer from equipment corrosion, high volume of wastewater and expensive and challenging recovery and recycling. ${ }^{269}$ Furthermore, considering high selectivity and efficient and simple regeneration, the development of cheap heterogeneous catalysts, deriving from low-cost precursors, may constitute the key element in the green intensification of biomass valorisation. ${ }^{203,269}$

Finally, to improve the economics of the process, attention to the lignin should be paid; this lignocellulosic component is far too often underestimated, considered more similar to waste than a resource component. In the hydrothermal treatments of biomass for the production of levulinic acid and its esters, lignin is generally regarded as the main waste stream, being a solid hydro-char residue. As well as being a possible immediate source of energy recovery, lignin represents an origin of a large amount of bio-based chemicals, rich source of hydroxylic and carboxylic functional groups, potentially employable as substituents in polyurethane foam formulation, as adsorbents, precursors of catalysts, soil additives and energy store materials. ${ }^{345,346}$ Due to the heterogeneous structure, its recovery can be a critical industrial challenge but several integrated biorefineries ${ }^{347}$ have been designed, including it and significantly improving the overall process economy. ${ }^{203}$ Depending on the primary target product asset, the lignin recovery could be designed as an upstream step, potentially advantageous thanks to the availability of organic solvent from pretreatments and efficient in the lignin fraction, or as a downstream step in the process. ${ }^{203,347}$ Besides solvent-based fractioning, membranes could also be effectively used in lignin recovery. ${ }^{347}$ From the perspective of integrated processes, humins are also a potentially valuable "waste" product. Produced by the degradation of sugars, furan and 5-HMF in the production of levulinic acid and alkyl esters, humins is a polymeric network of furanic derivatives containing sugarderived moieties, that can be transformed into a range of valuable chemicals and fuels, through steam reforming for $\mathrm{H}_{2}$ and other fractioning techniques. ${ }^{348,349}$ Currently, lignin and humins are not recovered in the production process of LA and LEs, but, in line with the principles of biorefinery, ${ }^{350}$ an integrated multiproduct biorefinery should be developed to improve sustainability and cost-effectiveness of the processes. $^{2,37}$

From the environmental point of view, in literature, there are only a few but meaningful studies related to LA, ELs, and related biochemicals and biofuels. In 2015, Khoo and co-workers proposed an LCA for the Synthesis of 2-methyl tetrahydrofuran from various lignocellulosic feedstocks using an acidic pretreatment, the Biofine process followed by the hydrogenation of LA. ${ }^{351}$ The main results were that the energy used for the pretreatment was negligible with respect to that required for the separation of LA from furfural, and the authors highlighted that bio-based chemicals may not automatically be synonymous 
with "green". Therefore efforts should be made to ensure sustainability in particular for what concerns land-use footprint. Again in 2019, Khoo et al. ${ }^{352}$ assessed the sustainability of various supply chains for the production of LA from different feedstocks with a more sophisticated LCA approach, aimed at a geographical comparison of LA production, concluding that the highest environmental impacts are caused by land use, fuel and agro-chemicals consumption. ${ }^{352}$

In 2015, Mukherjee et al. ${ }^{353}$ discussed the sustainable production of HMF and LA by qualitatively comparing different substrates and reaction systems. The authors commended microwave irradiation-heated systems in their review because of their dual advantages of high product yields and low environmental footprint. ${ }^{353}$

Gonzalez-García et al. ${ }^{354}$ (2016) analysed by means of LCA, four different scenarios characterised by the same raw material (wood chips) converted to soluble poly-saccharides versus LA to identify the most sustainable biorefining route. The results showed that the production had the worst environmental performances due to the acidic treatment, but this is no longer true if an economic revenue normalization is proposed. The study revealed many uncertainties and the authors concluded that further research should be done. 354

In 2018, Leal Silva et al. ${ }^{32}$ made a techno-economic and environmental assessment of the possible production routes for LA and ELs comparing different geographical locations, showing that the key factors affecting the performances are related to the inefficiencies in the reaction technologies and to the complexities in downstream processing (in particular with wastewater treatment, catalyst recycling). Attention is given to improve ionic liquids (that are currently too expensive to be used at industrial scale), reduce the formation of humins, avoid the use of organic solvents. ${ }^{32}$

In the same year, Isoni et al. ${ }^{339}$ studied the sustainability of a biomass to LA biorefinery processes in Southeast Asia, showing again the issues related to land use and agricultural nutrients. ${ }^{339}$ In 2019, Hafyan and co-workers ${ }^{278}$ studied the overall sustainability (i.e. simultaneously considering economic, environment, and safety aspects) for the production of LA from empty fruit bunch in Malaysia by means of acid-hydrolysis. Their main results confirmed what previously reported in literature: process utilities related to the separation of LA from water are the largest contributors to costs and environment, whereas acid hydrolysis is relatively safer than hydrogenation. ${ }^{355,356}$

Finally, in 2021, Kapanji et al. ${ }^{357}$ proposed an LCA and sustainability assessments of biorefineries producing glucaric acid, sorbitol or levulinic acid annexed to a sugar mill. They showed that, despite the socio-economic attractiveness of the $\mathrm{LA}$, it was the worst-case environmental scenario due to high loads from GVL production, associated with the manufacture, transportation and use of $n$-butyl acetate solvent and hydrogen from natural gas. ${ }^{357}$

In conclusions, there are several essential attempts in the literature to evaluate the sustainability related to LA and LEs, but a comprehensive and overall comparative quantitative study is still missing. Such study should be carried out to support aware decision making for the scale up and the industrial implementation of alternative production processes and technologies.

\section{Conclusions}

The energy transition is a significant structural change of the actual energy system, based mainly on unrenewable fossil fuels, towards a renewable energy system; key element in the policy of several countries around the world through the various agreements stipulated to achieve climate neutrality. In this panorama, biomass can significantly contribute to the achievement of targets, allowing the development of greener and more sustainable production processes of chemical building blocks and biofuels. Levulinic acid and alkyl levulinates are promising value-added platform chemicals, directly manufacturable from different biomass generations, particularly from lignocellulosic biomass (second generation).

This review has explored the different possible substrates, from sugar monomers to raw lignocellulosic biomasses and intermediate precursors, that produce levulinates mainly for catalyzed acid-solvolysis, and, in addition to the reaction phase, the different phases that characterize the production process: pre-treatment and product purification phase. Some significant outlooks are listed below based on what was discussed through this review:

1. Pre-treatment is a mandatory step in transforming LCB to levulinic acid and its esters to open its structure, containing crystalline cellulose and recalcitrant lignin. Several studies relate the employ of pre-treatment techniques to increasing product yields and emphasize the need to choose a method appropriate to the type of biomass. Diluted acid pre-treatments result to be the most common methods, especially with LCB, being highly efficient, albeit with some drawbacks: equipment corrosion, neutralization post-treatments and eco-toxicity. Considering all the different types of techniques and biomass affinity, combined pre-treatments can provide an efficient action, low energy demand, low corrosivity and pollution.

2. According to the recent literature, acid mineral homogeneous catalysts $\left(\mathrm{H}_{2} \mathrm{SO}_{4}, \mathrm{HCl}\right)$ are still widely used in converting raw biomass and sugars monomers to levulinic acid and alkyl levulinates thanks to higher product yields, low catalyst costs and high availability. Although advantageous from the reaction point of view, such catalysts are intensive costenergy demanding as they require the use of specific corrosionresistant materials and post-reaction neutralization treatments. Replacing homogeneous acid catalysts with green and efficient heterogeneous catalysts can be a critical challenge for the hydrolysis process in the future. The possibility of fine-tuning catalytic properties makes heterogeneous catalysts particularly suitable for dealing with substrates of variable composition. Catalysts with a dual-acid nature, Lewis and Bronsted acids are particularly active in the solvolysis of LCB to levulinates. The catalytic activity is combined with easy recovery and regeneration of these catalysts and no corrosion effects. In addition, the use of special aprotic polar solvents, as GVL, makes 
it possible to extend the life of the catalyst by avoiding the formation of insoluble by-products, such as humins, which can deposit on the catalyst and poison it and to stabilize reactive reaction intermediates by preventing their degradation.

3. Separation and purification of biorefinery products have to consider various factors which affect their complexity: low feed concentration and heterogeneity of the feedstock, inhibition effects, low product yields, presence of insoluble by-products, high content of water and oxygenated compounds, possible azeotropes. Thus, the recovery and purification of levulinic acid and its esters largely depend on the starting biomass and the production technology. Although distillation is commonly used in industrial separation, techniques as liquid-liquid extraction are particularly suitable for dilute high boilers and strongly active compounds as levulinic acid. For alkyl levulinates, the downstream processes are less complex being acid-free and highly volatile; thus, they are easily separated from the alcoholysis mixture via distillation. Less explored but promising methods combine reaction and separation steps in the same system; reactive distillation (RD) and pervaporation catalytic membrane reactor (PVCMR) lead to high-purity products with possible reduced energy-cost-demanding.

Based on the current situation, future researches in the production of levulinic acid and alkyl levulinates should be focused on the development of intensive and direct conversion strategies, based on the one-pot cascade approach, which is particularly advantageous in terms of process economy, process time, work and resources management, and waste generation. 206 The development of efficient, cheap heterogeneous catalysts, preferably obtained from low-cost substrates, can convert a significant composition range of raw biomasses; the development of integrated-multiproducts biorefinery systems allows profit from the conversion of waste biomass residues or secondary reaction products, such as lignin and humins. In addition, industrial scale-up must include a techno-economic analysis, which considers cost-contributing factors as logistics, i.e. pre-processing, transportation and storage, to have a clear and accurate evaluation of the project feasibility. With the aim of sustainable exploitation of renewable feedstocks to $\mathrm{LA}$ and its esters, quantitative comparative assessments, integrating economic, environmental and process safety aspects should be carried out to support a conscious decision making with respect to the scale-up and the industrial implementation of alternative production processes and technologies.

\section{Conflicts of interest}

"There are no conflicts to declare".

\section{Acknowledgements}

The authors thank the Region Normandie for the funding. The Daniele Di Menno Di Bucchianico's doctoral thesis is done in the framework of "ARBRE RIN 100\%" funded by Region Normandie, and this thesis is a part of the research activities of "pôle CTM (Continuum Terre-Mer) de Normandie Université".

\section{Notes and reference}

1 European Commission. Directorate General for Climate Action., State of the Union 2020: EU climate target plan 2030 : key contributors and policy tools., Publications Office, LU, 2020.

2 R. A. Sheldon, ACS Sustainable Chem. Eng., 2018, 6, 44644480.

3 F. Rosillo-Calle, J. Chem. Technol. Biotechnol., 2016, 91, 19331945.

4 N. Scarlat, J. F. Dallemand, N. Taylor and M. Banja, Publications Office of the European Union, 2019.

5 IEA, World Energy Outlook 2020, Paris, 2020

6 European Commission, 2020, doi:10.2834/453015.

7 Agora Energiewende and Ember, 2021, 18.

8 G. Fiorentino, M. Ripa, S. Mellino, S. Fahd and S. Ulgiati, Journal of Cleaner Production, 2014, 66, 174-187.

9 A. T. Adeleye, H. Louis, O. U. Akakuru, I. Joseph, O. C. Enudi and D. P. Michael, AIMS Energy, 2019, 7, 165-185.

10 A. Corma, S. Iborra and A. Velty, Chem. Rev., 2007, 107, 24112502.

11 E. Henrich, N. Dahmen, E. Dinjus and J. Sauer, Chemie Ingenieur Technik, 2015, 87, 1667-1685.

12 F. Wang, D. Ouyang, Z. Zhou, S. J. Page, D. Liu and X. Zhao, Journal of Energy Chemistry, 2021, 57, 247-280.

13 C. Zhou and Y. Wang, Science and Technology of Advanced Materials, 2020, 21, 787-804.

14 Y. Liao, B. O. de Beeck, K. Thielemans, T. Ennaert, J. Snelders, M. Dusselier, C. M. Courtin and B. F. Sels, Molecular Catalysis, 2020, 487, 110883.

15 M. Beller, G. Centi and L. Sun, ChemSusChem, 2017, 10, 6-13. 16 P. T. Anastas and J. C. Warner, Green Chemistry: Theory and Practice, Oxford University Press: New York, 1998.

17 S. Takkellapati, T. Li and M. A. Gonzalez, Clean Techn Environ Policy, 2018, 20, 1615-1630.

18 Z. Miao, Y. Shastri, T. E. Grift, A. C. Hansen and K. C. Ting, Biofuels, Bioprod. Bioref., 2012, 6, 351-362.

19 J. Kudakasseril Kurian, G. Raveendran Nair, A. Hussain and G. S. Vijaya Raghavan, Renewable and Sustainable Energy Reviews, 2013, 25, 205-219.

20 A. A. Rentizelas, I. P. Tatsiopoulos and A. Tolis, Biomass and Bioenergy, 2009, 33, 223-233.

21 J. Leboreiro and A. K. Hilaly, Bioresource Technology, 2011, 102, 2712-2723.

22 N. T. Albashabsheh and J. L. Heier Stamm, Biomass and Bioenergy, 2021, 144, 105888.

23 T. Lin, L. F. Rodríguez, S. Davis, M. Khanna, Y. Shastri, T. Grift, S. Long and K. C. Ting, GCB Bioenergy, 2016, 8, 160-170.

24 Y. Wang, J. Wang, J. Schuler, D. Hartley, T. Volk and M. Eisenbies, Energy, 2020, 197, 117260.

25 T. Werpy and G. Petersen, Top Value Added Chemicals from Biomass: Volume I -- Results of Screening for Potential Candidates from Sugars and Synthesis Gas, 2004.

26 P\&S market research, 2020., Levulinic Acid Market Research Report: By Technology (Biofine, Acid Hydrolysis), Application (Food Additives, Pharmaceuticals, Agricultural Products, Personal Care Products, Plasticizers, Fuel Additives) - Global Industry Analysis and Demand Forecast to 2030. https://www.psmarketresearch.com/market-analysis/levulinicacid-market.

27 Marketdataforecast, Levulinic Acid Market By Application (Pharmaceuticals, Agriculture, Food Additives, Cosmetics), By Potential Downstream (Delta aminolevulinic acid (DALA), Diphenolic Acid, Methyltetrahydrofuran (MTHF)) \& By Region 
(North America, Latin America, Europe, Asia Pacific, Middle East \& Africa) - Industry Analysis on Size, Share, Growth, Trends \& Forecast Report | $2020 \quad$ - 2025, https://www.marketdataforecast.com/market-reports/levulinicacid-market.

28 A. Morone, M. Apte and R. A. Pandey, Renewable and Sustainable Energy Reviews, 2015, 51, 548-565.

29 A. Démolis, N. Essayem and F. Rataboul, ACS Sustainable Chem. Eng., 2014, 2, 1338-1352.

30 P. Gallezot, Chem. Soc. Rev., 2012, 41, 1538-1558.

31 H. Kobayashi and A. Fukuoka, Green Chem., 2013, 15, 1740.

32 J. F. Leal Silva, R. Grekin, A. P. Mariano and R. Maciel Filho, Energy Technol., 2018, 6, 613-639.

33 Y. W. Tiong, C. L. Yap, S. Gan and W. S. P. Yap, Ind. Eng. Chem. Res., 2018, 57, 4749-4766.

34 V. Trombettoni, L. Bianchi, A. Zupanic, A. Porciello, M. Cuomo, O. Piermatti, A. Marrocchi and L. Vaccaro, Catalysts, 2017, 7, 235 35 W. R. H. Wright and R. Palkovits, ChemSusChem, 2012, 5 $1657-1667$.

36 J. Zhang, S. Wu, B. Li and H. Zhang, ChemCatChem, 2012, 4 $1230-1237$.

37 D. W. Rackemann and W. O. S. Doherty, INTERNATIONAL SUGAR JOURNAL, 2012, 114, 8.

38 M. J. Climent, A. Corma and S. Iborra, Green Chem., 2014, 16 516-547.

39 M. J. Climent, A. Corma and S. Iborra, Green Chem., 2011, 13 520-540.

40 F. D. Pileidis and M.-M. Titirici, ChemSusChem, 2016, 9, 562582.

41 E. Christensen, A. Williams, S. Paul, S. Burton and R. L. McCormick, Energy Fuels, 2011, 25, 5422-5428.

42 G. Shrivastav, T. S. Khan, M. Agarwal and M. A. Haider, ACS Sustainable Chem. Eng., 2017, 5, 7118-7127.

43 R.-J. van Putten, J. C. van der Waal, E. de Jong, C. B. Rasrendra H. J. Heeres and J. G. de Vries, Chem. Rev., 2013, 113, 1499-1597. 44 C. Liu, X. Lu, Z. Yu, J. Xiong, H. Bai and R. Zhang, Catalysts, 2020, 10, 1006.

45 S. B. Onkarappa, M. Javoor, S. S. Mal and S. Dutta, ChemistrySelect, 2019, 4, 2501-2504.

46 Y. Wang, M. Cipolletta, L. Vernières-Hassimi, V. CassonMoreno and S. Leveneur, Chemical Engineering Journal, 2019, 374, 822-831.

47 W. Zhao, H. Ding, Y. Tian, Q. Xu and X. Liu, J Chin Chem Soc, 2021, 68, 1339-1345.

48 B. Girisuta, L. P. B. M. Janssen and H. J. Heeres, Green Chem. 2006, 8, 701

49 A. Crivellari, V. Casson Moreno, V. Cozzani and I. Dincer Journal of Cleaner Production, 2021, 293, 126226.

50 S. W. Fitzpatrick, The Biofine Technology: A "Bio-Refinery" Concept Based on Thermochemical Conversion of Cellulosic Biomass, ACS Symposium Series., 2006, vol. 921.

51 M. M. Cajnko, J. Oblak, M. Grilc and B. Likozar, Bioresource Technology, 2021, 340, 125655.

52 A. W. Bhutto, K. Qureshi, K. Harijan, R. Abro, T. Abbas, A. A. Bazmi, S. Karim and G. Yu, Energy, 2017, 122, 724-745.

53 D. Kumari and R. Singh, Renewable and Sustainable Energy Reviews, 2018, 90, 877-891.

54 J. U. Hernández-Beltrán, I. O. Hernández-De Lira, M. M. CruzSantos, A. Saucedo-Luevanos, F. Hernández-Terán and N Balagurusamy, Applied Sciences, 2019, 9, 3721.

55 E. P. Dagnino, E. R. Chamorro, S. D. Romano, F. E. Felissia and M. C. Area, Industrial Crops and Products, 2013, 42, 363-368.

56 M. Germec, N. B. Bader and I. Turhan, Biomass Conv. Bioref., 2018, 8, 529-544.

57 Y.-Y. Liu, J.-L. Xu, Y. Zhang, C.-Y. Liang, M.-C. He, Z.-H. Yuan and J. Xie, Fuel Processing Technology, 2016, 143, 1-6.

58 K. Zhang, Z. Pei and D. Wang, Bioresource Technology, 2016 $199,21-33$.
59 Q. Zhang, J. Hu and D.-J. Lee, Renewable Energy, 2017, 111 77-84.

60 Z. N. Akhlisah, R. Yunus, Z. Z. Abidin, B. Y. Lim and D. Kania, Biomass and Bioenergy, 2021, 144, 105901.

61 K. Ullah, V. K. Sharma, M. Ahmad, P. Lv, J. Krahl, Z. Wang, and Sofia, Renewable and Sustainable Energy Reviews, 2018, 82, 3992-4008.

62 S. S. Hashemi, K. Karimi and S. Mirmohamadsadeghi, Energy, 2019, 172, 545-554.

63 D. Wang, Y. Xin, H. Shi, P. Ai, L. Yu, X. Li and S. Chen, Biosystems Engineering, 2019, 180, 182-190.

64 R. Sindhu, P. Binod and A. Pandey, Bioresource Technology, 2016, 199, 76-82.

65 R. Kumar, V. Strezov, H. Weldekidan, J. He, S. Singh, T. Kan and B. Dastjerdi, Renewable and Sustainable Energy Reviews, 2020, 123, 109763.

66 P. P. T. Sah and S.-Y. Ma, 1930, 52, 4.

67 H. A. Schuette and M. A. Cowley, Journal of the American Chemical Society, 1931, 53, 3485-3489.

68 United States Patent, US2029412, 1933, 3391-3394.

69 G. Pasquale, P. Vázquez, G. Romanelli and G. Baronetti, Catalysis Communications, 2012, 18, 115-120.

70 A. Najafi Chermahini and M. Nazeri, Fuel Processing Technology, 2017, 167, 442-450.

71 M. A. Tejero, E. Ramírez, C. Fité, J. Tejero and F. Cunill, Applied Catalysis A: General, 2016, 517, 56-66.

72 K. C. Badgujar, V. C. Badgujar and B. M. Bhanage, Fuel Processing Technology, 2020, 197, 106213.

73 S. Dutta and N. S. Bhat, Chem CatChem, 2021, 13, 3202-3222.

74 M. Varkolu, V. Moodley, F. S. W. Potwana, S. B. Jonnalagadda and W. E. van Zyl, Reac Kinet Mech Cat, 2017, 120, 69-80.

75 K. Y. Nandiwale and V. V. Bokade, Environ. Prog. Sustainable Energy, 2015, 34, 795-801.

76 D. H. Morawala, A. K. Dalai and K. C. Maheria, Catal Lett, 2020 150, 1049-1060.

77 C. R. Patil, P. S. Niphadkar, V. V. Bokade and P. N. Joshi, Catalysis Communications, 2014, 43, 188-191.

78 Q. Luan, L. Liu, S. Gong, J. Lu, X. Wang and D. Lv, Process Safety and Environmental Protection, 2018, 117, 341-349.

79 K. Manikandan and K. K. Cheralathan, Applied Catalysis A: General, 2017, 547, 237-247.

80 N. A. S. Ramli, N. H. Zaharudin and N. A. S. Amin, Jurnal Teknologi, 2016, 79, 137-142.

81 M. B. Kokare, R. V and C. S. Mathpati, Chemical Engineering Research and Design, 2018, 137, 577-588.

82 F. G. Cirujano, A. Corma and F. X. Llabrés i Xamena, Chemical Engineering Science, 2015, 124, 52-60.

83 Y. Tian, R. Zhang, W. Zhao, S. Wen, Y. Xiang and X. Liu, Catal Lett, 2020, 150, 3553-3560.

84 F. Yang and J. Tang, ChemistrySelect, 2019, 4, 1403-1409. 85 S. S. Enumula, V. R. B. Gurram, R. R. Chada, D. R. Burri and S. R. R. Kamaraju, Journal of Molecular Catalysis A: Chemical, 2017, 426, 30-38.

86 H. I. Lazarova, M. D. Popova, A. Szegedi, B. Likozar, V. Dasireddy and N. Novak-Tusar, Bulgarian Academy of Sciences, Union of Chemists in Bulgaria, 2018, 50, 56-60.

87 G. D. Yadav and A. R. Yadav, Chemical Engineering Journal, 2014, 243, 556-563.

88 Z. Li, R. Wnetrzak, W. Kwapinski and J. J. Leahy, ACS Appl. Mater. Interfaces, 2012, 4, 4499-4505.

89 D. Song, S. An, Y. Sun, P. Zhang, Y. Guo and D. Zhou, ChemCatChem, 2016, 8, 2037-2048.

90 S. Ghosh, P. Bhanja, N. Salam, R. Khatun, A. Bhaumik and Sk. M. Islam, Catalysis Today, 2018, 309, 253-262.

91 M. Popova, P. Shestakova, H. Lazarova, M. Dimitrov, D. Kovacheva, A. Szegedi, G. Mali, V. Dasireddy, B. Likozar, N. Wilde and R. Gläser, Applied Catalysis A: General, 2018, 560, 119-131. 
92 S. G. Kalghatgi and B. M. Bhanage, Journal of Molecular Liquids, 2019, 281, 70-80.

93 K. C. Badgujar and B. M. Bhanage, Fuel Processing Technology, 2015, 138, 139-146.

94 K. S. Jaiswal and V. K. Rathod, Catalysis Today, 2021, 375, 120131.

95 A. Lee, N. Chaibakhsh, M. B. A. Rahman, M. Basri and B. A. Tejo, Industrial Crops and Products, 2010, 32, 246-251.

96 K. Y. Nandiwale, P. S. Niphadkar, S. S. Deshpande and V. V. Bokade, J. Chem. Technol. Biotechnol., 2014, 89, 1507-1515.

97 K. Y. Nandiwale and V. V. Bokade, Process Safety and Environmental Protection, 2016, 99, 159-166.

98 L. Hu, L. Lin, Z. Wu, S. Zhou and S. Liu, Applied Catalysis B: Environmental, 2015, 174-175, 225-243.

99 X. Zhou, Z. X. Li, C. Zhang, X. P. Gao, Y. Z. Dai and G. Y. Wang, Journal of Molecular Catalysis A: Chemical, 2016, 417, 71-75.

100 A. Yamaguchi, O. Sato, N. Mimura and M. Shirai, Catalysis Today, 2016, 265, 199-202.

101 F. Su, Q. Wu, D. Song, X. Zhang, M. Wang and Y. Guo, J. Mater. Chem. A, 2013, 1, 13209.

102 P. Gupta and S. Paul, Catalysis Today, 2014, 236, 153-170. 103 A. G. Khiratkar, K. R. Balinge, M. Krishnamurthy, K. K. Cheralathan, D. S. Patle, V. Singh, S. Arora and P. R. Bhagat, Catal Lett, 2018, 148, 680-690.

104 A. Jakob, M. Grilc, J. Teržan and B. Likozar, Processes, 2021, 9, 924.

105 K. C. Badgujar and B. M. Bhanage, Biomass and Bioenergy, 2016, 84, 12-21.

106 V. A. da Silva Junior, L. R. Shigueyuki Kanda, A. ZandonáFilho, M. L. Corazza and C. Sutile de Lima, Journal of $\mathrm{CO} 2$ Utilization, 2020, 39, 101158.

107 D. Unlu, O. Ilgen and N. Durmaz Hilmioglu, Chemical Engineering Research and Design, 2017, 118, 248-258.

108 I. Delidovich, K. Leonhard and R. Palkovits, Energy Environ. Sci., 2014, 7, 2803-2830.

109 C. Barberot, A. Moniot, I. Allart-Simon, L. Malleret, T. Yegorova, M. Laronze-Cochard, A. Bentaher, M. Médebielle, J.-P. Bouillon, E. Hénon, J. Sapi, F. Velard and S. Gérard, European Journal of Medicinal Chemistry, 2018, 146, 139-146.

110 M. P. Negus, A. C. Mansfield and N. E. Leadbeater, Journal of Flow Chemistry, 2015, 5, 148-150.

111 K. Y. Nandiwale, S. K. Yadava and V. V. Bokade, Journal of Energy Chemistry, 2014, 23, 535-541.

112 K. C. Maheria, J. Kozinski and A. Dalai, Catal Lett, 2013, 143, 1220-1225.

113 C. B. Vilanculo, L. C. de Andrade Leles and M. J. da Silva, Waste and Biomass Valorization, 2020, 11, 1895-1904.

114 C. Liu, K. Zhang, Y. Liu and S. Wu, BioResources, 2019, 14, 2186-2196.

115 F. D. Pileidis, M. Tabassum, S. Coutts and M.-M. Titirici, Chinese Journal of Catalysis, 2014, 35, 929-936.

116 M. M. Zainol, N. A. S. Amin and M. Asmadi, Fuel Processing Technology, 2017, 167, 431-441.

117 M. M. Zainol, N. A. S. Amin and M. Asmadi, Renewable Energy, 2019, 130, 547-557.

118 G. Shen, B. Andrioletti and Y. Queneau, Current Opinion in Green and Sustainable Chemistry, 2020, 26, 100384.

119 W. Guo, Z. Zhang, J. Hacking, H. J. Heeres and J. Yue, Chemical Engineering Journal, 2021, 409, 128182.

120 Y. Kim, A. Mittal, D. J. Robichaud, H. M. Pilath, B. D. Etz, P. C. St. John, D. K. Johnson and S. Kim, ACS Catal., 2020, 10, 1470714721.

121 D. Garces, L. Faba, E. Diaz and S. Ordonez, ChemSusChem, 2018, 12, 924-934.

122 R. Šivec, M. Grilc, M. Huš and B. Likozar, Ind. Eng. Chem. Res., 2019, 58, 16018-16032.

123 S. Bhagia, H. Akinosho, J. F. S. Ferreira and A. J. Ragauskas, Biofuel Res. J., 2017, 4, 587-599.

124 X. Chen, Y. Zhang, T. Hou, L. Han and W. Xiao, Journal of Energy Chemistry, 2018, 27, 552-558.
125 S. Quereshi, E. Ahmad, K. K. Pant and S. Dutta, Catalysis Today, 2017, 291, 187-194.

126 Z. Wang and Q. Chen, Green Chem., 2016, 18, 5884-5889. 127 E. Ramírez, R. Bringué, C. Fité, M. Iborra, J. Tejero and F. Cunill, Applied Catalysis A: General, 2021, 612, 117988.

128 Y. Wang, Y. Huang, L. Liu, L. He, T. Li, C. Len and W. Yang, ACS Sustainable Chem. Eng., 2020, 8, 14576-14583.

129 S. Saravanamurugan and A. Riisager, Catalysis Communications, 2012, 17, 71-75.

130 B. Torres-Olea, I. Fúnez-Núñez, C. García-Sancho, J. A. Cecilia, R. Moreno-Tost and P. Maireles-Torres, Chem. Proc., 2, 34. 131 K. Kumar, A. Dahiya, T. Patra and S. Upadhyayula, ChemistrySelect, 2018, 3, 6242-6248.

132 Z. Wang and Q. Chen, Nanomaterials, 2018, 8, 492.

133 C. P.A. and S. Darbha, Catalysis Communications, 2020, 140, 105998.

134 B. Srinivasa Rao, P. Krishna Kumari, D. Dhana Lakshmi and N. Lingaiah, Catalysis Today, 2018, 309, 269-275.

135 P. Neves, S. Lima, M. Pillinger, S. M. Rocha, J. Rocha and A. A. Valente, Catalysis Today, 2013, 218-219, 76-84.

136 J. Slak, B. Pomeroy, A. Kostyniuk, M. Grilc and B. Likozar, Chemical Engineering Journal, 2022, 429, 132325.

137 J. M. R. Gallo, D. M. Alonso, M. A. Mellmer and J. A. Dumesic, Green Chem., 2013, 15, 85-90.

138 Y. Wang, D. Zhao, K. S. Triantafyllidis, W. Ouyang, R. Luque and C. Len, Molecular Catalysis, 2020, 480, 110630.

139 X. Hu, S. Jiang, L. Wu, S. Wang and C.-Z. Li, Chem. Commun., 2017, 53, 2938-2941.

140 L. Zhang, G. Xi, K. Yu, H. Yu and X. Wang, Industrial Crops and Products, 2017, 98, 68-75.

141 X. Peng, S. Nie, X. Li, X. Huang and Q. Li, Molecules, 2019,

24, 212.

142 L. Zhang, H. Yu, P. Wang and Y. Li, Bioresource Technology, 2014, 151, 355-360.

143 L. Zhang, L. Tian, R. Sun, C. Liu, Q. Kou and H. Zuo, Bioresource Technology, 2019, 276, 60-64.

144 A. Chareonlimkun, V. Champreda, A. Shotipruk and N Laosiripojana, Bioresource Technology, 2010, 101, 4179-4186.

145 E. Lam, J. H. Chong, E. Majid, Y. Liu, S. Hrapovic, A. C. W. Leung and J. H. T. Luong, Carbon, 2012, 50, 1033-1043.

146 X. Lyu and G. G. Botte, Chemical Engineering Journal, 2021, 403, 126271

147 X. Li, R. Xu, Q. Liu, M. Liang, J. Yang, S. Lu, G. Li, L. Lu and C. Si, Industrial Crops and Products, 2019, 141, 111759.

148 E. I. Gürbüz, J. M. R. Gallo, D. M. Alonso, S. G. Wettstein, W. Y. Lim and J. A. Dumesic, Angew. Chem. Int. Ed., 2013, 52, 1270-1274.

149 C. B. T. L. Lee and T. Y. Wu, Renewable and Sustainable Energy Reviews, 2021, 137, 110172.

150 E. I. Gürbüz, S. G. Wettstein and J. A. Dumesic, ChemSusChem, 2012, 5, 383-387.

151 P. Demma Carà, R. Ciriminna, N. R. Shiju, G. Rothenberg and M. Pagliaro, ChemSusChem, 2014, 7, 835-840.

152 B. Chen, F. Li, Z. Huang and G. Yuan, Journal of Energy Chemistry, 2016, 25, 888-894.

153 S. Zhu, Y. Cen, J. Guo, J. Chai, J. Wang and W. Fan, Green Chem., 2016, 18, 5667-5675.

154 P. Jiang, X. Li, W. Gao, X. Wang, Y. Tang, K. Lan, B. Wang and R. Li, Catalysis Communications, 2018, 111, 6-9.

155 W. Gong, C. Chen, H. Wang, R. Fan, H. Zhang, G. Wang and H. Zhao, Chinese Chemical Letters, 2018, 29, 1617-1620.

156 J. Zhang, K. Dong, W. Luo and H. Guan, ACS Omega, 2018, 3, 6206-6216

157 J. M. Tukacs, M. Bohus, G. Dibó and L. T. Mika, RSC Adv., 2017, 7, 3331-3335.

158 M. Chatterjee, A. Chatterjee, T. Ishizaka and H. Kawanami, RSC Adv., 2018, 8, 20190-20201.

159 J. Du, J. Zhang, Y. Sun, W. Jia, Z. Si, H. Gao, X. Tang, X. Zeng, T. Lei, S. Liu and L. Lin, Journal of Catalysis, 2018, 368, 69-78. 
160 Y. Wang, D. Zhao, D. Rodríguez-Padrón and C. Len, Catalysts, 2019, 9, 796.

161 D. Wang and D. Astruc, Chem. Rev., 2015, 115, 6621-6686

162 K. Tang, S. Xie, G. R. Cofield, X. Yang, E. Tian and H. Lin, Energy Technol., 2018, 6, 1826-1831.

163 H. Chen, H. Ruan, X. Lu, J. Fu, T. Langrish and X. Lu, Chemical Engineering Journal, 2018, 333, 434-442.

164 L. Peng, X. Gao, X. Yu, H. Li, J. Zhang and L. He, Energy Fuels, 2019, 33, 330-339.

165 G. Wang, Z. Zhang and L. Song, Green Chem., 2014, 16, 1436-1443.

166 A. Kojčinović, Ž. Kovačič, M. Huš, B. Likozar and M. Grilc, Applied Surface Science, 2021, 543, 148836.

167 L. Peng, X. Gao and K. Chen, Fuel, 2015, 160, 123-131.

168 X. Liu, W. Yang, Q. Zhang, C. Li and H. Wu, Front. Chem. 2020, 8, 794.

169 K. Y. Nandiwale, A. M. Pande and V. V. Bokade, RSC Adv., 2015, 5, 79224-79231.

170 R. Bringué, E. Ramírez, M. Iborra, J. Tejero and F. Cunill, Fuel, 2019, 257, 116010.

171 H. Gómez Bernal, P. Benito, E. Rodríguez-Castellón, A. M. Raspolli Galletti and T. Funaioli, Applied Catalysis A: General, 2019, 575, 111-119.

172 D. Song, S. An, Y. Sun and Y. Guo, Journal of Catalysis, 2016, 333, 184-199.

173 S. S. Enumula, K. S. Koppadi, V. R. Babu Gurram, D. R. Burri and S. R. Rao Kamaraju, Sustainable Energy Fuels, 2017, 1, 644651.

174 Y.-B. Huang, T. Yang, M.-C. Zhou, H. Pan and Y. Fu, Green Chem., 2016, 18, 1516-1523.

175 D. Zhao, P. Prinsen, Y. Wang, W. Ouyang, F. Delbecq, C. Len and R. Luque, ACS Sustainable Chem. Eng., 2018, 6, 69016909.

176 C. Antonetti, D. Licursi, S. Fulignati, G. Valentini and A. Raspolli Galletti, Catalysts, 2016, 6, 196.

177 I. van Zandvoort, Y. Wang, C. B. Rasrendra, E. R. H. van Eck P. C. A. Bruijnincx, H. J. Heeres and B. M. Weckhuysen, ChemSusChem, 2013, 6, 1745-1758.

178 C. Fang, Y. Liu, W. Wu, H. Li, Z. Wang, W. Zhao, T. Yang and S. Yang, Waste Biomass Valor, 2019, 10, 1141-1150.

179 M. Li, J. Wei, G. Yan, H. Liu, X. Tang, Y. Sun, X. Zeng, T. Lei and L. Lin, Renewable Energy, 2020, 147, 916-923.

180 M. M. Antunes, S. Lima, P. Neves, A. L. Magalhães, E. Fazio, A. Fernandes, F. Neri, C. M. Silva, S. M. Rocha, M. F. Ribeiro, M. Pillinger, A. Urakawa and A. A. Valente, Journal of Catalysis, 2015 329, 522-537.

181 M. M. Antunes, S. Lima, P. Neves, A. L. Magalhães, E. Fazio, F. Neri, M. T. Pereira, A. F. Silva, C. M. Silva, S. M. Rocha, M. Pillinger, A. Urakawa and A. A. Valente, Applied Catalysis B: Environmental, 2016, 182, 485-503.

182 Y. Shao, X. Hu, Z. Zhang, K. Sun, G. Gao, T. Wei, S. Zhang, S. Hu, J. Xiang and Y. Wang, Green Energy \& Environment, 2019 4, 400-413.

183 B. Chen, F. Li, Z. Huang, T. Lu, Y. Yuan and G. Yuan, ChemSusChem, 2014, 7, 202-209.

184 S. Karnjanakom, A. Bayu, P. Maneechakr, C. Samart, S. Kongparakul and G. Guan, ACS Sustainable Chem. Eng., 2021, 9, 14170-14179.

185 K. Y. Nandiwale, M. Vishwakarma, S. Rathod, I. Simakova and V. V. Bokade, Energy Fuels, 2021, 35, 539-545.

186 L. Peng, H. Li, L. Xi, K. Chen and H. Chen, BioResources, 2014, 9, 3825-3834.

187 X. Gao, X. Yu, R. Tao and L. Peng, BioResources, 2017, 12 15.

188 L. Peng, X. Gao and K. Chen, Fuel, 2015, 160, 123-131.

189 J. N. Appaturi, M. R. Johan, R. J. Ramalingam, H. A. AlLohedan and J. J. Vijaya, RSC Adv., 2017, 7, 55206-55214.
190 D. Song, S. An, B. Lu, Y. Guo and J. Leng, Applied Catalysis B: Environmental, 2015, 179, 445-457.

191 M. S. Tiwari, A. B. Gawade and G. D. Yadav, Green Chem., 2017, 19, 963-976.

192 C. R. Patil, S. P. Kamble and C. V. Rode, ChemistrySelect, 2021, 6, 6636-6643.

193 J. R. Kean and A. E. Graham, Catalysis Communications, 2015, 59, 175-179.

194 Z. Mohammadbagheri and A. Najafi Chermahini, Chemical Engineering Journal, 2019, 361, 450-460.

195 M. S. Tiwari, J. S. Dicks, J. Keogh, V. V. Ranade and H. G. Manyar, Molecular Catalysis, 2020, 488, 110918

196 B. S. Rao, P. K. Kumari, D. Dhanalakshmi and N. Lingaiah, Molecular Catalysis, 2017, 427, 80-86.

197 E. Siva Sankar, K. Saidulu Reddy, Y. Jyothi, B. David Raju and K. S. Rama Rao, Catal Lett, 2017, 147, 2807-2816.

198 S. H. Krishna, K. Huang, K. J. Barnett, J. He, C. T. Maravelias, J. A. Dumesic, G. W. Huber, M. De bruyn and B. M. Weckhuysen, AIChE J., 2018, 64, 1910-1922.

199 O. Rosales-Calderon and V. Arantes, Biotechnol Biofuels, 2019, 12, 240 .

200 J. C. Serrano-Ruiz, R. Luque, J. M. Campelo and A. A. Romero, Challenges, 2012, 3, 114-132.

201 R. R. Chada, K. S. Koppadi, S. S. Enumula, M. Kondeboina, S. R. R. Kamaraju and D. R. Burri, Catal Lett, 2018, 148, 17311738.

202 M. Audemar, Y. Wang, D. Zhao, S. Royer, F. Jérôme, C. Len and K. De Oliveira Vigier, Energies, 2020, 13, 1002.

203 C. Antonetti, D. Licursi and A. M. Raspolli Galletti, Catalysts, 2020, 10, 961

204 Z. Xu, P. Yan, W. Xu, S. Jia, Z. Xia, B. Chung and Z. C. Zhang, RSC Adv., 2014, 4, 59083-59087.

205 C. Li, Y. Wang, Y. Zhang, M. Wang, X. Sun, H. Cui and Y. Xie, ChemistrySelect, 2020, 5, 270-279.

206 C. Chang, X. Ma and P. Cen, Chinese Journal of Chemical Engineering, 2006, 14, 708-712.

207 H. E. van Dam, A. P. G. Kieboom and H. van Bekkum, Starch/Stärke, 1986, 38, 95-101.

208 H. Heeres, R. Handana, D. Chunai, C. Borromeus Rasrendra, B. Girisuta and H. Jan Heeres, Green Chem., 2009, 11, 1247.

209 M. Brasholz, K. von Kanel, C. H. Hornung, S. Saubern and J. Tsanaktsidis, Green Chem., 2011, 13, 1114-1117.

210 L. Peng, L. Lin, H. Li and Q. Yang, Applied Energy, 2011, 88 , 4590-4596.

211 V. Choudhary, S. H. Mushrif, C. Ho, A. Anderko, V. Nikolakis, N. S. Marinkovic, A. I. Frenkel, S. I. Sandler and D. G. Vlachos, J. Am. Chem. Soc., 2013, 135, 3997-4006.

212 N. Ya'aini, N. A. S. Amin and M. Asmadi, Bioresource Technology, 2012, 116, 58-65.

213 W. Wei and S. Wu, Fuel, 2018, 225, 311-321.

214 S. Kang and J. Yu, Sugar Tech, 2018, 20, 182-193.

215 T. C. Acharjee and Y. Y. Lee, Environ. Prog. Sustainable Energy, 2018, 37, 471-480.

216 X. Hu, S. Wang, R. J. M. Westerhof, L. Wu, Y. Song, D. Dong and C.-Z. Li, Fuel, 2015, 141, 56-63.

217 M.-R. Park, S.-K. Kim and G.-T. Jeong, Journal of Industrial and Engineering Chemistry, 2018, 61, 119-123.

218 X. Zhang, X. Zhang, N. Sun, S. Wang, X. Wang and Z. Jiang, Renewable Energy, 2019, 141, 802-813.

219 G. Xu, C. Chang, W. N. Zhu, B. Li, X. J. Ma and F. G. Du, Chem. Pap., 2013, 67, 1355-1363.

220 C. H. Kuo, A. S. Poyraz, L. Jin, Y. Meng, L. Pahalagedara, S. Y. Chen, D. A. Kriz, C. Guild, A. Gudz and S. L. Suib, Green Chem. 2014, 16, 785-791.

221 L. Zhou, H. Zou, J. Nan, L. Wu, X. Yang, Y. Su, T. Lu and J. $\mathrm{Xu}$, Catalysis Communications, 2014, 50, 13-16. 
222 J. Liu, B.-B. Yang, X.-Q. Wang, C.-L. Liu, R.-Z. Yang and W.S. Dong, Applied Clay Science, 2017, 141, 118-124.

223 J. Heda, P. Niphadkar and V. Bokade, Energy Fuels, 2019, 33, 2319-2327.

224 X. Hu and C.-Z. Li, Green Chem., 2011, 13, 1676-1679.

225 X. Hu, Y. Song, L. Wu, M. Gholizadeh and C.-Z. Li, ACS Sustainable Chem. Eng., 2013, 1, 1593-1599.

226 M. Mascal and E. B. Nikitin, ChemSusChem, 2010, 3, 13491351.

227 R. Liu, J. Chen, X. Huang, L. Chen, L. Ma and X. Li, Green Chem., 2013, 15, 2895.

228 E.-E. Oprescu, C.-E. Enascuta, R. Doukeh, C. Calin and V. Lavric, Renewable Energy, 2021, 176, 651-662.

229 J.-P. Lange, W. D. van de Graaf and R. J. Haan, ChemSusChem, 2009, 2, 437-441.

230 D. Ren, J. Fu, L. Li, Y. Liu, F. Jin and Z. Huo, RSC Adv., 2016 6, 22174-22178.

231 L. Peng, R. Tao and Y. Wu, Catalysts, 2016, 6, 143.

232 G. Wang, Z. Zhang and L. Song, Green Chem., 2014, 16 1436-1443.

233 M. Hronec, K. Fulajtárová and T. Soták, Journal of Industrial and Engineering Chemistry, 2014, 20, 650-655.

234 G. M. Gonzàlez Maldonado, R. S. Assary, J. A. Dumesic and L. A. Curtiss, Energy Environ. Sci., 2012, 5, 6981-6989.

235 C. Wang, Q. Zhang, Y. Chen, X. Zhang and F. Xu, ACS Sustainable Chem. Eng., 2018, 6, 3154-3161.

236 B. Chamnankid, C. Ratanatawanate and K. Faungnawakij, Chemical Engineering Journal, 2014, 258, 341-347.

237 D. W. Rackemann, J. P. Bartley and W. O. S. Doherty, Industrial Crops and Products, 2014, 52, 46-57.

238 P. P. Upare, J.-W. Yoon, M. Y. Kim, H.-Y. Kang, D. W. Hwang, Y. K. Hwang, H. H. Kung and J.-S. Chang, Green Chem., 2013, 15, 2935

239 R. A. Schraufnagel and H. F. Rase, Product R\&D, 1975, 14 40-44.

240 J. Jow, G. L. Rorrer, M. C. Hawley and D. T. A. Lamport, Biomass, 1987, 14, 185-194.

241 X. Xu, X. Zhang, W. Zou, H. Yue, G. Tian and S. Feng, Catalysis Communications, 2015, 62, 67-70.

242 X. Yang, J. Yang, B. Gao, T. Lu and L. Zhou, Catalysis Communications, 2019, 130, 105783

243 S. Saravanamurugan, O. Nguyen Van Buu and A. Riisager, ChemSusChem, 2011, 4, 723-726.

244 N. Mulik, P. Niphadkar and V. Bokade, Environ Prog Sustainable Energy, 2019, 38, 13173.

245 M. Balakrishnan, E. R. Sacia and A. T. Bell, Green Chem. 2012, 14, 1626.

246 S. Saravanamurugan and A. Riisager, ChemCatChem, 2013, 5, 1754-1757.

247 S. Zhao, G. Xu, J. Chang, C. Chang, J. Bai, S. Fang and Z. Liu, BioResources, 2015, 10, 2223-2234.

248 S. Zhao, G. Xu, C. Chang, S. Fang, Z. Liu and F. Du, Catalysts, 2015, 5, 1897-1910.

249 E. C. Njagi, H. C. Genuino, C.-H. Kuo, S. Dharmarathna, A. Gudz and S. L. Suib, Microporous and Mesoporous Materials, 2015, 202, 68-72.

250 P. F. Pinheiro, D. M. Chaves and M. J. da Silva, Cellulose, 2019, 26, 7953-7969.

251 C. Fang, Y. Li, W. Zhao, W. Wu, H. Li, C. He and S. Yang, RSC Adv., 2018, 8, 16585-16592.

252 M. M. Zainol, M. Asmadi, P. Iskandar, W. A. N. Wan Ahmad, N. A. S. Amin and T. T. Hoe, Journal of Cleaner Production, 2021, 281, 124686.

253 J. Zhang and J. Chen, Journal of Energy Chemistry, 2016 25, 747-753.

254 S. Quereshi, E. Ahmad, K. K. Pant and S. Dutta, ACS Sustainable Chem. Eng., 2020, 8, 1721-1729.

255 S. Karnjanakom, P. Maneechakr, C. Samart, S. Kongparakul, G. Guan and A. Bayu, Catalysis Communications, 2020, 143, 106058.
256 S. Nazer, A. Najafi Chermahini, B. H. Monjezi and H. A. Dabbagh, Journal of the Taiwan Institute of Chemical Engineers, 2020, 114, 168-175.

257 M. Wang, L. Peng, X. Gao, L. He and J. Zhang, Sustainable Energy Fuels, 2020, 4, 1383-1395.

258 X. Lyu, Z. Zhang, F. Okejiri, H. Chen, M. Xu, X. Chen, S. Deng and X. Lu, ChemSusChem, 2019, 12, 4400-4404.

259 M. Signoretto, S. Taghavi, E. Ghedini and F. Menegazzo, Molecules, 2019, 24, 2760.

260 A. M. Raspolli Galletti, C. Antonetti, V. De Luise, D. Licursi and N. Nassi, BioResources, 2012, 7, 1824-1835.

261 D. B. Bevilaqua, M. K. D. Rambo, T. M. Rizzetti, A. L. Cardoso and A. F. Martins, Journal of Cleaner Production, 2013, 47, 96-101.

262 C. Chang, P. Cen and X. Ma, Bioresource Technology, 2007, 98, 1448-1453.

263 L. Yan, N. Yang, H. Pang and B. Liao, Clean Soil Air Water, 2008, 36, 158-163.

264 D. Licursi, C. Antonetti, J. Bernardini, P. Cinelli, M. B. Coltelli, A. Lazzeri, M. Martinelli and A. M. R. Galletti, Industrial Crops and Products, 2015, 76, 1008-1024.

265 J. C. Serrano-Ruiz, D. J. Braden, R. M. West and J. A. Dumesic, Applied Catalysis B: Environmental, 2010, 100, 184-189. 266 B. Girisuta, L. P. B. M. Janssen and H. J. Heeres, Ind. Eng. Chem. Res., 2007, 46, 1696-1708.

267 L. Peng, L. Lin, J. Zhang, J. Zhuang, B. Zhang and Y. Gong, Molecules, 2010, 15, 5258-5272.

268 C. Xiros, M. Janssen, R. Byström, B. T. Børresen, D. Cannella, H. Jørgensen, R. Koppram, C. Larsson, L. Olsson, A Tillman and S. Wännström, Biofuels, Bioprod. Bioref., 2017, 11, $15-27$.

269 L. G. Covinich, N. M. Clauser, F. E. Felissia, M. E. Vallejos and M. C. Area, Biofuels, Bioprod. Bioref., 2020, 14, 417-445.

270 S. G. Wettstein, D. M. Alonso, Y. Chong and J. A. Dumesic, Energy Environ. Sci., 2012, 5, 8199-8203.

271 M. A. Mellmer, C. Sener, J. M. R. Gallo, J. S. Luterbacher, D. M. Alonso and J. A. Dumesic, Angew. Chem. Int. Ed., 2014, 53 11872-11875

272 Á. Szabolcs, M. Molnár, G. Dibó and L. T. Mika, Green Chem., 2013, 15, 439-445.

273 A. de la Hoz, Á. Díaz-Ortiz and A. Moreno, Chem. Soc. Rev., 2005, 34, 164-178.

274 J. Feng, J. Jiang, J. Xu, Z. Yang, K. Wang, Q. Guan and S. Chen, Applied Energy, 2015, 154, 520-527.

275 L. Peng, L. Lin, H. Li and K. Chen, BioResources, 2013, 8 5895-5907.

$276 \mathrm{H}$. Li, L. Peng, L. Lin, K. Chen and H. Zhang, Journal of Energy Chemistry, 2013, 22, 895-901.

277 X. Wu, J. Fu and X. Lu, Carbohydrate Research, 2012, 358, 37-39.

278 J. Dai, L. Peng and H. Li, Catalysis Communications, 2018, 103, 116-119.

279 C. Chang, G. Xu and X. Jiang, Bioresource Technology, 2012, 121, 93-99.

280 R. Le Van Mao, Q. Zhao, G. Dima and D. Petraccone, Catal Lett, 2011, 141, 271-276.

281 A. Démolis, M. Eternot, N. Essayem and F. Rataboul, New J. Chem., 2016, 40, 3747-3754

282 Y. Hishikawa, M. Yamaguchi, S. Kubo and T. Yamada, J Wood Sci, 2013, 59, 179-182.

283 C. Antonetti, S. Gori, D. Licursi, G. Pasini, S. Frigo, M. López, J. C. Parajó and A. M. Raspolli Galletti, Catalysts, 2020, 10, 509.

284 S. Elumalai, B. Agarwal, T. M. Runge and R. S. Sangwan, Carbohydrate Polymers, 2016, 150, 286-298.

285 K. Lappalainen, N. Vogeler, J. Kärkkäinen, et al., Biomass Conv. Bioref., 2018, 8, 965-970.

286 A. G. Laurenza, O. Losito, M. Casiello, C. Fusco, A. Nacci, V. Pantone and L. D'Accolti, Sci Rep, 2021, 11, 15775.

287 Y. Shen, J.-K. Sun, Y.-X. Yi, B. Wang, F. Xu and R.-C. Sun, Bioresource Technology, 2015, 192, 812-816. 
288 X. Liang, Y. Fu and J. Chang, Fuel, 2020, 259, 116246.

289 M. Hao, L. Jin-Xing, W. Fu-Rong, W. Le-Fu, L. Xue-Hui, Acta Physico-Chimica Sinica, 2015, 31, 973-979.

290 J. J. Bozell and G. R. Petersen, Green Chem., 2010, 12, 539. 291 United States Patent, US5608105, 1997.

292 S. W. Fitzpatrick, Commercialization of the Biofine technology for levulinic acid production from paper sludge., U.S. Department of Energy, 2002.

293 D. J. Hayes, S. Fitzpatrick, M. H. B. Hayes and J. R. H. Ross, in Biorefineries-Industrial Processes and Products, eds. B. Kamm, P. R. Gruber and M. Kamm, Wiley-VCH Verlag GmbH, Weinheim, Germany, 2005, pp. 139-164.

294 J. Matías, A. Gil, V. López, L. Arribas and C. González, 23rd European Biomass Conference and Exhibition, 2015.

295 WALEVA-LIFE13 ENV/ES/001165, The WALEVA Project: An innovative way to turn waste into resource. (Layman's report), 2018.

296 D. Hayes, Report on Optimal Use of DIBANET Feedstocks and Technologies, 2017.

297 B. Girisuta, K. G. Kalogiannis, K. Dussan, J. J. Leahy, M. H. B. Hayes, S. D. Stefanidis, C. M. Michailof and A. A. Lappas, Bioresource Technology, 2012, 126, 92-100.

298 Dibanet, Final Report Summary - DIBANET (The Production of Sustainable Diesel-Miscible-Biofuels from the Residues and Wastes of Europe and Latin America), 2014.

299 United States Patent, US10618864B2, 2020, 60

300 EUROPEAN PATENT APPLICATION, EP3115352A1, 2017.

301 United States Patent, US9073841B2, 2015, 19.

302 GFBiochemicals, GFBiochemicals acquires leading levulinic acid derivatives producer Segetis and enters the US market,

http://www.gfbiochemicals.com/_media/Document/2017/4/26/ GFBiochemicals\%20acquires\%20leading\%20levulinic\%20acid\%2 Oderivatives\%20producer\%20Segetis.pdf.

303 M. Gozan, B. Ryan and Y. Krisnandi, IOP Conf. Ser.: Mater. Sci.Eng., 2017, 345, 15.

304 M. Przypis, K. Matuszek, A. Chrobok, M. Swadźba-Kwaśny and D. Gillner, Journal of Molecular Liquids, 2020, 308, 113166

305 M. Deetlefs and K. R. Seddon, Green Chem., 2010, 12, 17-

30.

306 A. S. Amarasekara and B. Wiredu, Bioenerg. Res., 2014, 7, 1237-1243.

307 N. V. Plechkova and K. R. Seddon, Chem. Soc. Rev., 2008, 37, 123-150.

308 M. Martínez Aguilar, X. Duret, T. Ghislain, D. P. Minh, A Nzihou and J.-M. Lavoie, Energy Conversion and Management: $X$, 2021, 10, 100049.

309 J. Tan, Q. Liu, L. Chen, T. Wang, L. Ma and G. Chen, Journal of Energy Chemistry, 2017, 26, 115-120.

310 H. Chen, B. Yu and S. Jin, Bioresource Technology, 2011, 102, 3568-3570.

311 B. Velaga, R. P. Parde, J. Soni and N. R. Peela, Microporous and Mesoporous Materials, 2019, 287, 18-28.

312 S. S. Joshi, A. D. Zodge, K. V. Pandare and B. D. Kulkarni, Ind. Eng. Chem. Res., 2014, 53, 18796-18805.

313 D. M. Alonso, J. M. R. Gallo, M. A. Mellmer, S. G. Wettstein and J. A. Dumesic, Catal. Sci. Technol., 2013, 3, 927-931.

314 P. Sudarsanam, R. Zhong, S. Van den Bosch, S. M. Coman, V. I. Parvulescu and B. F. Sels, Chem. Soc. Rev., 2018, 47, 83498402.

315 M. Kang, S. W. Kim, J.-W. Kim, T. H. Kim and J. S. Kim, Renewable Energy, 2013, 54, 173-179.

316 S. Yamaguchi, Y. Kawada, H. Yuge, K. Tanaka and S. Imamura, Sci Rep, 2017, 7, 855.

317 R. Behling, S. Valange and G. Chatel, Green Chem., 2016, 18, 1839-1854.

318 R. An, G. Xu, C. Chang, J. Bai and S. Fang, Journal of Energy Chemistry, 2017, 26, 556-563.
319 H. Li, Z. Fang, J. Luo and S. Yang, Applied Catalysis B: Environmental, 2017, 200, 182-191.

320 J. Heda, P. Niphadkar, S. Mudliar and V. Bokade, Microporous and Mesoporous Materials, 2020, 306, 110474.

321 D. Lai, L. Deng, Q. Guo and Y. Fu, Energy Environ. Sci., 2011 4, 3552 .

322 Z. Zhang, Z. Huang and H. Yuan, New J. Chem., 2021, 45 5526-5539.

323 L. Tian, L. Zhang, Y. Liu, Y. He, Y. Zhu, R. Sun, S. Yi and J. Xiang, Journal of Cleaner Production, 2020, 268, 122296.

324 K. Tominaga, K. Nemoto, Y. Kamimura, A. Yamada, Y Yamamoto and K. Sato, RSC Adv., 2016, 6, 65119-65124.

325 K. Tominaga, A. Mori, Y. Fukushima, S. Shimada and K. Sato, Green Chem., 2011, 13, 810.

326 K. Nemoto, K. Tominaga and K. Sato, Chem. Lett., 2014, 43, 1327-1329.

327 A. A. Kiss, J. Chem. Technol. Biotechnol., 2013, 88, 13871404.

328 A. A. Kiss, J. Grievink and M. Rito-Palomares, J. Chem Technol. Biotechnol., 2015, 90, 349-355.

329 A. A. Kiss, J.-P. Lange, B. Schuur, D. W. F. Brilman, A. G. J. van der Ham and S. R. A. Kersten, Biomass and Bioenergy, 2016, 95, 296-309.

330 S. G. Wettstein, D. M. Alonso, E. I. Gürbüz and J. A. Dumesic, Current Opinion in Chemical Engineering, 2012, 1, 218224.

331 M. Errico, R. P. Stateva and S. Leveneur, Processes, 2021 9, 490.

332 L. C. Nhien, N. V. D. Long, S. Kim and M. Lee, Ind. Eng. Chem. Res., 2016, 55, 5180-5189.

333 H. Alcocer-García, J. G. Segovia-Hernández, O. A. PradoRubio, E. Sánchez-Ramírez and J. J. Quiroz-Ramírez, Chemica Engineering and Processing - Process Intensification, 2019, 136 123-137.

334 EUROPEAN PATENT APPLICATION, EP3156389A1, 2017.

335 Patent Application Publication, US20060047139A1, 2006.

336 UNITED STATES PATENT OFFICE, US2684981, 1951.

337 World Intellectual Property Organization, W02010030617A1, 2009.

338 T. Brouwer, M. Blahusiak, K. Babic and B. Schuur, Separation and Purification Technology, 2017, 185, 186-195.

339 V. Isoni, D. Kumbang, P. N. Sharratt and H. H. Khoo, Journal of Environmental Management, 2018, 214, 267-275.

340 V. Pace, P. Hoyos, L. Castoldi, P. Domínguez de María and A. R. Alcántara, ChemSusChem, 2012, 5, 1369-1379.

341 B. Nis and B. Kaya Ozsel, Renewable Energy, 2021, 169 1051-1057.

342 X. Tang, Y. Sun, X. Zeng, W. Hao, L. Lin and S. Liu, Energy Fuels, 2014, 28, 4251-4255.

343 C. Liang, Y. Wang, Y. Hu, L. Wu and W. Zhang, ACS Omega, 2019, 4, 9828-9834.

344 J. A. Vázquez-Castillo, G. Contreras-Zarazúa, J. G. SegoviaHernández and A. A. Kiss, J. Chem. Technol. Biotechnol., 2019, 94, 2131-2140.

345 L. F. Zilnik, M. Grilc and B. Likozar, Fluid Phase Equilibria, 2021, 546, 113115.

346 W. Schutyser, T. Renders, S. Van den Bosch, S.-F. Koelewijn, G. T. Beckham and B. F. Sels, Chem. Soc. Rev., 2018, 47 852-908.

347 A. Mazar, O. Ajao, M. Benali, N. Jemaa, W. Wafa Al-Dajani and M. Paleologou, ACS Sustainable Chem. Eng., 2020, 8, 1734517358.

348 E. Pfab, L. Filiciotto, A. A. Romero and R. Luque, Ind. Eng Chem. Res., 2019, 58, 16065-16070.

349 T. M. C. Hoang, L. Lefferts and K. Seshan, ChemSusChem 2013, 6, 1651-1658.

350 B. Kamm and M. Kamm, Applied Microbiology and Biotechnology, 2004, 64, 137-145. 
351 H. H. Khoo, L. L. Wong, J. Tan, V. Isoni and P. Sharratt, Resources, Conservation and Recycling, 2015, 95, 174-182.

352 H. H. Khoo, R. M. Eufrasio-Espinosa, L. S. C. Koh, P. N. Sharratt and V. Isoni, Journal of Cleaner Production, 2019, 235, 1116-1137.

353 A. Mukherjee, M.-J. Dumont and V. Raghavan, Biomass and Bioenergy, 2015, 72, 143-183.

354 S. González-García, B. Gullón, S. Rivas, G. Feijoo and M. T. Moreira, Journal of Cleaner Production, 2016, 120, 170-180.

355 R. H. Hafyan, L. Bhullar, Z. A. Putra, M. R. Bilad, M. D. H. Wirzal and N. A. H. M. Nordin, Process Integr Optim Sustain, 2020, 4, 37-50.

356 V. C. Casson Moreno, A. L. Garbetti, S. Leveneur and G. Antonioni, Safety Science, 2019, 112, 142-151.

357 K. K. Kapanji, S. Farzad and J. F. Görgens, Journal of Cleaner Production, 2021, 295, 126339. 